\title{
WestVirginiaUniversity
}

THE RESEARCH REPOSITORY @ WVU

Graduate Theses, Dissertations, and Problem Reports

2016

\section{Measuring and Changing Preschool Children's Stuttering Attitudes}

Mary E. Weidner

Follow this and additional works at: https://researchrepository.wvu.edu/etd

\section{Recommended Citation}

Weidner, Mary E., "Measuring and Changing Preschool Children's Stuttering Attitudes" (2016). Graduate Theses, Dissertations, and Problem Reports. 6931.

https://researchrepository.wvu.edu/etd/6931

This Dissertation is protected by copyright and/or related rights. It has been brought to you by the The Research Repository @ WVU with permission from the rights-holder(s). You are free to use this Dissertation in any way that is permitted by the copyright and related rights legislation that applies to your use. For other uses you must obtain permission from the rights-holder(s) directly, unless additional rights are indicated by a Creative Commons license in the record and/ or on the work itself. This Dissertation has been accepted for inclusion in WVU Graduate Theses, Dissertations, and Problem Reports collection by an authorized administrator of The Research Repository @ WVU.

For more information, please contact researchrepository@mail.wvu.edu. 
Measuring and Changing Preschool Children's Stuttering Attitudes

\begin{abstract}
Mary E. Weidner
Dissertation submitted to the College of Education and Human Services at West Virginia University
\end{abstract}

in partial fulfillment of the requirements for the degree of

Doctor of Philosophy in

Communication Sciences and Disorders

Committee:

Kenneth O. St. Louis, Ph.D., Chair

Mary Ellen Koay, Ph.D.

Michelle W. Moore, Ph.D.

Dennis M. Ruscello, Ph.D.

Christine J. Schimmel, Ph.D.

Department of Communication Sciences and Disorders

Morgantown, West Virginia

2016

Keywords: Stuttering, Children, Attitudes, Changing

Copyright 2016 Mary E. Weidner 


\title{
ABSTRACT \\ Measuring and Changing Preschool Children's Stuttering Attitudes
}

\author{
Mary E. Weidner
}

Background: Negative or uninformed stuttering attitudes proliferate among the general public, and bourgeoning research has shown that such attitudes might emerge as early as the preschool years. Despite decades of research on the topic, much remains unknown about the origin of stuttering attitudes and the factors that bear on their development. Moreover, conclusive recommendations to improve attitudes toward stuttering have yet to be advanced.

Purpose: This study sought (a) to objectively measure stuttering attitudes among preschool children, (b) to examine predictive factors that might account for those attitudes, and (c) to determine the effect of a new educational program on improving preschoolers' stuttering attitudes. It was hypothesized that children would hold uninformed or negative attitudes about stuttering, which would be amenable to improvement following the educational program. Children's experience with stuttering and their social cognitive skills were expected to have a positive effect on their stuttering attitudes. Other factors, such as parent attitudes and demographic variables, were expected to have little to no effect.

Method: The stuttering attitudes of 55 preschoolers were measured using the Public Opinion Survey of Human Attributes-Stuttering/Child (POSHA-S/Child). Data were interpreted relative to children's demographic variables, exposure to stuttering, personal factors, and parent stuttering attitudes (obtained from 38 parent respondents). Thirtyseven children learned about stuttering and sensitive peer interactions by participating in the Attitude Change and Tolerance (InterACT) program. Their POSHA-S/Child ratings were obtained following the program, and compared to a control group.

Results: Pre-post comparisons showed statistically significant improvements in stuttering beliefs and self reactions for children in the experimental group, and no significant attitude change for control participants. Prior exposure to stuttering was associated with more positive baseline attitudes, but other variables had marginal-to-negligible predictive power. 


\section{Acknowledgements}

This dissertation is a culmination of the support I received from those who believed in this project and in my ability to achieve it. First and foremost, I extend deepest gratitude to my advisor, Ken St. Louis. Through his constant mentorship and guidance, I learned what it means to be persistent in the pursuit of a vision, how to be resilient in times of adversity, and that growth occurs beyond the confines of one's comfort zone. He helped me become a better researcher, teacher, and person. I am both humbled and privileged to have had the opportunity to learn from one of the "greats."

I am indebted to my doctoral committee-Dr. Mary Ellen Koay, Dr. Michelle Moore, Dr. Robert Orlikoff, Dr. Dennis Ruscello, and Dr. Christine Schimmel. Their insight and expertise was truly invaluable and broadened my understanding of research and the field at large. Many colleagues also played an important role over the course of my studies, especially Craig Coleman. He helped me understand the critical importance of advocacy, creativity, and commitment in supporting the needs of children who stutter.

My sincere appreciation goes to the entire Communication Sciences and Disorders faculty, who took a chance on me as the program's first doctoral student. In addition, I would like to thank the College of Education and Human Services and the National Stuttering Association for their financial support for this project, as well as the creative team who brought the InterACT program to life.

Finally, I am eternally grateful for my family and friends whose unwavering support has been the backbone of this journey. A particularly heartfelt recognition goes to my parents, Marjorie and Len, who have endured their four children's collective 63 semesters over 28 years. Love you most! 


\section{Table of Contents}

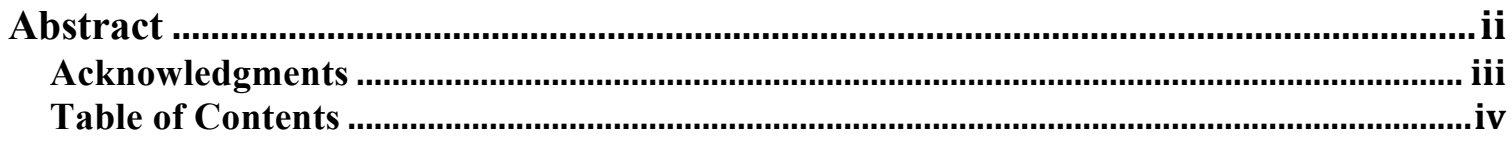

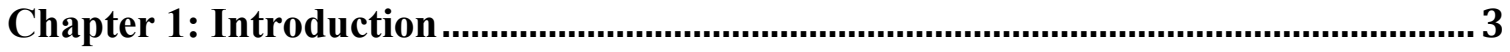

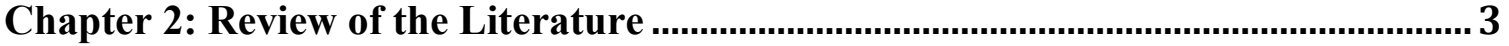

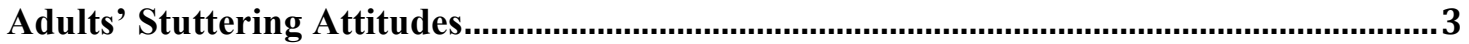

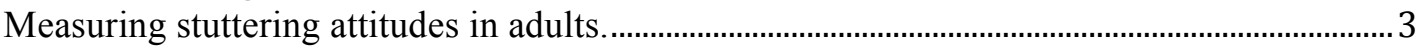
Influential factors on adult's stuttering attitudes....................................................................... 5

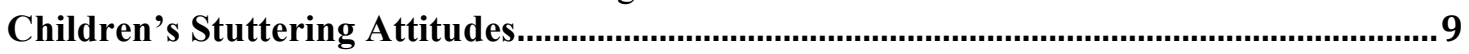
Stuttering awareness among fluent and stuttering children. ...................................................

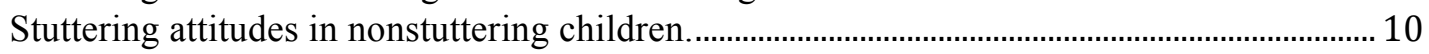
Influential factors on children's stuttering attitudes............................................................. 14
Call for Attitude Change in Children .................................................................................... 19
Ramifications of negative stuttering attitudes in children................................................... 19

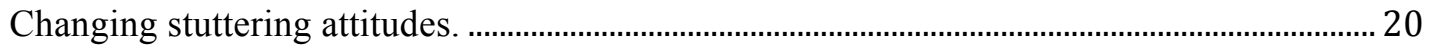

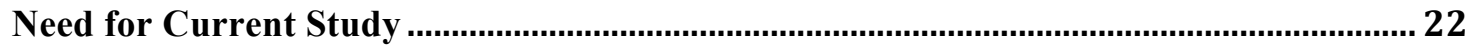

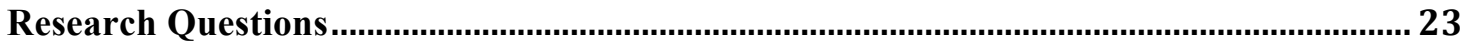

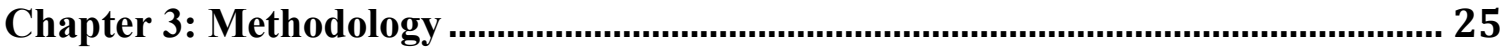

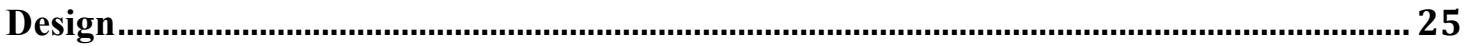

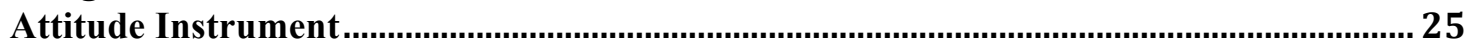

Child stuttering attitude measure: The POSHA-S/Child. …………….......................................... 25

Adult stuttering attitude measure: The POSHA-S. ……............................................................... 31

Social cognitive measure: Theory of Mind Task Battery ........................................................... 32

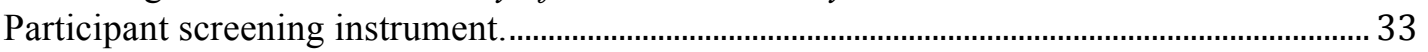

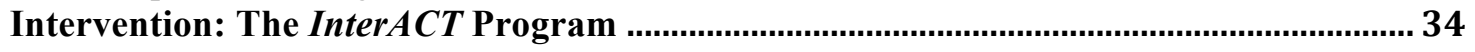

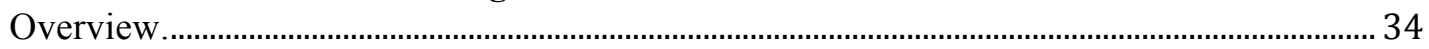

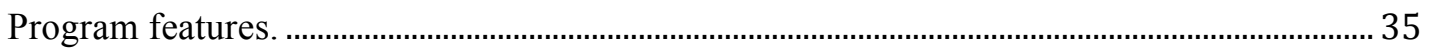

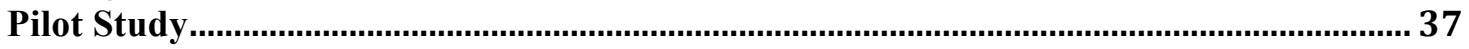

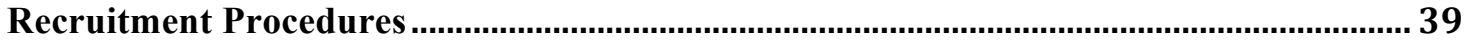

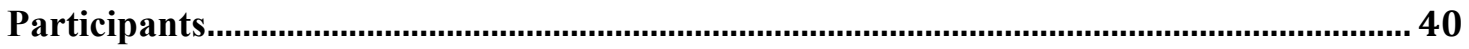

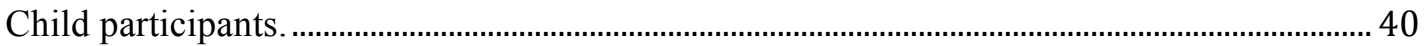

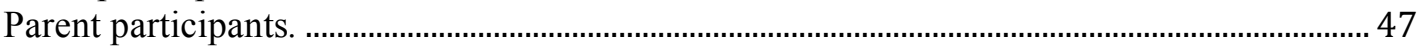

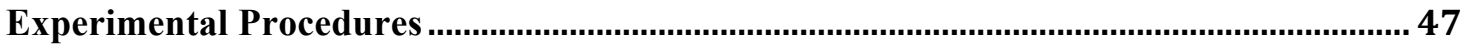

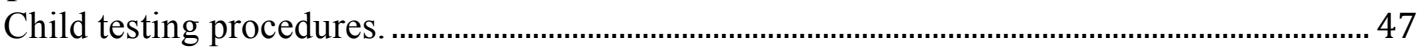

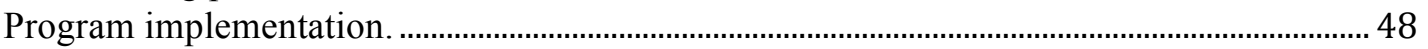

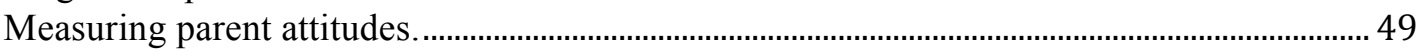

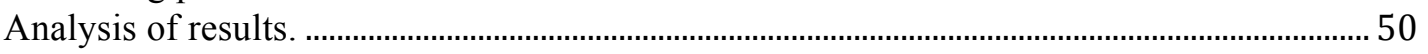

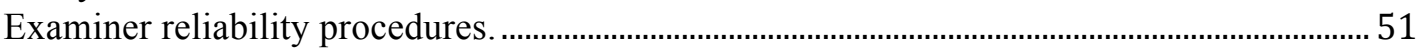

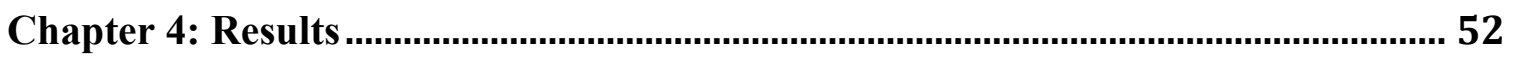

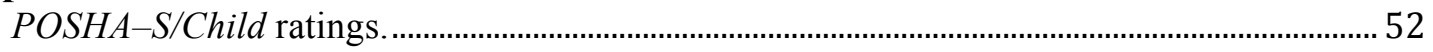

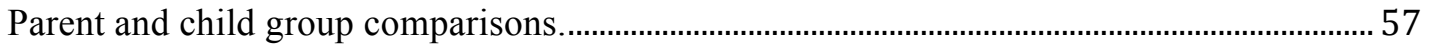

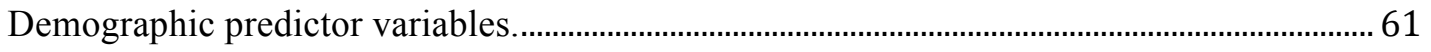

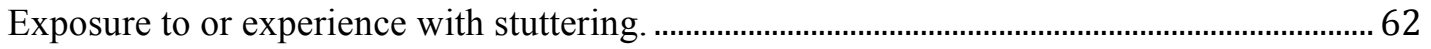

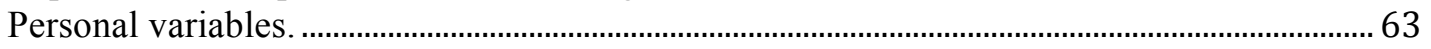

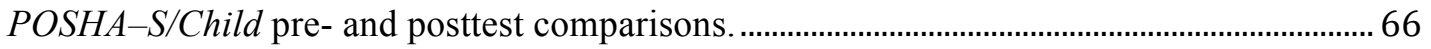

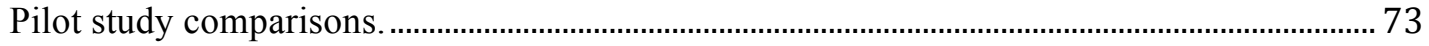




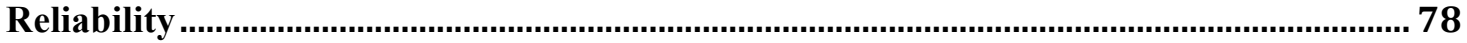

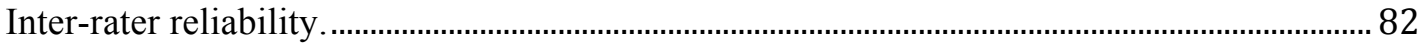

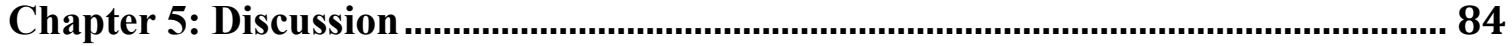

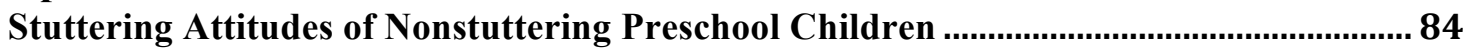

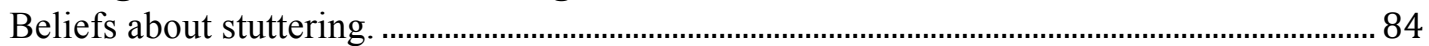

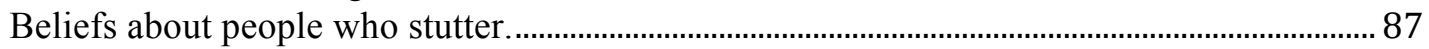

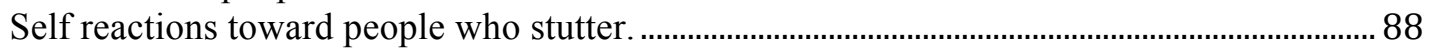

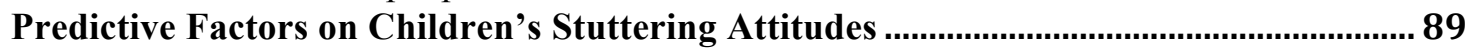

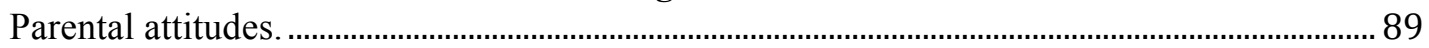

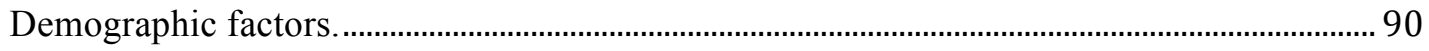

Exposure to or experience with stuttering. …………............................................................ 91

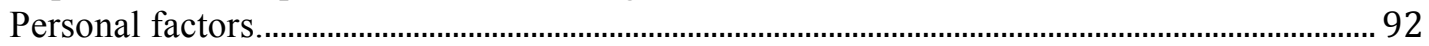

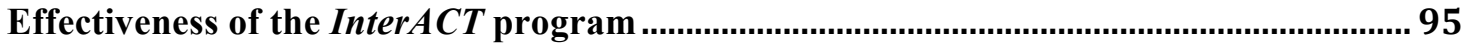

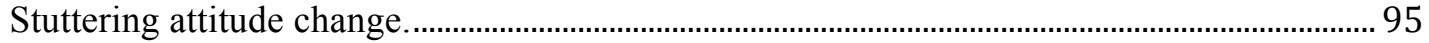

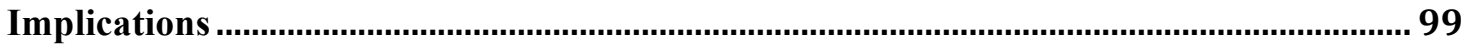

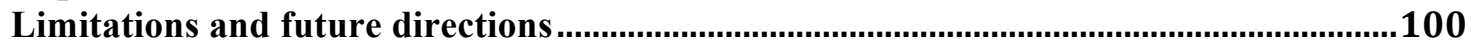

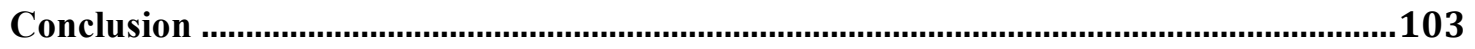

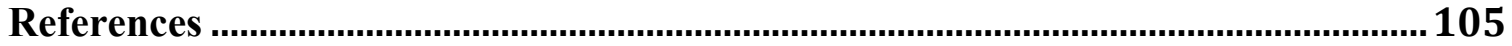

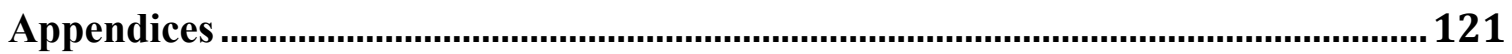

Appendix A: Public Opinion Survey of Human Attributes-Stuttering/Child ...........................121

Appendix B: Public Opinion Survey on Human Attributes-Stuttering ..................................122

Appendix C: Theory of Mind Task Battery (Adapted) and Scoring Form................................123

Appendix D: Participation Screening Instrument ...............................................................124

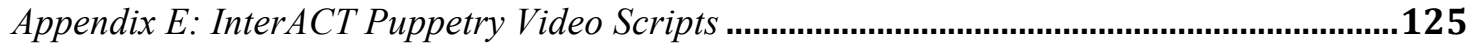

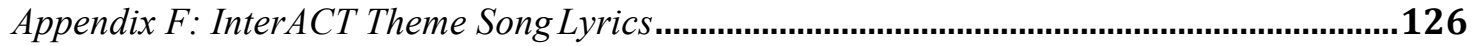

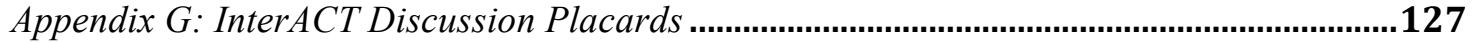

Appendix H: InterACT Coloring/Activity Book .....................................................................128

Appendix I: Institutional Review Board Approval Letter ....................................................129

Appendix J: Letter of Permission to Conduct Research ...........................................................130

Appendix K: Cover Letter and Consent Form ..................................................................131

Appendix L: Classroom of Attendance and Group Assignment/s ..........................................132

Appendix M: Demographic Ratings for 38 Parent Respondents ..........................................134

Appendix N: Images of the Six Classroom Sites........................................................................136

Appendix O: Schedule of Classroom Visits..............................................................................137

Appendix P: POSHA-S/Child Means for the Pilot and Experimental Groups ......................137

Appendix Q: Responses to the Prompt "What Does the Word 'Stuttering' Mean? "..............142 


\section{Chapter 1: Introduction}

Stuttering is a neurophysiological and genetically based communication disorder characterized by disruptions in forward flowing speech (Manning, 2010). The average age of stuttering onset is 33 months, with $95 \%$ occurring by 4 years of age. It is estimated that $5 \%$ of the preschool population stutters, and approximately $1 \%$ of the adult population stutters (Manning, 2010). The etiology of stuttering has long borne misunderstanding by the general public, which has contributed to the divisive stereotyping of people who stutter as being "nervous, shy, anxious, and incompetent" (Woods \& Williams, 1976). Those inaccurate beliefs about stuttering and stutterers ${ }^{1}$ are often inextricably linked to subsequent negative feelings about—and reactions towardpeople who stutter (St. Louis, 2015). The nexus of those beliefs, feelings, and reactions toward the disorder or the stuttering speaker is what is referred to as a stuttering attitude (Weidner, St. Louis, Burgess, \& LeMasters, 2015).

Over the past several decades, stuttering attitude research has claimed a strong foothold in the literature and continues to proliferate. Hundreds of studies from around the world have confirmed that negative stuttering attitudes transcend culture, race, sex, education level, income level, profession, and religious affiliation, and can have serious social ramifications on the lives of people who stutter (St. Louis, 2015). In fact, negative public stuttering attitudes can pervade various aspects of stutterers' lives, impeding their ability to form meaningful relationships, advance in their careers, and maintain a high quality of life (e.g., Boyle \& Blood, 2015; Craig, Blumgart, \& Tran, 2009; Gabel, 2015;

\footnotetext{
${ }^{1}$ The term stutterer and equivalent person-first derivations (e.g., person who stutters) are used interchangeably throughout this manuscript. It has been clearly documented that the terms are equal in connotation (St. Louis, 1999). Both are used in order to enhance the manuscript's readability, and at times, to distinguish between the actual attribute of stuttering and the person who stutters.
} 
Klompas \& Ross, 2004). Numerous calls have been made to educate the public about stuttering so that stereotypes, stigma, and discrimination toward people who stutter might be greatly diminished or eliminated. To date, the collective attempts to do so have yielded mixed results. Some studies have documented significant attitude improvement (e.g., Flynn \& St. Louis, 2011), while others evoked little to no attitude change (Kuhn \& St. Louis, 2015; McGee, Kalinowski, \& Stuart, 1996; Węsierska, Błachnio, Przepiórka, \& St. Louis, 2015).

Until recently, most stuttering attitude research (including that which has attempted to improve attitudes) has been carried out with school-aged children, adolescents, and adults. Consequently, it lacks a convincing explanation about the origin of stuttering attitudes and definitive recommendations about how attitudes might be improved for persons of different ages. Budding extensions of this line of research to young children are showing that negative stuttering attitudes might emerge as early as the preschool years (Langevin, Packman, \& Onslow, 2009; Weidner, St. Louis, Burgess, et al., 2015; Weidner, St. Louis, Nakıscı, \& Özdemir, 2015). These preliminary findings have generated many questions relative to the nature of young children's stuttering attitudes, factors that bear on those attitudes, and whether or not those attitudes are responsive to improvement. Answers to such questions could not only provide critical insight into the etiology of stuttering attitudes in the nonstuttering majority, but also inform how attitude improvement programs might be best carried out.

The purpose of this study, therefore, was to investigate preschool children's stuttering attitudes and their amenability to change. In order to do so, the study examined the nature of preschoolers' beliefs about stuttering and reactions toward stutterers. 
Importantly, it also measured the effect of an educational program aimed to improve their stuttering attitudes. The ensuing four sections provide (a) a comprehensive review of pertinent literature in this area and related fields (b) a detailed description of the methodology employed in this study, (c) a report of the qualitative and quantitative results, and (d) an interpretation about the meaningfulness and implications of the findings.

\section{Chapter 2: Review of the Literature}

\section{Adults' Stuttering Attitudes}

\section{Measuring stuttering attitudes in adults.}

Various instruments including semantic differential (bipolar adjective) scales (e.g., Woods \& Williams, 1976), surveys (e.g., Cooper, 1975), interviews (e.g., Hughes, 2008), and physiological measures (e.g., Guntupalli, Everhart, Kalinowski, Nanjundeswaran, \& Saltuklaroglu, 2007) have all documented that the general public holds misinformed or inaccurate perceptions of stuttering and stutterers. Such attitudes have been documented among divergent groups including: teachers (Abdalla \& St. Louis, 2012; Arnold, Li, \& Golt1, 2015; Crowe \& Walton, 1981; Ruscello, Lass, Schmitt, \& Pannbacker, 1994), speech-language pathologists (Cooper \& Cooper, 1996; Lass, Ruscello, Pannbacker, Schmitt, \& Everly-Myers, 1989), college students (Betz, Blood, \& Blood, 2008; Dorsey \& Guenther, 2000; Hughes, 2008; Hughes, Gabel, Roseman, \& Daniels, 2015; St. Louis \& Lass, 1981), and employers (Gabel, Blood, Tellis, \& Althouse, 2004; Gabel, Hughes, \& Daniels, 2008; Hurst \& Cooper, 1983a,1983b; Irani, Gabel, Hughes, Swartz, \& Palasik, 2009). However, differences in the instrumentation and methodologies used in those studies preclude accurate cross-study comparisons. Recognizing the need for a standard attitude measure, St. Louis (2011) developed the Public Opinion Survey on Human 
Attributes-Stuttering $(P O S H A-S)$. It has since become the most widely used instrument in both measuring stuttering attitudes and detecting change in those attitudes.

The POSHA-S is a byproduct of the International Project on Attitudes toward Human Attributes (IPATHA), a global initiative aimed to "understand and improve public attitudes toward stuttering and other stigmatizing human conditions worldwide through objective measurement" (St. Louis, 2015). The initiative was conceived from a "social epidemiological" paradigm so that conclusions about stuttering attitudes across populations — not individuals — could be drawn. Accordingly, the POSHA-S was designed for widespread use across diverse groups, cultures, and languages. With the contribution of more than 200 international collaborators, the $P O S H A-S$ has culminated in a master database of nearly 15,000 adult respondents from 42 countries and 26 languages from 225 different samples that represent diverse professions, religions, health and abilities, life priorities, and socio-economic status (St. Louis, 2015; 2016). Means are generated for each $P O S H A-S$ rating for every sample in the database. Thus, individual samples can be compared to the "average" sample (medians of the sample means to minimize the effect of outliers) as well as the outlying highest and lowest sample means reported to date. Not only have these epidemiological investigations confirmed that negative stuttering attitudes are widespread, but they have also helped to elucidate some of the various factors that might explain those stuttering attitudes. Better understanding those variables can broaden our understanding about the underpinnings of attitudes and also lead to focused and efficacious efforts to improve public stuttering attitudes. 


\section{Influential factors on adult's stuttering attitudes.}

Cultural variables. In adults, it appears that the influence of one's prevailing culture and family has an important, albeit not well understood, influence on stuttering attitudes. Although comparisons using the POSHA-S have shown that cross-cultural stuttering attitudes are more similar than dissimilar, important differences exist both within and across samples (e.g., Abdalla \& St. Louis, 2012; Ip, St. Louis, Myers, \& An Xue, 2012; Özdemir, St. Louis, \& Topbaş, 2011a; St. Louis, 2012; St. Louis, Przepiórka, et al., 2014; St. Louis, Sønsterud, Carlo, Heitmann, \& Kvenseth, 2014). Circa May 2016, stuttering attitudes appear to be lowest in Asian countries (e.g., India, Sri Lanka, Japan, and China), and highest in North America (i.e., the United States and Canada) and Western Europe (especially Scandinavian countries). A recent landmark study has further advanced our understanding of cultural influences on adults' stuttering attitudes (St. Louis et al., 2016). Using translated versions of the POSHA-S, researchers conducted between and within country comparisons of over 1,000 respondents from several European countries. Within country comparisons generated similar attitude ratings, but the between country ratings were much different. The researchers concluded that the prevailing culture of persons' geographical location seems to have an influential role on their stuttering attitudes.

Within-cultural differences have also been examined in select groups (e.g., speech-language pathologists and speech-language pathology students) as well as family and social units. In a study of Kuwaiti public school teachers and teachers in training, stuttering attitudes between the groups were quite similar prior to - but not followingan educational documentary (Abdalla \& St. Louis, 2014). The trainees' attitudes 
significantly increased, whereas the teachers' reflected little to no change. Those findings suggested that, while there are clear within-country similarities between groups prior to an intervention, some groups might have a higher propensity for attitude change. Another study examining within-country influences involved Turkish family units (i.e., parents, children, and adult relatives), and neighbors (Özdemir, St. Louis, \& Topbaş, 2011b). That study employed a probability sampling scheme to compare groups' $P O S H A-S$ ratings. Few differences emerged between those groups, suggesting a strong effect of one's social environment (i.e., their family and friends) on stuttering attitudes. Additional studies such as these—especially those which are carried out using probability sampling—will help to confirm or deconfirm suspected family and cultural influences on adults' stuttering attitudes.

Exposure to and familiarity with stuttering. Preliminary research has suggested that nonstutterers' exposure to stuttering or familiarity with the disorder, or lack thereof, have a notable impact on stuttering attitudes. Studies have shown that knowing a stutterer or having other personal contact with a stutterer tends to enhance stuttering attitudes (Delaney, 2001; Klassen, 2002; St. Louis \& Rogers, 2011a). Klassen (2002) used a semantic differential scale and questionnaire to measure the attitudes of nonstutterers who had a friend, colleague, family member, student, or teacher who stuttered. Results were compared to respondents with no ongoing contact with a stutterer. The study revealed that those who had personal contact with a stutterer held more favorable attitudes than persons with no prior contact. Specifically, those with personal contact were significantly less likely to rate stutterers as "shy, insecure, withdrawn, and anxious." Similarly, St. Louis and Rogers (2011a) used the POSHA-S database of nearly 4,000 
respondents to examine the effect of one's personal experience with stuttering (i.e., persons known who stutter) on their stuttering attitudes. Results showed that more personal experience with stuttering was associated with better stuttering attitudes, and the effects were often large. Studies of board-recognized specialists in fluency disorders, self-help leaders in stuttering, and parents of children who stutter, further uphold that personal contact with stutterers can have a profound, positive effect on stuttering attitudes (St. Louis \& George, 2008; St. Louis, Kuhn, \& Lytwak, 2015). It should be noted, however, that some studies have reported no significant effect of personal contact with stutterers on stuttering attitudes (e.g., Boyle, Blood, \& Blood, 2009; Gabel, et al., 2004). As such, there remains a need to examine how the nature and quality of those interactions might influence one's perceptions of people who stutter.

One's familiarity with stuttering, as gained through coursework or general information, has also been shown to enhance stuttering attitudes. In several studies, speech-language pathology students have consistently demonstrated more positive stuttering attitudes compared to students in other fields of study (Hughes et al., 2015; Junuzović-Žunić et al., 2015; Węsierska, Węsierska, St. Louis, Beste-Guldborg, 2015). Speech-language pathology students' general interest in the field, familiarity with stuttering as learned through coursework, as well as their personal interactions with people who stutter via presentations and attendance at stuttering support group meetings, were suggested to account for those differences. St. Louis, Przepiórka, and colleagues (2014) termed this a "halo effect." The collective findings of the aforementioned studies are particularly important because they suggest that persons' stuttering attitudes might be improved via increased knowledge and exposure to stuttering. 
Socioeconomic and personal variables. The effect of socioeconomic factors (i.e., level of education and income) on adults' stuttering attitudes remains somewhat inconclusive. In a recent study, Arnold and colleagues (2015) showed a positive relationship between teachers' number of years of education and their stuttering attitudes. St. Louis and Rogers (2011b) reported similar findings, showing that stuttering attitudes are positively related to higher levels of education as well as income, although their reported effect was small. By contrast, a study by Özdemir and colleagues (2011b) revealed no such relationship within a probability sample.

Personal variables (i.e., sex and age) have also been examined, but convincing conclusions about their impact on stuttering attitudes have yet to be reached. Using a random sample of 100 respondents generated from the POSHA-S database, St. Louis (2012a) showed virtually no difference between male and female respondents. Those findings are consistent with a probability sample involving 331 respondents across the entire country of Portugal (Valente, Jesus, Leahy, \& St. Louis, 2014). In addition, a study of over 200 respondents from the United States and Iran reported that neither the sex of the respondent nor the stuttering speaker was a strong predictor on stuttering attitudes (St. Louis, LeMasters, \& Poormohammad, 2015). By contrast, some studies have detected a very small effect on stuttering attitudes, with women holding more positive reactions to stutterers than men (Arnold \& Li, 2016; Arnold et al., 2015; Li \& Arnold, 2015). The impact of age on attitudes has also been of interest, but by virtue of the POSHA-S design, most respondents have been adults or young adults. Some studies have suggested that stuttering attitudes might fluctuate throughout adulthood, but the patterns are not yet well understood. Valente and colleagues (2014) showed significant differences in attitudes 
among 18- to 24-year-olds and 25- to 64-year-olds compared to respondents 65 years and older, with the two younger age groups having more positive attitudes than the oldest age group. In addition, Arnold and colleagues (2015) reported a positive, significant effect of age on beliefs about stuttering for respondents 18 to 89 years of age. Only a few studies to date have used the $P O S H A-S$ with older children and adolescents. Özdemir et al. (2011b) showed that 11- to 12-year-old children held stuttering attitudes comparable to their parents, extended family, and neighbors. Consistent with those findings, Kuhn and St. Louis (2015) reported that stuttering attitudes of junior high students were similar to POSHA-S database medians of adult respondents. Taken together, attitudes of schoolaged children and adolescents appear to be closely related to those of adults. Recent extensions of this line of research, however, suggest young children might hold quite disparate attitudes from adults (Weidner, St. Louis et al., 2016; Weidner, St. Louis, Burgess, et al., 2015; Weidner, St. Louis, Nak1sc1, et al., 2015). These preliminary findings suggest that young children's attitudes may be of particular importance in understanding how stuttering attitudes emerge and change over the course of one's life.

\section{Children's Stuttering Attitudes}

\section{Stuttering awareness among fluent and stuttering children.}

It has been consistently shown that young children who do and do not stutter are aware of stuttered speech (Ambrose \& Yairi, 1994; Ezrati-Vinacour, Platzky, \& Yairi, 2001; Griffin \& Leahy, 2007). Studies examining children's stuttering awareness (i.e., their ability to distinguish between fluent and stuttered speech) have traditionally used a video stimulus of stuttering and nonstuttering puppets followed by a short "yes/no" survey, presented orally (Ambrose \& Yairi, 1994; Ezrati-Vinacour et al., 2001). Using 
such methodology, Ambrose and Yairi examined 20, 2- to 6-year-old children who stutter and 20 fluent, age-matched peers in three different visits over the course of three years. Children were classified into an "older" or "younger" group at time of enrollment, with mean ages of 4.3 years and 3.0 years, respectively. At each visit, children were asked to identify the puppet whose speech was most like their own. Comparisons between the two groups revealed a significant effect of age on one's stuttering awareness, with the older children demonstrating a more acute awareness of fluent or stuttered speech than the younger children. Importantly, however, several children in the younger group accurately judged their own speech patterns, indicating that stuttering awareness might emerge at a young age. Ezrati-Vinacour and colleagues (2001) replicated that study with 3- to 5-yearold stuttering and nonstuttering children. In that study, $25 \%$ of 3 year-olds were able to differentiate between stuttered and fluent speech, and children's ability to do so steadily increased with age. In addition to stuttering awareness, several studies also examined stuttering children's attitudes toward their own speech (e.g., Vanryckeghem, Brutten, \& Hernandez, 2005). These studies revealed two pertinent findings. First, as early as preschool, stuttering children were shown to hold considerably worse attitudes toward their own communication skills than fluent children. Second, children's stuttering awareness and the emergence of negative stuttering attitudes appeared to be closely linked processes. Those findings prompted subsequent investigations to determine if nonstuttering preschool children also have negative attitudes toward stuttered speech.

\section{Stuttering attitudes in nonstuttering children.}

Although measuring children's stuttering attitudes has been a fairly recent undertaking, there is considerable evidence of stuttering stereotypes among school-aged, 
kindergarten, and preschool children. A recent study by Panico, Healy, and Knopik (2015) used a mixed methods design to measure elementary school children's perceptions of stuttering. In that study, 88 children 8 - to 12 -years-old watched four videos each depicting a peer speaking fluently (control condition), or with mild, moderate, and severe stuttering. On 7-point Likert scales, participants rated their level of agreement with five statements about the speaker's talking (e.g., "This girl is a good speaker" and, "I would feel comfortable making friends with this girl"). Results showed that children were more inclined to negatively rate the speaker's fluency compared to ratings of their comfort level in listening to or making friends with the speaker. Comparisons between the severity conditions revealed that respondents were less likely to rate a severe stutterer as being a "good speaker" and having "smooth speech" compared to a mild or moderate stutterer. Participants also described the speaker's talking in each of the conditions. Results showed that participants generated significantly more negative comments for each of the stuttering conditions compared to the control condition. Franck, Jackson, Pimentel, and Greenwood (2003) reached similar conclusions about school-aged children's perceptions of stutterers. Seventy-five fourth and fifth grade students, placed in two conditions, watched a video of either a stuttering or fluent speaker. They then rated their perceptions of the speaker's traits using a semantic differential scale (e.g., friendlyunfriendly, outgoing-shy, brave-afraid). Results showed that the participants were significantly more inclined to favorably rate the fluent speaker compared to the stuttering speaker. In a similar study by Hartford and Leahy (2007), 80, 6- to 13-year-old children listened to audio recordings of both fluent and stuttered speech. They then assigned one of the speakers to various statements such as "Who do you think would be a quiet 
person?" and "Who would you like to be friends with?" The respondents consistently associated negative attributes with the stuttering speaker, and described the stuttering speaker as a "nervous person," "quiet," and "shy."

Several other studies have expanded this line of research to examine the stuttering perceptions among slightly younger children. Griffin and Leahy (2007) evaluated the stuttering awareness and attitudes of 183 - to 5-year-old nonstuttering children. After watching a video featuring a fluent and stuttering puppet, they were asked "yes/no" questions relating to the puppets' communication skills (e.g., "Do you think it was easy for the puppet to tell the story?") and the child's behavioral intentions toward the puppet (e.g., "Would you like to be friends with the puppet?"). The children also described the puppets using a semantic differential or bipolar adjective scale (e.g., "happy/sad, many friends/no friends, outgoing/shy, and clever/stupid"). Children in all age groups expressed more negative perceptions of the stuttering puppet compared to the fluent puppet, with the 4-year-old children holding the most negative attitudes.

Langevin and colleagues (2009) used a qualitative approach to investigate the reactions among typically fluent preschoolers toward their stuttering peers. The researchers video recorded the naturalistic interactions of four preschool children who stutter (each of whom attended a different school) with their fluent peers during play. Peer responses to moments of stuttering were qualitatively categorized as being "positive/neutral" or "negative." A majority of the peer responses were positive/neutral, ranging from $71.4 \%$ to $97.2 \%$ across the four stuttering children. The inverse negative peer responses, ranging from $2.8 \%$ to $28.6 \%$, included changing the topic or activity, exhibiting outward confusion, walking away, interrupting, mocking, and ignoring the 
stuttering child. As a result, children who stutter were shown to have a disadvantage in leading play activities, participating in dramatic play, and resolving conflicts.

As made clear by the foregoing research, several methodologies involving scales, open-ended questions, and observations have been used to detect negative stuttering attitudes among school-aged and preschool children. Until recently, no standard measure of stuttering attitudes was available. In response to that need, Weidner \& St. Louis (2014) developed the POSHA-S/Child. The instrument, described in the methodology section, is an extension of the POSHA-S and is the first known standard instrument to objectively measure what children think about stuttering and their stuttering peers. The POSHAS/Child was used to compare the stuttering attitudes of 27 nonstuttering preschool-aged children and 24 nonstuttering kindergarten children from a mid-Atlantic state in the USA (Weidner, St. Louis, Burgess, et al., 2015). Several important findings emerged from that study. First, children in the preschool and kindergarten groups held negative or uninformed stuttering attitudes. They expressed little knowledge about the causes of stuttering and how to appropriately interact with a stutterer. Most children reported they would say, "slow down" and would finish the words of a peer who stuttered. (In studies of preferences of adults and children who stutter, these responses were regarded as undesired [Rodriguez et al., 2015; Weidner, Coleman, et al., 2015]). It should be noted, however, that the children almost unanimously reported that they would not laugh at a person who stutters. Second, results revealed that children's attitudes toward the "stutterer" were considerably more positive (or less negative) than toward the actual attribute of "stuttering" (p. 81). Respondents expressed that stutterers are fun to play with, are able to do the same things as others, and have the potential to make friends and make 
good choices. At the same time, they noted they would be "worried" if they, their family, or their friends stuttered. The third and perhaps most intriguing finding was that preschoolers' stuttering attitudes were significantly worse than the attitudes of the kindergarten children. The preschoolers were more likely to perceive stutterers as being "different" and "[un]able to talk well" compared to the kindergarteners. A replication of that study was carried out with Turkish children (Weidner, St. Louis, Nakısc1, et al., 2015). In that study, a Turkish translation of the POSHA-S/Child was administered to 31 Turkish nonstuttering children and compared to the American preschool sample from the aforementioned study. Results were remarkably similar between the groups. In fact, children's overall stuttering attitude score between the American and Turkish groups was exactly the same.

These combined studies not only uphold the existence of negative thoughts and beliefs about stuttering among typically fluent preschoolers, but also provide evidence that adverse reactions toward stuttering peers might also arise during the preschool years. Children's stuttering attitude research, interpreted against the backdrop of research in related fields, is generating discussion about what might account for the origin of stuttering attitudes. As with adults, this is an important step in expanding epidemiological research of and devising programs intended to improve stuttering attitudes.

\section{Influential factors on children's stuttering attitudes.}

Cultural and parental variables. To date, the only between-culture investigation of children's stuttering attitudes was carried out between the American and Turkish preschool groups previously described (Weidner, St. Louis, Nakısc1, et al., 2015). Not only did comparisons between those groups reveal limited cultural effects, but the groups' 
overall stuttering attitude scores were identical. The lack of cultural differences led researchers to examine other within-culture variables, such as the influence of parental stuttering attitudes. St. Louis, Weidner, and Mancini (2016) compared the stuttering attitudes of 4- to 6-year-old children and parents using the adult and child versions of the POSHA-S. Results revealed large differences between the groups, with the children holding worse attitudes than the parents. By comparison, a study of 11- to 12-year-old Turkish children revealed virtually identical attitudes between the children, their parents, grandparents, and neighbors (Özdemir, St. Louis, \& Topbaş, 2011b). Taken together, these studies suggest that school-aged children might be more influenced by parental attitudes than preschool and kindergarten aged children. The findings are consistent with psychology research on racial prejudice, which has shown that older children (i.e., over 7 years of age) tend to be more influenced by their parents' attitudes than preschool-aged children (Aboud, 1988).

To date, there is a lack of evidence supporting an influence of between and within cultural variables on children's stuttering attitudes. This is particularly surprising, given that adult research has cited respondents' nationality as being a contributing factor on stuttering attitudes (St. Louis, 2015). A great deal more research needs to be conducted to support such claims, which will undoubtedly involve more cross-country comparisons obtained via representative sampling.

Exposure to stuttering. Consistent with the adult attitude literature, children's exposure to or experience with stuttering has been suggested to be an influential factor on their stuttering attitudes (Langevin et al., 2009; Weidner, St. Louis, Burgess, et al., 2015; Weidner, St. Louis, Nakısc1, et al., 2015). Preschool children from the USA and Turkey, 
for example, held virtually equivalent prior exposure to or experience with stuttering. None of the participants stuttered and only two children had previously interacted with a person who stuttered. Thus, for nearly all of the child respondents, their only exposure to stuttering was a brief video stimulus featuring stuttering children. The pervasive negative stuttering attitudes across these otherwise diverse groups pointed to a very limited stuttering experience as a potential influential factor on their stuttering attitudes. Studies involving older children and adolescents also suggest that personal contact might mitigate and/or improve stuttering attitudes (Flynn \& St. Louis, 2011; Langevin, 2000, 2015).

Demographic and personal variables. Unlike the adult research, children's socioeconomic (SES) status has not been shown to correlate with stuttering attitudes. In the study carried out by Weidner, St. Louis, Burgess, et al. (2015), the preschool and kindergarten samples represented significantly different social backgrounds, with the kindergarten children having significantly lower SES than the preschool children. The results, which showed higher stuttering attitudes among the kindergartners, are counter to what has been previously observed in adults. Further support for minimal effect of SES on children's stuttering attitudes was gained from the study comparing American and Turkish preschool children. Despite significantly lower SES ratings among the Turkish sample, scant attitudinal differences emerged between the groups.

Beyond demographic variables, children's personal factors are also of interest. It has been suggested that the rapid cognitive-linguistic changes that occur between 2 and 6 years of age influence children's ability to detect stuttered speech. Ambrose and Yairi (1994) stated, “ [children's] precocious development in the area of awareness or other environmental factors no doubt play a role in the realization of fluency patterns" (p. 240). 
Further, Griffin and Leahy (2007) reported a suspected influence of age on the emergence of children's stuttering attitudes, with 4-year-old children holding the most negative attitudes compared to 3 and 5 year old children. Weidner, St. Louis, Burgess, and colleagues (2015) detected similar findings. In that study, significant differences in the attitudes of preschool and kindergarten children emerged, with preschoolers holding worse or less informed stuttering attitudes than slightly older children. The explanation for those findings remains unclear. However, children's ability to detect differences in others might be at play.

Social cognition is also suspected to underlie children's recognition that stutterers may have unique communication experiences. Social cognition, also known as "theory of mind," involves children's ability to understand that others have different mental states, recognize social groups and social norms, and adapt to various social contexts (Flavell, 1999). A recent meta-analysis on the topic revealed that advanced social cognition was significantly associated with positive peer relationships (Slaughter, Imuta, Peterson, \& Henry, 2015). During the preschool years, children's egocentrism diminishes, and they become increasingly aware that others have different experiences, perceptions, knowledge, and emotions than their own (Wellman, Cross, \& Watson, 2001). This paradigm shift allows young children to detect salient differences in others such as their race (e.g., Aboud, 1988), sex (e.g., Cvencek, Greenwald, \& Meltzoff, 2011; Gelman, Collman, \& Maccoby, 1986), physical abilities (e.g., Cooper, 2003), and communication skills (e.g., Gertner \& Rice, 1994; Guralnick, Connor, Hammond, Gottman, \& Kinnish, 1996). Children often classify persons by one characteristic, lacking the ability to simultaneously process the many different characteristics of a person. They use those 
classifications to generate beliefs about how persons with a given characteristic should behave. For example, classification by one's sex might cause children to falsely expect that boys — but not girls - play with trucks (Gelman et al., 1986). Such stereotyping of persons into rigid classifications may cause children to formulate inaccurate perceptions about others and be a precursor to prejudice (Bigler \& Liben, 2006; Mulvey, Hitti, \& Killen, 2010). In fact, in her seminal "social-cognitive developmental theory," psychologist Frances Aboud (1988) posited that prejudice, the negative appraisal of others based on salient features, is closely tied to children's cognitive ability to think dynamically about differences in others. She noted that affective processes drive preschool children's attitudes whereas cognitive processes drive attitudes in slightly older children. As noted, Aboud proposed that prejudice peaks during the preschool years around 4 years of age and declines around 7 years of age, and attitudinal patterns in stuttering support this pattern (Weidner, St. Louis, Burgess, et al., 2015).

Negative appraisal of others may also cause young children to show favorable bias toward those similar to themselves and to fear or exclude those who exhibit different traits or attributes (Levy \& Killen, 2008). In stuttering, typically fluent children may demonstrate those biased behaviors toward children who stutter (Ezrati-Vinacour et al., 2001; Griffin and Leahy, 2007; Weidner, St. Louis, Burgess, et al., 2015; Weidner, St. Louis, Nak1sc1, et al., 2015). In the international study, Weidner and colleagues (2015) showed that preschool children from both Turkey and the USA are inclined to evaluate children who stutter as being "[un]able to talk well" and to exhibit negative or uninformed social responses. Similarly, Ezrati-Vinacour et al. (2001) observed that 4year-old nonstuttering children labeled stuttered speech as "not good" and expressed 
preference for fluent versus stuttering friends. Further, Griffin and Leahy (2007)

documented biased behaviors among typically fluent preschool children. In that study, nearly half of the respondents exhibited overt negative reactions in response to a stuttering puppet such as laughing or looking at the examiner, and rated fluent speech significantly more favorably than stuttered speech. Clearly, these studies support that social-cognitive development influences children's stuttering attitudes, but the relationship has yet to be fully understood.

\section{Call for Attitude Change in Children Ramifications of negative stuttering attitudes in children.}

Children's negative stuttering attitudes have the potential to be detrimental to the social and emotional well-being of children who stutter. Research has shown that as early as preschool, children who stutter are at risk for social distancing or exclusion (EzratiVinacour et al., 2001; Langevin et al., 2009; Griffin and Leahy, 2007). When talking to a peer who stutters, children may lack knowledge about how to respond appropriately to episodes of stuttering and may walk away, finish their peers' sentences, express confusion, or say, "slow down" (Langevin et al., 2009; Weidner, St. Louis, Burgess, et al., 2015). As noted, such responses have been reported to be generally undesired or unhelpful among stuttering school-aged children (Weidner, Coleman, et al., 2015). As a result, preschool children who stutter may not have communication opportunities commensurate to that of their fluent peers. Even though no known longitudinal studies have investigated the long-term ramifications of negative attitudes toward preschool children, evidence suggests that negative attitudes toward stuttering children persist through the elementary school-aged years and adolescence. There is considerable 
documentation of teasing and bullying toward stuttering children, which may include name-calling and mocking stuttered speech (Blood \& Blood, 2004; Langevin, 2015; Langevin, Bortnick, Hammer, \& Wiebe, 1998; Mooney \& Smith, 1995; Yaruss, Murphy, Quesal, \& Reardon, 2004). In two separate studies of school-aged children who stutter, it was shown that over $80 \%$ of children experienced teasing and bullying secondary to their stuttering (Langevin et al., 1998; Mooney \& Smith, 1995). Children who stutter are also prone to social exclusion as well as having low social status among their peers (Davis, Howell, \& Cooke, 2002; Evans, Healey, Kawai, \& Rowland, 2008; Hartford \& Leahy, 2007). Similar ramifications have been documented with adults, further confirming the need to mitigate negative stuttering attitudes at an early age.

\section{Changing stuttering attitudes.}

The literature clearly highlights the need for peer education about stuttering (Hartford \& Leahy, 2007; Murphy \& Quesal, 2002; Murphy, Yaruss, \& Quesal, 2007). To date, attempts to do so in school-aged children and adolescents have yielded mixed results. Flynn \& St. Louis (2011) investigated high-school students' attitude change after

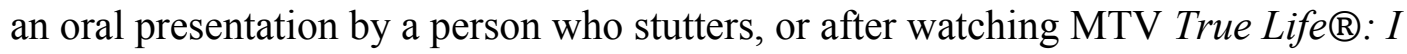

Stutter, followed by a shortened oral presentation. Adolescents' attitudes were about equally amenable to change in both conditions. By contrast, McGee and colleagues (1996) showed that high school students' attitudes actually worsened following a video about stuttering. Further, a recent study conducted among Polish high school students showed virtually no attitude change after either a video or information session about stuttering (Węsierska et al., 2015). This was also the case in another recent study that 
used a video intervention to improve middle school students' stuttering attitudes (Kuhn \& St. Louis, 2015).

Unlike research with adolescents, which has shown generally equivocal results, school-aged children's stuttering attitudes have been shown to be amenable to change (Langevin, 2000, 2015; Langevin \& Prasad, 2012). In a large-scale feasibility study, over 600 school-aged children participated in a multimodal educational program, the Teasing and Bullying: Unacceptable Behavior (TAB) program. The program is comprised of classroom lessons, a video of a child who stutters, guided discussion, as well as takehome activities. Changes in stuttering attitudes were determined using the Peer Attitudes Toward Children who Stutter scale (PATCS). The instrument, which has sound psychometric properties (Langevin, 2009), measures children's comfort level being with a stutterer, intentions or responses when interacting with a stutterer, and frustration level when talking with a stutterer. The study showed that the $T A B$ program resulted in better stuttering attitudes, increased interest in stuttering, as well as improved attitudes toward bullying (Langevin, 2000, 2015; Langevin \& Prasad, 2012).

Considering that nonstuttering children might react negatively to stuttering peers at a young age, attitude change programs introduced in the later school-age years or adolescence may be overdue. By that point in time, stutterers may have already been subject to negative or insensitive reactions from their peers, and may have experienced emotional or social harm secondary to their stuttering. Recognizing that concern, Weidner, St. Louis, Burgess and colleagues (2015) posited that stuttering education should be carried out when negative stuttering attitudes first start to emerge, i.e., during the preschool years. Accordingly, Weidner (2015) developed a new program aimed teach 
young children about the nature and causes of stuttering and how to appropriately respond to peers who stutter. The program, entitled the Attitude Change \& Tolerance Program (InterACT), was used in a recent pilot study to investigate whether or not preschool children's stuttering attitudes are amenable to change (Weidner \& St. Louis, 2015). Researchers measured children's stuttering attitudes before and after the program using the POSHA-S/Child. Preliminary results, described later, revealed notable improvement in preschoolers' stuttering attitudes following the program. The study provided strong support for the expansion of the study with a larger sample size.

\section{Need for Current Study}

Two main factors drive the need for this study. The first is to measure children's stuttering attitudes and to determine the factors that contribute to attitudinal development. Nearly 40 years ago, Woods and Williams (1976) noted the need for this research, posing, "At what age do stutterers (and normally speaking persons) develop their stereotype of a stutterer and by what mechanisms is it learned?" (p. 277). For decades, that question has remained largely unanswered, even after several follow-up calls to investigate the origin of stuttering attitudes (e.g., Ezrati-Vinacour et al., 2001; Franck et al., 2003; Hartford \& Leahy, 2007). Although preliminary research points to a stuttering stereotype origin among preschool-aged children, there is not yet substantial evidence to corroborate those claims. As has been successfully carried out in adult stuttering attitude research, there is a critical need to establish a consistent methodology using a standard measure among young children. Doing so will result in a greater understanding about the origin of stuttering attitudes, thereby extending epidemiological research in this area. In 
addition, results pertaining to influential variables will be used to inform programs for attitude change.

The second impetus of this study is to investigate the degree to which preschool children's stuttering attitudes are amenable to change. The need to do so is grounded in a compelling literature base. In fact, Ezrati-Vinacour and colleagues (2001) stated, "The fact that normally fluent children begin to perceive differences negatively by age 5 may help us to focus on the appropriate age for educational intervention. This education process may prevent stereotyping and negative images of people with stuttering or other disabilities" (p. 377). Echoing those claims, there is a critical need to educate young children about stuttering as close as possible to the onset of stuttering awareness and attitude development. As has been made clear in the literature, that time is the preschool years. The preliminary study by Weidner \& St. Louis (2015) provided compelling evidence that preschoolers' attitudes are indeed amenable to change, and urged that a larger-scale investigation be undertaken. Such research will provide a more complete understanding of the etiology and trajectory of stuttering attitudes and help to identify the developmental period in which stuttering attitudes are most amenable to improvement. It is hoped that intervention at an early age will mitigate stuttering attitudes so that subsequent negative reactions toward stuttering children might be diminished or prevented altogether.

\section{Research Questions}

To more fully understand the etiology of young children's stuttering attitudes and to determine of their attitudes can be changed, this study addressed the following research questions: 
1. What do nonstuttering preschool-aged children believe about stuttering and people who stutter, and what are their self-reactions toward stuttering peers, as measured using the POSHA-S/Child?

2. To what extent do parental stuttering attitudes, demographic variables (i.e., parental education level and relative income), exposure to stuttering (i.e., personal experience with stuttering and persons known), and personal variables (i.e., social cognition, health and abilities, and age) correlate with or predict preschool children's stuttering attitudes?

3. To what extent does the InterACT program effect change on preschool children's stuttering attitudes?

Based on the current understanding of stuttering attitudes in young children, it is hypothesized that preschool children will hold negative or uninformed stuttering attitudes prior to the InterACT program. Specifically, it is expected that children will have little knowledge about the causes of stuttering and how to appropriately react to people who stutter. Second, it is hypothesized that children's social cognitive skills and experience with or exposure to stuttering will be positively and significantly associated with their stuttering attitudes. Given that preschool children's attitudes toward persons with disabilities are suggested to be independent of their parents' attitudes (St. Louis, Weidner, et al., 2016), significant differences between the groups are expected. Other variables relating to children's demographics and health and abilities are not predicted to be associated with children's stuttering attitudes. Third, based on preliminary findings of the Inter ACT program, it is expected that children's overall stuttering attitudes will 
improve (Weidner \& St. Louis, 2015), with notable gains relative to their knowledge about stuttering and reactions toward people who stutter.

\section{Chapter 3: Methodology}

\section{Design}

This study involved both descriptive and experimental components. The descriptive portion of the study, which addressed the first and second research questions, involved measuring children's stuttering attitudes quantitatively using the POSHAS/Child and then interpreting attitudes relative to the various predictor factors previously mentioned. The experimental component of the study, which addressed the third research question, involved examining the change in children's stuttering attitudes following their participation in the InterACT program. Qualitative data was used to augment the quantitative results, but the qualitative component was not robust enough to classify this study as employing a mixed-methods design. The study follows the extensive line of social epidemiological research in the arena of public attitudes toward stuttering (St. Louis, 2015, 2016). Accordingly, the methodology was designed so that impressions of stuttering attitudes held by a diverse sample of preschool children, not individuals themselves, could be deduced.

\section{Attitude Instrument}

\section{Child stuttering attitude measure: The POSHA-S/Child.}

Overview. The Public Opinion Survey on Human Attributes-Stuttering/Child (POSHA-S/Child) was used to measure children's stuttering attitudes before and after the InterACT program (Appendix A). The POSHA-S/Child, which is an extension of its adult counterpart, measures young children's beliefs about stuttering and self reactions toward 
people who stutter. It is intended to be used with children 3 to 10 years of age, and can be administered either verbally (i.e., for non- or novice readers) or using a pencil-and-paper version (i.e., for proficient readers). Prior to this study, the POSHA-S/Child has been used with 69 English-speaking children from the USA ranging from 3- to-7 years old, and a Turkish translation of the instrument has been used with 31 Turkish children 3 - to 5-years-old (Weidner, St. Louis, Nakısc1, et al., 2015; Weidner, St. Louis, Burgess, et al., 2015). Those studies provided preliminary evidence of the instrument's construct and face validity.

The psychometric properties of the POSHA-S/Child were further examined in a recent study in which 378 adults took both child and adult versions of the POSHA-S (St. Louis, Weidner, et al., 2016). (An adult sample was used, as only adults could complete of the instrument whereas young children could complete only the child version.) Results revealed a high concordance between the versions, and provided additional evidence of the concurrent and construct validity of the POSHA-S/Child.

Demographic section. The POSHA-S/Child begins with a demographic section to gather information about the child and the child's family, and is filled out by a parent or guardian. Information about the family includes relative income derived from incomes of friends and family as well as all of the people in one's country and the highest level of education completed by the parent who is most often with the child. General information about the child pertains to his/her involvement in school or daycare and the number of brothers and sisters. Parents also rate the child's physical and emotional health as well as their cognitive and speech/language skills on 5-point Likert scales. These scores are averaged into an overall Health and Abilities rating. Finally, children's exposure to or 
personal experience with stuttering, obesity, and wheelchair-use is reported. The obesity and wheelchair items are treated as "anchor traits" to better understand children's stuttering attitudes within the context of other stigmatizing human attributes (St. Louis, 2015). Obesity and wheelchair use are easily recognized by children (e.g., Bell \& Morgan, 2000; Hong, et al., 2014) and have been historically viewed as stigmatizing conditions.

Stimulus video. The child portion of the POSHA-S/Child begins with a 1.25 minute stimulus video featuring two animated stuttering avatars, one girl and one boy. Following the video, the administrator defines the term stuttering, "These children stutter. Stuttering is what happens when a person's words or sounds bounce 1-1-1-ike this, or stretch liiiiiike this, or when no words or sounds come out l-----ike this.” The stimulus video and follow-up definition of stuttering provide the children with concrete examples of stuttering so that they may accurately respond to subsequent survey items. The video was developed using the iPad application, Buddy Poke (Westwood \& Ho, 2013), which permits users to design custom avatars relative to race, sex, features (i.e., eye and hair color), and clothing. Users record voice-overs for the avatars, which causes the avatars' mouths to move. The video used in this study controlled for potential confounding variables including the avatars' race, sex, and appearance. The inclusion of two avatars permits the use of gender-neutral and plural form on survey items (e.g., "children who stutter" versus "the boy who stutters"). It also allows children to base their responses on exposure to more than one person who stutters. The avatars engage in a brief conversation about their interests (i.e., 5 lines each) at a language level appropriate for young children, e.g., "I like to play outside. Do you?" Each of the avatars' stuttering, 
which was recorded by the author, consists of initial sound and syllable repetitions, prolongations, and blocks. Physical tension is marked using unnatural prosody, including rising pitch changes. The avatars' stuttering was judged to be "severe" by two Board Certified Specialists in Fluency, Ken St. Louis and Craig Coleman.

Stuttering items. After showing and explaining the video, the examiner proceeds to ask the child 40 "yes/no" questions about stuttering. The items are grouped into seven components, namely: “Traits," "Who Should Help," “Cause," "Potential," “Accommodating/Helping," "Distance/Sympathy," and "Knowledge." For example, the "Traits" component is an average of items including: children who stutter are (a) nervous, (b) shy, (c) different than others, (d) able to talk well, and (e) at fault. The first four of the above-listed components are clustered into a "Beliefs" subscore and the remaining three components are clustered into a "Self Reactions" subscore. The Beliefs and Self Reactions subscores are averaged into an Overall Stuttering Score. A third subscore, described in the next section, relates to obesity and wheelchair use.

As is the case for the POSHA-S for adults, the valence of the stuttering items as being either "positive or informed" or "negative or uninformed" is based on three primary factors. First, many items (such as those grouped in the Causes, Traits, and Who Should Help components) are judged based on the accuracy of the response. For example, our current understanding of stuttering causes supports genetic involvement and rejects other theories such as learning or trauma (Drayna, 2014; Manning, 2010). Accordingly, affirmative responses on the POSHA-S/Child item, "stuttering came from [their] mom or dad when they were born" is considered to be positive or informed, whereas affirmative responses on the item, "stuttering happens because [they] learned to 
talk that way" is considered to be negative or uninformed. This reasoning also holds true for the Traits and Who Should Help components. For example, research has made clear that being "shy" and "nervous" are independent of stuttering, even though such beliefs are commonly held among the general public (Woods \& Williams, 1976). Second, the valence of items is also based on studies investigating stutterers' support preferences (Rodriguez et al., 2015; Weidner, Coleman, et al., 2015). Those studies concluded that both adults and children who stutter consider it helpful when listeners are patient and give them time to speak, and unhelpful when listeners finish their words, walk away, laugh, or say, "slow down." In a similar way, children who stutter viewed "pity" as being helpful, but their parents did not. As such, that item was judged to reflect a positive attitude among children and is the only inversely rated item between the adult and child versions. Third, the social acceptability of responses is also factored into item ratings. For example, "[children who stutter] are fun to play with" is considered to reflect a positive attitude because it suggests social intentions of inclusivity. By contrast, "[I would] laugh at a child who stutters" reflects an undesired social response and is rated negatively.

Obesity/Wheelchair subscore. The final portion of the POSHA-S/Child generates values for children's preference of stuttering and the two anchor traits, obesity and wheelchair use. Children are shown $4.4 \times 8.8 \mathrm{~cm}$ line drawings of a child who is obese, is in a wheelchair, or who stutters (Appendix A). One set of drawings, depicting essentially the avatars in the stimulus video, represents a girl with each of those attributes, and another set represents a boy with each of those attributes. Respondents are shown the sets of their respective sex. The stuttering drawings are the same as the avatars in the video; the others are modified to show obese or wheelchair bound children. The examiner 
presents pairs of drawings in a counterbalanced sequence and asks the child, "Which one would you want to be?" Their responses, along with their parent report of exposure to and experience with the traits, are used to derive an "Obesity/Wheelchair" subscore.

Scoring. The examiner instructs children to respond "yes" or "no" to the survey items, and assures that "there are no right or wrong answers." If a child spontaneously responds, "I don't know" (or an equivalent statement thereof), that item is marked as "not sure." If a child does not respond at all, the examiner repeats the item one time. If the child still is unsure, the item is recorded as "not sure," and the examiner proceeds to the next item. Responses are assigned a value where "no" $=1$, "not sure" $=2$, and "yes" $=3$. After that, scores are converted to a -100 to +100 scale, wherein "no" responses are assigned a value of -100 , and "yes" responses are assigned a value of +100 . "Unsure" responses are assigned a value of " 0 ," as they represent a neutral rating that is neither positive nor negative. The rationale for the conversion to the -100 to +100 continuum bears on extensive research with the POSHA-S. St. Louis (2012) explained that the conversion of attitudes from ordinal to ratio scales is justifiable, and the 201-point continuum is intuitively more reflective of subtleties in stuttering attitudes than the equivalent number from 1 to 3 with one or two decimal point values, e.g., -48 versus 1.52. The scores of some items (e.g., "I would laugh at a child who stutters") are inverted so that, for all items, negative attitudes correspond to lower scores and positive attitudes correspond to higher scores. Again, the seven component scores are derived from the means of associated items, and the two stuttering-related subscores, Self Reactions and Beliefs, reflect means of associated components. 


\section{Adult stuttering attitude measure: The $P O S H A-S$.}

The adult version of the $P O S H A-S$ was used to measure parents' stuttering attitudes (Appendix B). Through its extensive use, the POSHA-S has been shown to demonstrate adequate test-retest reliability (St. Louis, 2012; St. Louis, Lubker, Yaruss, \& Aliveto, 2009), internal consistency (Al-Khaledi, Lincoln, McCabe, Packman, \& Alshatti, 2009; St. Louis, 2012), construct and discriminant validity (Abdalla \& St. Louis, 2014; Flynn \& St. Louis, 2011; St. Louis, Reichel, Yaruss, \& Lubker, 2009; St. Louis, Williams, Ware, Guendouzi, \& Reichel, 2014), translatability (St. Louis \& Roberts, 2010), and equivalency with paper versus online administration (St. Louis, 2012b).

The adult and child versions are quite similar relative to the survey items and scoring procedures; however, there are a few important distinctions between them. The demographic section on the adult version is somewhat longer, including information about respondents' race, religion, and life priorities. Like the child version, obesity serves as one anchor trait, but the $P O S H A-S$ also includes left-handedness, mental illness, and intelligence anchors. In the POSHA-S/Child, a wheelchair anchor trait is included for the Obesity/Wheelchair subscore because young children would not be expected to know about mental illness. Unlike the child version, the adult version does not include a video stimulus or visual representation of the anchor traits. Although the items of the child version parallel as closely as possible those of the adult instrument, there are slight differences in wording for the respective versions. For example, on the adult version, respondents are asked whether or not they would "make a joke about stuttering" when talking to a person who stutters; in the child version, respondents are asked if they would "laugh [at a child who stutters] because of their stuttering." The components and 
subscores are generally the same in the two versions, with the adult version having an additional Self Reactions component relative to their stuttering knowledge and source of that knowledge. Scoring of the stuttering items follows the same -100 to +100 continuum on both versions. The "Experience" component on the child version is weighted to reflect both child and parent reports of the child's experience with and exposure to stuttering. Finally, the adult version can be taken in online or pencil-and-paper formats, whereas an examiner administers the child version orally and records the child's responses on a paper-and-pencil survey. In all, the versions have 32 similar items, 7 similar components, the same stuttering subscores, and an Overall Stuttering Score.

Despite the differences between the child and adult versions, the study by St. Louis, Weidner, et al. (2016) revealed high concordance between the POSHA-S and POSHA-S/Child ratings for 378 adult respondents. For example, Beliefs means were 48 compared to 39, Self Reactions were 11 compared to 22, and the Overall Stuttering Score was 30 compared to 41 . Results of that study provided empirical support for comparing the means for the versions' shared items, components, subscores, and Overall Stuttering Score.

\section{Social cognitive measure: Theory of Mind Task Battery.}

Only recently has a standard measure to examine children's social cognition (i.e., Theory of Mind) been introduced. The instrument, the Theory of Mind Task Battery (Hutchins, Prelock, \& Chace, 2008), can be used with children 3- to 12-years-old with diverse cognitive and linguistic abilities. It comprises a series of tasks, arranged in increasing difficulty, that examine various aspects of social cognition relating to children's ability to make inferences and take another person's perspective. The examiner 
presents each task orally via pictures or short vignettes, and the child responds by pointing to one of four picture choices. Correct responses are recorded as "1" and incorrect responses are recorded as "0." The instrument has shown strong internal consistency, test-retest reliability, and validity (Hutchins, Prelock, \& Bonazinga Bouyea, 2014).

For the purposes of this study, the test was adapted to include a subset of eight items appropriate for preschool-aged children (Hutchins et al., 2014) (Appendix C). The first four items assess children's emotional recognition (i.e., happy, sad, mad, or scared). Each of the next four items is based on a short vignette, presented orally. Those items assess children's ability: (a) to infer a desire-based emotion (i.e., "Brynn wants a cookie. How will she feel if she gets a cookie?"), (b) to understand that seeing-leads-to-knowing (i.e., "This morning Patty saw her glasses on the table. Now she wants her glasses. Where does Patty think her glasses are?"), (c) to infer others' perception-based action (i.e., "Today Franklin saw the keys on the couch. He did not see the keys on the bed. Where will he go to get the keys?"), and (d) to infer others' behavior based on a false-belief (i.e., "When he is done [reading], Anthony puts the book on the table. Look, Sonya comes and moves the book from the table to a drawer... Where will Anthony look for the book first?"). According to the instrument's authors, the selected questions provide an index of children's "basic" theory of mind capabilities.

\section{Participant screening instrument.}

A participant screening instrument was developed for this study to identify individuals who likely could not provide valid information on the POSHA-S/Child (Appendix D). Examiners rate their impressions of a child's intelligibility, ability to 
understand and follow directions, hearing, and attention during one-on-one interactions. Each area is scored on a 1-to-3 point scale wherein $1=$ child's ability poses a strongly suspected or clear threat to the validity of the study, 2 = child's ability poses an unlikely threat to the validity of the study, and 3 = child's ability poses no threat to the validity of the study. Specific criteria for the ratings of each area are outlined on the screening instrument. If an examiner rates any of the areas as " 1 ," two additional trained examiners independently watch the video recording of that child and rescore the screening instrument. If two out of three examiners award a " 1 " in any area, that child is excluded from the study.

\section{Intervention: The Inter ACT Program}

\section{Overview.}

The InterACT program was developed for use in this study (Weidner, 2015). The overall goal of the program is to increase children's knowledge about stuttering and how to interact with people who stutter. Although the focus of the program is on stuttering, other conditions, such as wheelchair use, are also discussed. This provides a multidisability context in which to promote understanding and tolerance of differences that are either clearly observable (i.e., wheelchair use) or less salient (i.e., stuttering).

The InterACT program is composed of two 30-minute lessons that each includes a puppet video, small group discussion, and a custom coloring/activity book. The program was designed for young children ranging from 3- to 7-years-old, and can be conducted with small groups or in a full-classroom setting. A trained professional (e.g., speechlanguage pathologist, counselor, or teacher) can implement the program; however, only the author, a speech-language pathologist, has implemented it to date. 


\section{Program features.}

Videos. Each lesson of the InterACT program begins with a 10-minute video featuring five puppets, two boys and three girls. The puppets are 25 -inch, full-body stage puppets, similar to those used in the Sesame Street programs, and were selected based on their representativeness of young children. One boy puppet stutters (based on the higher prevalence of stuttering in boys than girls [Yairi \& Ambrose, 2013]), one puppet is in a wheelchair, and the remaining puppets represent typically developing children. Other features, such as race and clothing, are as neutral as possible. Also, the scenarios in the videos reflect common activities among persons of diverse cultures (e.g., blowing bubbles, playing in a park) while minimizing obvious reference to a given time period. For example, the characters do not use currently popular types of technology, such as video games. Four different speakers of Standard American English, three women and one man, recorded the voices of the puppets. All of the voices had fundamental frequency ranges similar to those of young children. (The male speaker spoke in falsetto register). The author recorded the speech of the stuttering puppet using pseudo-stuttering. The stuttered speech consists of prolongations, part and whole word repetitions, and blocks, with an average rate of $20 \%$ syllables stuttered. Because the design of the puppets precluded animation of visible secondary behaviors, such as eye blinking, pitch breaks were included in the stuttered speech to convey significant physical effort during speaking tasks. Stuttering specialists, Ken St. Louis and Craig Coleman, judged the stuttering to be "moderate-to-severe." The video script was written in consideration of the language abilities and interests of preschool children. It is devoid of slang phrases and terms, thereby supporting the ease of possible future translations (e.g., St. Louis \& 
Roberts, 2010). A child counselor, an expert of child development, and another speechlanguage pathologist reviewed the script, and modifications were made based on their collective feedback. The collaborators deemed the content of the final script suitable for the target audience (Appendix E). An original theme song, written by Hollingsworth \& Hollingsworth (2015), accompanies the video. The lyrics promote tolerance and acceptance of differences both in oneself and others (Appendix F).

The objectives of the first video are (a) to raise children's awareness about human differences, (b) to teach children about the nature and causes of stuttering, and (c) to promote human differences as being unique and special. This is carried out in a series of vignettes in which the physically disabled character and the stuttering character talk about their respective differences. Each character asks common questions of the other such as, "Why are you in a wheelchair/Why do you stutter?" The characters respond matter-offactly, in language that is understandable by the target preschool audience. For example, the character who stutters says, "Stuttering happens because I was born this way. Even though I stutter, I can still do all of the same things other people can do.” Another character, who serves as the narrator, is featured between the vignettes to emphasize salient themes.

The objectives of the second video are (a) to teach children appropriate ways to interact with a person who stutters, and (b) to reinforce peer acceptance, regardless of differences. One vignette depicts a typically fluent child who responds to the stuttering child in a negative or undesired way (i.e., she finishes his words, laughs, tells him to "slow down," and finally walks away). In a follow-up scene, she responds in a neutral or positive way (i.e., she waits patiently and makes good eye contact). The narrator then re- 
emphasizes how to appropriately interact with a person who stutters. In the final scene, all of the characters interact together and talk about the similarities between them, despite their differences.

Discussion. A group discussion follows each video. Six still photographs from the videos (three from each video) were printed on separate 15.5 x 8.7 inch placards (Appendix G). The images represent critical periods in the videos during which a prominent theme was discussed (e.g., an image of when the child in the wheelchair and the child who stutters talked about their differences). On the reverse side of the placard is a scripted one- to three-sentence summary of the scene followed by a series of questions aimed to facilitate group discussion (e.g. "In this scene Ben and Rosie learn about ways people can be different. What is one way Rosie is different?'). The examiner shows the group the placard, and reads the summary and questions verbatim. During the discussion, the facilitator can further emphasize important terminology and themes.

Coloring/activity book. At the end of each lesson, the children complete a section of the InterACT coloring/activity book (Appendix H). The book illustrations depict scenes, characters, and direct quotes from the videos. In addition, there are dedicated pages on which the children are prompted to draw a picture that reinforces the target themes such as, "Differences make people special. Draw what makes you special," and, "Draw how you would interact with a someone who is different." The children take home their completed book at the end of the program.

\section{Pilot Study}

Prior to the current study, a pilot study was carried to determine the feasibility of the InterACT program, using the POSHA-S/Child to measure changes in preschoolers' 
stuttering attitudes before and after it. Six nonstuttering children from one preschool participated. The sample included four males and two females, with a mean age of $4.3 \mathrm{yr}$ (range $=4.1 \mathrm{yr}$ to $4.9 \mathrm{yr}$ ). The pilot study was conducted in accordance with the procedures above, with few important differences relative to both the survey instrument and InterACT program.

No qualitative data (i.e., children's reactions to the video stimulus and responses to the question "what does the word stuttering mean?") were collected in the pilot study. As such, analyses were based solely on quantitative $P O S H A-S / C h i l d$ results. Further, the pilot study did not include a participant screening form or the Theory of Mind Task Battery. These were subsequently added to the procedure so that a more objective impression of children's social cognitive skills and their candidacy for enrollment could be gained. Regarding the Inter $A C T$ program, the examiner also used the stuttering puppet featured in the video during the small group discussions. The children had an opportunity to interact with the puppet, but became quite excitable and difficult to redirect. For that reason, coupled with the lack of standardization using the puppet, it was decided that subsequent iterations of the InterACT program should rely only on the use of the placards during small group discussion. Doing so would help minimize any confounding threats secondary to children's attention and participation. Also, the author conducted the testing and intervention for the pilot study alone. In order to standardize the procedure as much as possible, the final design involved using trained research assistants to help with logistical tasks such as video recording, seating children, distributing coloring materials, managing individual child issues, and so on. Finally, the pilot study used an earlier version of the POSHA-S/Child, containing the item "children who stutter are different," 
which was regarded as a negative attitude (Weidner, St. Louis, Burgess, et al., 2015). Subsequent re-evaluation of that item indicated that it is primarily an index of stuttering awareness and cannot be classified as a strictly positive or negative attitude, especially after the InterACT program's focus on "difference." Accordingly, that POSHA-S/Child item has since been changed to, "Do you think children who stutter have a bad problem?" wherein an affirmative to that statement is judged as negative.

Pre-post comparisons of the pilot data provided preliminary evidence that children's stuttering attitudes are amenable to change following participation in the InterACT program. Children's Overall Stuttering Score (OSS), Beliefs (BEL), and Self Reactions (SR) each improved 12 units; OSS $($ Pre $=1$, Post $=12)$, BEL $($ Pre $=25$, Post $=$ 37), and SR (Pre $=-23$, Post $=-11$ ). Out of all of the 56 POSHA-S/Child ratings, 24 increased (43\%), 17 (30\%) did not change, and 15 decreased (27\%). The average unit change for those ratings was +8 . The pilot study findings are discussed in greater detail in subsequent sections.

\section{Recruitment Procedures}

After obtaining Institutional Review Board approval at West Virginia University (Appendix I), preschool children and their parents were recruited via convenience sampling. The author contacted and met with administrators from five different preschool sites in Morgantown, WV to explain the nature of the study and answer questions. All of the administrators subsequently signed a form permitting research to be conducted at their site (Appendix J). One site gave permission for the study to be carried out in both of their preschool classrooms. Accordingly, the study was carried out in six different 
preschool classrooms (C1, C2 ..C6). Most classrooms operated 5 full-days per week, with the exception of $\mathrm{C} 6$, which operated 3 half-days per week.

The administrators and classroom teachers helped distribute consent forms and the POSHA-S/Child demographic questionnaire to the parents of all students in the classrooms $(N=106)$. The consent forms included a cover letter explaining the project, and sections specific to the child and parent portions of the study (Appendix K). Seventythree parents provided written consent for their child to participate (response rate $=$ $68.9 \%$ ), and 68 parents consented to participate in the parent portion of the study (response rate $=64.2 \%$ ).

\section{Participants}

\section{Child participants.}

Inclusion and exclusion criteria. Given the epidemiological nature of this study, it was important to include children within the normal range of cognitive and linguistic abilities from diverse backgrounds so that a representative impression of preschool children's stuttering attitudes could be obtained. At the same time, it was necessary to assure that the respondents were able to participate in the necessary study components. Consented children's candidacy for inclusion was based on their age (i.e., 3- to 5-yearsold), their compliance during testing administration and InterACT lessons, and scores generated from the participant screening instrument previously described. Children were not excluded nor stratified on the basis of race, reported family income, parent education, sex, or reported health or ability status. Nevertheless, they were excluded from the study if they could not see or hear well enough to complete the POSHA-S/Child or participate in the program, or lacked the comprehension or attention skills requisite for reliably 
responding to $\mathrm{POSHA}-\mathrm{S} / \mathrm{Child}$ survey items. The examiners judged those areas based on their observations of each child during one-on-one interactions. Children who stutter (as reported by a parent and confirmed by a teacher and/or the author) were excluded from the analyses pertaining to the first and third research questions. Those questions were concerned with measuring nonstuttering children's attitude and attitude change, it was important to minimize bias that may have occurred secondary to personal experiences with stuttering. However, children who stutter were retained for the second research question, which sought to elucidate factors that might account for children's stuttering attitudes. It was deemed useful to include stutterers in those analyses so that the influence of one's personal experience with stuttering could be understood in the context of other predictors.

Four children were absent on all testing and lesson days, yielding a total of 69 children with whom the examiners met face-to-face. Based on the aforementioned conditions, $14 / 69$ children $(20.3 \%)$ failed to meet the inclusionary criteria secondary to non-compliance $(n=4)$ and/or insufficient comprehension $(n=10)$. Altogether, 55 children were included in the study, and three of them were reported to stutter.

Group assignments for analyses. As shown in Figure 1, participants were differently grouped for the three research questions. The 52 nonstuttering children (Figure 1, box Ib) were included in analyses for research question one, which pertained to the stuttering attitudes of typically fluent children. Their distribution across the various preschool classrooms was: C1 $(n=7), \mathrm{C} 2(n=11), \mathrm{C} 3(n=16), \mathrm{C} 4(n=3), \mathrm{C} 5(n=9)$, and C6 $(n=6)$. Three children stuttered (Figure 1, box Ia) and attended C2, C3, and C5. Those children (in addition to the 52 nonstutterers) were included in analyses for research 
question two, which pertained to predictive factors on children's stuttering attitudes. Thirty-seven nonstuttering children completed the InterACT program (Figure 1, box IIIb) and were included in analyses for research question three, which examined stuttering attitude change in nonstuttering children. They attended: $\mathrm{C} 1(n=5), \mathrm{C} 2(n=7), \mathrm{C} 3(n=$ $10)$, C4 $(n=2)$, C5 $(n=9)$, and C6 $(n=4)$. Further, six children who completed the pre and post $P O S H A-S / C h i l d$ but were not present for either lesson were included in a control group (Figure 1, boxes IVa and IVb). At least one control subject was obtained from $\mathrm{C} 1, \mathrm{C} 2, \mathrm{C} 3$, and $\mathrm{C} 4$. Due to classroom scheduling constraints, no control participants could be obtained from C5 or C6. A summary of each child's school and their inclusion in research question analyses is further detailed in Appendix L.

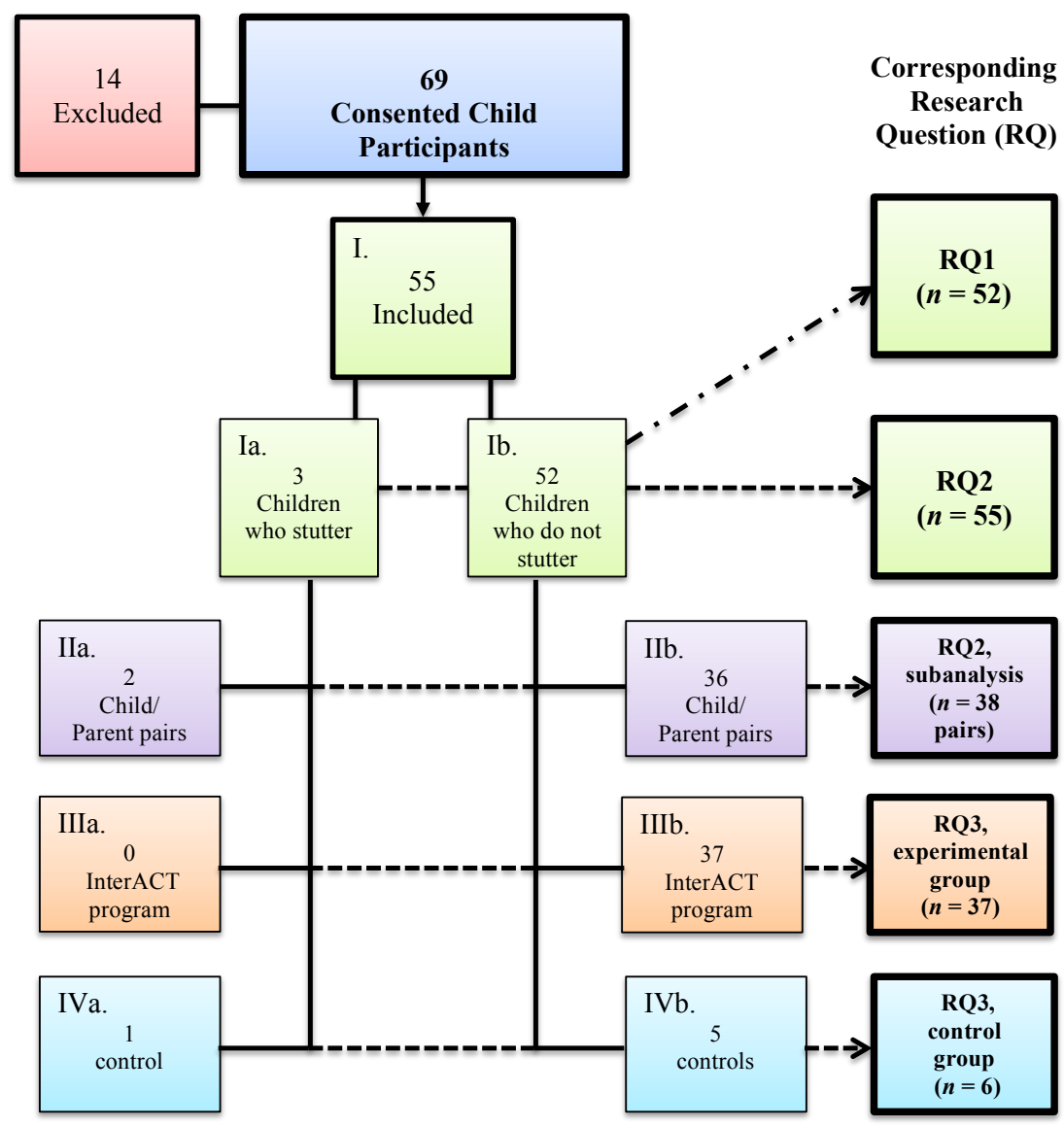

Figure 1. Participant distribution for the three research questions (RQ1, RQ2, RQ3). 
Demographic Variables. Table 1 provides a comprehensive summary of children's demographic information. The average age of the 55 children was $4.9 \mathrm{yr}$ (range $3.2 \mathrm{yr}$ to $5.7 \mathrm{yr} ; S D=.5$ ). A one-way analysis of variance (ANOVA) revealed a significant difference between children's ages from the six preschools, $F(5,45)=5.19, p$ $=.001$, with a younger group of children at $\mathrm{C} 1$ compared to $\mathrm{C} 2, \mathrm{C} 3$, and $\mathrm{C} 4$. The average age at each of those sites was, respectively $4.3 \mathrm{yr}(S D=.6), 5.0 \mathrm{yr}(S D=.3), 5.1 \mathrm{yr}(S D=$ $.4)$, and $4.9 \mathrm{yr}(S D=.2)$. Children included 27 males $(49 \%)$ and 28 females (51\%). All children spoke English as their primary language; 45 (82\%) were monolingual, six (11\%) spoke more than one language, and the multilingualism capability of four children (7\%) was not reported. Languages spoken by the multilingual children included: American Sign Language, Pushtu, Chinese, Korean, and Greek. Children's average Health and Abilities score, rated on a -100 to +100 continuum, was $88(S D=20)$, with physical health $=92(S D=19)$, mental health $=90(S D=20)$, ability to learn $=90(S D=23)$, and speaking ability $=78(S D=35)$. None of the Health and Abilities ratings significantly differed across the preschools. According to parental report, 28 children (51\%) had prior exposure to a person who is obese, six children (11\%) had prior exposure to a person in a wheelchair, and four children (7\%) had prior exposure to a person who stutters. None of the children were reportedly obese or used a wheelchair.

On the -100 to +100 continuum, parents reported an average composite income score of $14(S D=38)$, and there were no significant differences in income ratings across preschools. This is higher than the median of 0 derived from 143 sample means from adults around the world. The mean education of informants was $18.1 \mathrm{yr}(S D=2.8)$. A one-way ANOVA revealed significant differences in average parent education across 
study sites, $F(5,44)=4.82, p=.001$, with parents from C6 having significantly lower education levels than parents from $\mathrm{C} 2$ and $\mathrm{C} 3$. The average education of parents from those classrooms was: 14.0 yr $(S D=4.0), 18.9 \mathrm{yr}(S D=2.0)$, and 19.4 $\mathrm{yr}(S D=1.8)$, respectively. 
Table 1

POSHA-S/Child Mean Demographic Characteristics for Six Classroom Samples (C1 - C6) and All Samples Combined. Means are Shown and Followed, Where Relevant, by Standard Deviations in Parentheses.

\begin{tabular}{|c|c|c|c|c|c|c|c|}
\hline & C1 & $\mathrm{C2}$ & C3 & $\mathrm{C4}$ & C5 & C6 & $\begin{array}{c}\text { Combined } \\
\text { Sample }\end{array}$ \\
\hline Sample Size & $n=7$ & $n=12$ & $n=17$ & $n=3$ & $n=10$ & $n=6$ & $N=55$ \\
\hline Age: Mean yr ${ }^{a}$ & $4.3(.6)$ & $5.0(.3)$ & $5.1(.4)$ & $4.9(.2)$ & $5.1(.3)$ & $4.6(.6)$ & $4.9(.5)$ \\
\hline $\begin{array}{l}\text { Education level by person } \\
\text { child is with most often: } \\
\text { Mean } \mathrm{yr}^{\mathrm{a}}\end{array}$ & $17.4(2.2)$ & $18.9(2.0)$ & $19.4(1.8)$ & $19.0(1.7)$ & $17.1(2.8)$ & $14.0(4.0)$ & $18.1(2.8)$ \\
\hline $\begin{array}{l}\text { Composite family income } \\
(-100 \text { to }+100)\end{array}$ & $-15(65)$ & $1(23)$ & $27(37)$ & $21(30)$ & $21(40)$ & $13(25)$ & $14(38)$ \\
\hline Sex: Males / females ( $\%$ total $)$ & $71 \% / 29 \%$ & $33 \% / 67 \%$ & $47 \% / 53 \%$ & $33 \% / 67 \%$ & $50 \% / 50 \%$ & $67 \% / 33 \%$ & $49 \% / 51 \%$ \\
\hline Native Language English & $100 \%$ & $100 \%$ & $100 \%$ & $100 \%$ & $100 \%$ & $100 \%$ & $100 \%$ \\
\hline $\begin{array}{l}\text { Knows }>1 \text { language }(\% \\
\text { responding })\end{array}$ & $28.6 \%$ & $16.7 \%$ & $11.8 \%$ & $0 \%$ & $0 \%$ & $0 \%$ & $10.9 \%$ \\
\hline $\begin{array}{l}\text { Has siblings: yes/no/not } \\
\text { reported }(\% \text { total })\end{array}$ & $\begin{array}{c}86 \% / 14 \% / \\
0 \%\end{array}$ & $\begin{array}{c}67 \% / 8 \% / \\
25 \%\end{array}$ & $\begin{array}{c}59 \% / 35 \% / \\
6 \%\end{array}$ & $\begin{array}{c}67 \% / 33 \% / \\
0 \%\end{array}$ & $\begin{array}{c}60 \% / 20 \% / \\
20 \%\end{array}$ & $\begin{array}{c}50 \% / 17 \% / \\
33 \%\end{array}$ & $\begin{array}{c}64 \% / 18 \% / \\
18 \%\end{array}$ \\
\hline $\begin{array}{l}\text { Attends daycare regularly: } \\
\text { yes } / \text { no }(\% \text { total })^{\mathrm{a}}\end{array}$ & $57 \% / 43 \%$ & $100 \% / 0 \%$ & $94 \% / 6 \%$ & $100 \% / 0 \%$ & $90 \% / 10 \%$ & $100 \% / 0 \%$ & $80 \% / 20 \%$ \\
\hline
\end{tabular}




\begin{tabular}{|c|c|c|c|c|c|c|c|}
\hline $\begin{array}{l}\text { Attends school regularly: } \\
\text { yes/no }(\% \text { total })^{\mathrm{a}}\end{array}$ & $29 \% / 71 \%$ & $42 \% / 58 \%$ & $23 \% / 77 \%$ & $33 \% / 67 \%$ & $60 \% / 40 \%$ & $83 \% / 17 \%$ & $42 \% / 58 \%$ \\
\hline $\begin{array}{l}\text { Parent rating of child's health } \\
\text { and abilities }(-100 \text { to }+100)\end{array}$ & $92(15)$ & $84(24)$ & $91(20)$ & $79(26)$ & $95(13)$ & $75(25)$ & $88(20)$ \\
\hline Physical health & $92(20)$ & $91(20)$ & $94(17)$ & $83(29)$ & $100(0)$ & $80(27)$ & $92(19)$ \\
\hline Ability to learn & $100(0)$ & $86(23)$ & $91(27)$ & $83(29)$ & $94(18)$ & $80(27)$ & $90(23)$ \\
\hline Speaking ability & $83(26)$ & $73(47)$ & $84(30)$ & $67(29)$ & $81(37)$ & $60(42)$ & $78(35)$ \\
\hline $\begin{array}{l}\text { Parent rating of child's } \\
\text { exposure to stuttering, } \\
\text { wheelchair-use, and obesity }\end{array}$ & $-74(19)$ & $-72(18)$ & $-69(24)$ & $-80(35)$ & $-70(27)$ & $-60(38)$ & $-70(24)$ \\
\hline
\end{tabular}

Note. Demographic information was analyzed based on 51 out of 55 returned demographic forms, completed by a parent. For the four questionnaires not returned, the examiner filled out missing data relative to the child's sex and whether or not the child was observed to stutter, use a wheelchair, or be obese. Mean substitution was carried out for children's exposure to persons who stutter, are obese, or use a wheelchair. The inclusion of this data was necessary to accurately calculate various POSHA-S/Child scores (e.g., the Experience component). Other missing demographic variables (i.e., family income, informant education, child's age, multilingualism, number of siblings, attendance frequency at daycare and school, and health and abilities) were calculated as missing data.

${ }^{a}$ Statistically significant differences between classroom samples $(p \leq .05)$. 


\section{Parent participants.}

Thirty-eight parents whose child completed the POSHA-S/Child filled out the POSHA-S (adult version). Thirty-three (87\%) were mothers, and 5 (13\%) were fathers with an average age of $37.9 \mathrm{yrs}(S D=7.9)$. Parents represented $\mathrm{C} 1(n=5), \mathrm{P} 2(n=7), \mathrm{C} 3$ $(n=9)$, C4 $(n=3)$, C5 $(n=10)$, and C6 $(n=4)$. Appendix M outlines additional parent demographic information.

\section{Experimental Procedures}

\section{Child testing procedures.}

Pretesting. On average, pretesting took place four days prior to the first InterACT lesson (range $=$ one to 10 days). The examiners went to $\mathrm{C} 1, \mathrm{C} 3, \mathrm{C} 4$, and $\mathrm{C} 5$ twice and $\mathrm{C} 2$ and C6 once to carry out pretesting. For all schools, testing took place in the morning during their semi-structured play period. An examiner met with each child individually and conducted the POSHA-S/Child, Theory of Mind Task Battery, and the participant screening instrument, in that order. The pretest procedure averaged 9.6 minutes. With the exception of C6, pretesting took place within the classroom, but as far away as possible from the main classroom activities. For C6, testing occurred in a separate room adjacent to the classroom. Appendix $\mathrm{N}$ displays pictures of the testing arrangements for the six classrooms. Each test was administered according to its procedures as previously outlined, but with one slight addition to POSHA-S/Child. The examiner asked, "What does the word 'stuttering' mean?" prior to showing the stimulus video and immediately following the survey questions. Children's responses were recorded verbatim. The children watched the POSHA-S/Child stimulus video on an iPad mini and wore over-the-ear headphones to diminish ambient noise. Children's responses to the POSHA-S/Child survey items and 
Theory of Mind Task Battery were recorded on a paper version of each instrument and video recorded.

Posttesting. Posttesting was carried out for the 37 children who completed the entire program, as well as for the six children in the control group. The Theory of Mind Task Battery was not re-administered, but all other testing procedures remained consistent with that of the pretest. On average, the posttest procedure took 6.7 minutes. For the 37 children in the experimental group, 32 posttests were conducted within an hour after the second InterACT lesson; however, due to classroom scheduling, posttests for five children from C5 were carried out two days after the second lesson. The average time period between posttest and pretest administration for children in the experimental group was 10 days and 9 days for children in the control group. In all, 31/43 (72\%) children were seen by the same examiner at pre-test and posttest. Pre-and post data collection for all six classrooms took place over an 8-week period. A schedule of all classroom visits is shown in Appendix O.

\section{Program implementation.}

The InterACT program was carried out in six different preschool classrooms, previously described. The two 30-minute lessons, which were delivered 5 to 7 days apart, were carried out at a time that avoided or minimized as much as possible disruptions to the classrooms' daily routine, but that also optimized children's attention and willingness to participate. Lessons were delivered to the entire classroom for C3, C4, C5, and C6, and in a small group removed from the main classroom activities for $\mathrm{C} 1$ and $\mathrm{C} 2$. While seated in a circle on the floor or in chairs, the children watched one of the educational videos on a 24-inch Sony television provided by the examiner. After each video, the children 
remained seated while the examiner led the small group discussion using the placards previously described. After the discussion, the children walked to a nearby table to complete three pages of their activity books (6 pages total over the two lessons). The examiner and a trained research assistant circulated to pass out coloring materials. They also wrote down each child's description of their drawings, which corresponded to an open-ended prompt in the book (e.g., "Draw one way that makes you special"). Across all sites, all of the children participated in the lessons, although minimal redirection was needed for some children at times. No unforeseeable events, such as a fire drill, occurred during the lessons.

\section{Measuring parent attitudes.}

Electronic or paper-and-pencil POSHA-S surveys were distributed to the 68 parents who consented to participate, coded in such a way that parent-child pairs could be matched. The selection of online or paper survey format, which has been shown not to influence POSHA-S results (St. Louis, 2012b), followed the school administrators' recommendations to achieve maximal response rate. At $\mathrm{C} 1, \mathrm{C} 3$, and $\mathrm{C} 4$, the school administrator first emailed parents a link to the survey via Qualtrics. Two weeks later, a paper-and-pencil survey was given to parents who did not respond to the electronic survey. At C2, C5, and C6, paper-and-pencil surveys were sent out initially. Because the response rate was high in those classrooms, no follow up with parents was needed. As stated previously, 38 parents returned a survey (Appendix L). The return rate was 55.9\%, with 17 electronic surveys and 21 pencil and paper copies. 


\section{Analysis of results.}

Quantitative. Each instrument used in the study was scored according to the procedures as previously mentioned. Statistical analyses were carried out using Excel and IBM SPSS software. For the first research question, the pre POSHA-S/Child results obtained from the 52 nonstuttering children were analyzed descriptively. For the second research question, results from the 55 stuttering and nonstuttering children were analyzed using a series of correlations and linear regressions. Correlations generated information about the relationship between variables of interest and stuttering attitudes, and the linear regressions provided information about the predictive power of those variables. Specifically, children's demographic variables (i.e., socioeconomic status), exposure to stuttering (i.e., personal experience with stuttering and persons known), and personal variables (i.e., social cognition, health and abilities, and age) were examined. In addition, the POSHA-S/Child and POSHA-S results of 38 parent-child pairs were compared for the 32 items shared by the surveys. Parent and child comparisons were carried out using the Mann-Whitney $U$ test $(p \leq .05)$. Effect sizes for significant differences were calculated using the resultant $\mathrm{z}$ score divided by the square root of the total number of observations. For the third research question, the pretest and posttest POSHA-S/Child scores of 37 children were compared. The Wilcoxon signed rank test was used for pairwise comparisons $(p \leq .05)$, and effect sizes for significant differences were calculated using the same procedures described above. The results of the six children in the control group were compared descriptively to the experimental group.

Qualitative. As noted, some qualitative data was analyzed to augment the quantitative pre-post findings. A portion of this data was gleaned from children's 
responses to the question, "What does the word stuttering mean?" presented twice at pretest and twice at posttest. Children's responses were categorized as either "correct" or "incorrect," and subcategorized based on their type of response. Subcategories of correct responses included: description of types of stuttering, demonstration of stuttered speech, and reference to aberrant talking. If needed, semantic and/or phonemic cueing was provided and documented accordingly. Subcategories of incorrect responses included: "I don't know" responses, inaccurate definitions, or no response. Qualitative data was also obtained from children's overt reactions (i.e., facial expression, body language, or comments) to the pre-and post $P O S H A-S / C h i l d$ stimulus video. Children's reactions were coded as "positive/neutral" or "negative/undesired." Informed by guidelines advanced by Langevin and colleagues (2009), responses were coded as "positive/neutral" if the child did not demonstrate any apparent adverse response to the video. Responses were coded as "negative/undesired" if the child exhibited any of the following reactions: was impatient

or confused (e.g., finished words, showed a confused expression); laughed at or imitated the stuttered speech; showed signs of discomfort or surprise (e.g., widened eyes, physically distanced from the video); or made negative comments about the children's stuttered speech.

\section{Examiner reliability procedures.}

Research assistant training. Four undergraduate students and one graduate student in Communication Sciences and Disorders attended a research training that the author led. They were instructed how to collect and record data using the POSHAS/Child, Theory of Mind Task Battery, and participant screening instrument. They were also taught how to assist with program implementation including how to seat the 
children, identify and respond to off-task behavior, prepare the various materials, and use the video camera. All trainees demonstrated their ability to collect data via a series of role-play scenarios, and were thereby included in the study as research assistants. Each research assistant collected data and assisted with program implementation in one assigned classroom, and one research assistant helped in two classrooms.

Coder reliability. The author reviewed three, 5-minute random video samples of each research assistant's interactions with the children. All videos reviewed confirmed their adherence to the testing procedure. In order to ensure inter-rater reliability, $20 \%$ of the pre- and posttest videos were randomly selected and analyzed by another research assistant.

\section{Chapter 4: Results}

\section{Research Question 1: As measured using the POSHA-S/Child, what do nonstuttering preschool-aged children believe about stuttering and people who stutter, and what are their self-reactions toward stuttering peers? \\ POSHA-S/Child ratings.}

Descriptive analysis of the initial or only POSHA-S/Child ratings were carried out for the 52 nonstuttering children who took the survey at least once. Results revealed adequate skewness (i.e., between -1 and 1) and kurtosis (i.e., between -1.5 to 2.0) for all items. Further, analyses using frequencies, normal quantile-quantile (Q-Q) plots, and histograms revealed no outliers within the dataset. Normality of distribution was examined using Q-Q plots, which appeared to have some slight violations on several ratings (i.e., Potential, Distance/Sympathy, and Experience components, as well as the Obesity/Wheelchair and Self Reaction subscores). Further, the Kolmogorov-Smirnov (KS) test revealed violations of normality for all of the component scores and the Obesity/Wheelchair subscore, $p<.00$, but not for Self Reaction (SR), Beliefs (BEL), or 
Overall Stuttering Score (OSS). These collective analyses indicate that the assumption of normality was not upheld.

Results revealed an average OSS of 4 on the -100 to +100 scale $(S D=27)$, BEL score of $23(S D=21)$, and SR score of $-16(S D=22)$. The rank order of the seven component scores from highest to lowest were: Potential $(M=74, S D=36)>$ Who Should Help $(M=30, S D=31)>$ Social Distance/Sympathy $(M=18, S D=47)>$ Accommodating/Helping $(M=7, S D=40)>$ Causes $(M=1, S D=41)>$ Traits/Personality $(M=-11, S D=50)>$ Experience $(M=-71, S D=38)$. Children's preference for stuttering was examined in the context of the obesity and wheelchair anchor traits. They showed strongest preference for stuttering $(M=40, S D=72)$, followed by wheelchair-use $(M=14, S D=57)$, and obesity $(M=-56, S D=61)$. Their preference scores were inversely related to their reported experience with or exposure to each of those disorders. The means and standard deviations of all POSHA-S/Child pretest ratings are shown in Table 2.

Independence of observations was also examined relative to the six classroom sites. Results of an intra-class correlation confirmed no effect of one's preschool on overall stuttering attitudes $(\alpha<.05)$, thereby reducing the threat of Type I error due to clustering. 
Table 2

POSHA-S/Child Means and Standard Deviations (in parentheses) for the 52

Nonstuttering Participants. With the Exception of the Items Marked by a Superscript,

"Yes" Responses Represent More Positive Attitudes. Ratings for Items with a

Superscript are Inverted So That "No" Responses Represent More Positive Attitudes.

\section{POSHA-S/Child Variable}

OVERALL STUTTERING SCORE

Beliefs About Children who Stutter

Traits / Personality

Are at fault ${ }^{\mathrm{a}}$

Nervous $^{\text {a }}$

Shy ${ }^{\text {a }}$

Have a bad problem ${ }^{\text {a }}$

Can talk well

Stuttering Should Be Helped by...

Speech-language pathologist

Other people who stutter

Medical doctor ${ }^{\mathrm{a}}$

Parent

Stuttering is Caused by...

Came from their mom or dad when they were

born

Learning $^{\text {a }}$

Something bad that happened ${ }^{\text {a }}$
52 Nonstuttering Preschoolers

4 (17)

23 (21)

$-11(50)$

$-6(100)$

$-10(98)$

-17 (98)

8 (99)

$-29(96)$

30 (31)

69 (73)

$54(80)$

$-69(73)$

65 (76)

1 (41)

33 (94)

$-31(96)$

$23(98)$ 
God/Allah ${ }^{\mathrm{a}}$

Germs like those that make you sick ${ }^{\mathrm{a}}$

Something we can't see ${ }^{a}$

Potential

Can make friends

Do same thing as others

Have any job as adult

Make good choices

Self Reactions to Children who

\section{$\underline{\text { Stutter }}$}

Accommodating / Helping

Ignore

I should help

Finish the person's words ${ }^{\text {a }}$

Tell the person to "Slow down" a

$\operatorname{Laugh}^{\mathrm{a}}$

Should try to hide their stuttering ${ }^{\text {a }}$

Social Distance / Sympathy

Fun to play with

Be bothered

Feel sorry for them

Feel patient ${ }^{\mathrm{a}}$

Worried about my doctor ${ }^{a}$
$-31(96)$

$-8(101)$

17 (98)

74 (36)

$96(28)$

$21(98)$

88 (47)

88 (47)

$-16(22)$

7 (40)

$-27(97)$

$46(90)$

$-10(100)$

-77 (65)

65 (76)

42 (91)

18 (47)

77 (65)

$54(85)$

69 (73)

85 (54)

$-31(94)$ 
Worried about my teacher ${ }^{\text {a }}$

Worried about my neighbor ${ }^{\mathrm{a}}$

Worried about a sibling $^{\text {a }}$

Worried about me ${ }^{\mathrm{a}}$

Worried about a friend

Worried about a parent

Preference

\section{Experience}

Persons known who stutter (informant report)

Persons known who stutter (child report)

Obesity/Wheelchair Subscore $^{\mathrm{a}}$

\section{Preference}

Obesity

Wheelchair

Experience

Obesity

Wheelchair
$-12(100)$

$-15(100)$

$-12(100)$

0 (101)

$-27(97)$

$-12(100)$

$40(72)$

$-71(38)$

$-97(6)$

$-51(67)$

$-47(22)$

$-21(37)$

$-56(61)$

$14(57)$

$-71(25)$

$-56(37)$

$-86(27)$

\footnotetext{
${ }^{\mathrm{a}}$ Mean ratings inverted so that higher scores reflect more accurate, sensitive attitudes.
} 
Research Question 2: To what extent do parental stuttering attitudes, demographic variables (i.e., parental education level and relative income), exposure to stuttering (i.e., personal experience with stuttering and persons known), and personal variables (i.e., social cognition, health and abilities, and age) correlate with or predict preschool children's stuttering attitudes?

\section{Parent and child group comparisons.}

Results of 38 parent POSHA-S surveys were analyzed and compared to the POSHA-S/Child means of their children. Before the comparisons were carried out, parent data were examined for outliers and normality using the same procedures as for the POSHA-S/Child. Results from skewness and kurtosis levels, Q-Q plots, and K-S test indicated that normality for the parent data was not upheld. POSHA-S results revealed an average Beliefs score of $56(S D=23)$, Self Reaction score of $6(S D=23)$, and Overall Stuttering Score of $31(S D=19)$. Overall, parents' means were consistently higher than the POSHA-S database medians of 33,1 , and 17 , respectively reflecting 143 samples from around the world

Parent and child stuttering attitudes were compared for the 32 items common to both the adult and child versions of the POSHA-S. Homogeneity of variances was examined using Levene's test of equality of error variances, revealing a violation of this assumption for a majority of items between the groups. For this reason, as well as the non-normal data distribution of child and parent samples, non-parametric comparisons for independent groups were carried out using the Mann-Whitney $U$ test $(p \leq .05)$. Descriptive statistics, significance values, z scores, and effect sizes for the parent and child comparisons are shown in Table 3.

Group comparisons of the 32 items revealed that the parents held more positive or informed attitudes for 22 items (69\%), the children held more positive attitudes for 9 
items (28\%), and both samples had the same mean attitude for 1 item (3\%), "people who stutter can make good choices." Twenty significant differences (59\%) emerged between the two groups, revealing higher parents ratings for 17 of those differences (85\%). The average effect size of those differences was medium (i.e., .49), ranging from .23 to .76 . Not surprisingly, the parent group was more informed about the causes of stuttering and how to interact with a stutterer. Compared to the children, parents were significantly less likely to attribute stuttering to learning (Parents $=29$, Children $=-32$ ), an act of God $($ Parents $=71$, Children $=-32)$, or something invisible $($ Parents $=100$, Children $=24)$. In addition, they were less inclined to finish a stutterer's words (Parents $=63$, Children $=3$ ), say "slow down" (Parents $=78$, Children $=-74$ ), and believe that a stutterer should try to "hide" his stuttering (Parents $=95$, Children $=42$ ). Parents' impressions about the traits of people who stutter were comparatively more positive with regard to stutterers being nervous $($ Parents $=37$, Children $=-5)$, or shy $($ Parents $=29$, Children $=-16)$. Compared to the children, parents were significantly less worried if their doctor, neighbor, or sibling stuttered. On the other hand, parents were more worried than children if they themselves stuttered, but this difference did not reach significance $($ Parents $=-3$, Children $=5)$. They were also significantly less inclined to help people who stutter compared to the children (Parents $=-29$, Children $=47)$. Further, parents had significantly lower ratings for the item, "I would feel sorry for a person who stutters" (Parents = 32, Children = 74). As previously noted, the valence for this item was inverted for the adult and child versions of the $P O S H A-S$, wherein "yes" responses were judged as being positive among the children and negative among adults. 
Despite the salient differences between the samples, there were notable similarities between them. Both groups held positive beliefs that people who stutter can make friends $($ Parents $=100$, Children $=95)$, have any job $($ Parents $=84$, Children $=89)$, and make good choices (Parents $=84$, Children $=84$ ). They were both likely to attribute stuttering to genetic factors and reject a traumatic event and germs as causal factors. When talking to a person who stutters, both groups reported that they would be generally be patient $($ Parents $=53$, Children $=84)$, not be bothered by the stuttering $($ Parents $=34$, Children $=63$ ), and would not laugh or make a joke about stuttering (Parents $=97$, Children $=74$ ). Regarding their stuttering experience, none of the parents self identified as a person who stutters, and 13 out of the 38 parents (34\%) declined knowing a stutterer (i.e., family member, acquaintance, close friend, relative, or other). Per parent report, two children from the 38 child-parent pairs stuttered (5\%), four children knew a stutterer (10\%), 28 children had no exposure to stuttering (74\%), and parents of 6 children were not sure if their child knew a stutterer $(16 \%)$.

Table 3

Thirty-two POSHA-S and Corresponding POSHA-S/Child Item Means, Standard Deviations (in Parentheses), Significance Values, Z Scores, and Effect Sizes for Significant Differences for 38 Child-Parent Pairs (Including Two Children who Stuttered and Their Parents).

\begin{tabular}{lccccc}
\hline POSHA $-S$ Variable & Parent & Child Sample & & Z & Effect \\
& Sample & & Sig. & value & Size \\
& $(N=38)$ & $(N=38)$ & & \\
\hline
\end{tabular}

Beliefs About Children who Stutter

Traits / Personality

Are at fault ${ }^{\mathrm{a}}$

$95(23) \quad 0(101)$

$.00 \quad-4.57$

.53 
Nervous ${ }^{a}$

Shy ${ }^{a}$

Stuttering Should Be Helped by...

Speech-language pathologist

Other people who stutter

Medical doctor $^{\mathrm{a}}$
$37(75)$

29 (77)

$$
-16(100)
$$

$.04 \quad-2.03$

.23

$\begin{array}{llllll}92(36) & 63(79) & .07 & -1.83 & \\ 11(86) & 71(65) & .001 & -3.40 & .39 \\ -34(88) & -68(74) & .04 & -2.07 & .24\end{array}$

Stuttering is Caused by...

Genetics

Learning $^{\text {a }}$

Something bad that happened ${ }^{\mathrm{a}}$

God/Allah ${ }^{\text {a }}$

Germs

Something we can't see ${ }^{a}$

Potential

Can make friends

Do same thing as others

Have any job as adult

Make good choices

$45(72)$

$26(98)$

$.64 \quad-.47$

$29(90)$

$45(83)$

$71(65)$

$47(80)$

$100(0)$

$-32(96)$

$\begin{array}{ll}.007 & -2.72\end{array}$

.31

$26(98)$

$.51 \quad-.67$

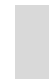

$\begin{array}{lllll}100(0) & 95(32) & .32 & -1.00 & \\ 100(0) & 16(100) & .00 & -4.47 & .51 \\ 84(49) & 89(45) & .42 & -.80 & \\ 84(43) & 84(55) & .53 & -.62 & \end{array}$

\section{$\underline{\text { Self Reactions to Children who Stutter }}$}

\section{Accommodating / Helping}

Ignore

I should help

$\begin{array}{llllll}95(32) & -21(99) & .00 & -5.39 & .62 \\ -29(87) & 47(89) & .00 & -3.55 & .41 \\ 63(67) & 3(100) & .01 & -2.70 & .31\end{array}$




\begin{tabular}{|c|c|c|c|c|c|}
\hline Tell the person to "Slow down" a & $78(58)$ & $-74(69)$ & .00 & -6.63 & .76 \\
\hline Laugh $^{\text {a }}$ & $97(16)$ & $74(69)$ & .08 & -1.75 & \\
\hline Should try to hide their stuttering ${ }^{a}$ & $95(23)$ & $42(92)$ & .00 & -2.89 & .33 \\
\hline \multicolumn{6}{|l|}{ Social Distance / Sympathy } \\
\hline Be bothered & $34(91)$ & $63(79)$ & .10 & -1.63 & \\
\hline Feel sorry for them & $32(90)$ & $74(69)$ & .02 & -2.43 & .28 \\
\hline Feel patient $^{\mathrm{a}}$ & $53(86)$ & $84(55)$ & .06 & -1.88 & \\
\hline Worried about my doctor ${ }^{a}$ & $82(56)$ & $-26(98)$ & .00 & -4.86 & .56 \\
\hline Worried about my neighbor ${ }^{\text {a }}$ & $95(32)$ & $-26(98)$ & .00 & -5.58 & .64 \\
\hline Worried about a sibling ${ }^{\text {a }}$ & $66(75)$ & $-11(101)$ & .00 & -3.43 & .39 \\
\hline Worried about me ${ }^{a}$ & $-3(97)$ & $5(101)$ & .72 & -.35 & \\
\hline Preference (Want/Have) Stuttering & $-62(39)$ & $32(74)$ & .02 & -5.23 & .60 \\
\hline Preference Obesity & $-82(32)$ & $-51(56)$ & .02 & -2.35 & .27 \\
\hline Preference Wheelchair & $-59(48)$ & $19(62)$ & .00 & -5.15 & .59 \\
\hline
\end{tabular}

Note. Statistically significant differences $(p \leq .05)$ are indicated by gray shading.

${ }^{\mathrm{a}}$ Mean ratings inverted so that higher scores reflect more accurate, sensitive attitudes.

\section{Demographic predictor variables.}

Relative income. Neither of the relative income scores (i.e., income compared to family/friends and compared to persons in one's country) was significantly correlated to children's POSHA-S/Child Beliefs (BEL), Self Reactions (SR), or Overall Stuttering Score (OSS). As shown in Table 4, most correlations were positive and small, ranging from $r=.07$ to $r=.23$. A linear regression of the Relative Income composite score did not significantly predict BEL, $F(1,40)=.139 p=.71$; SR, $F(1,40)=2.05, p=.16$; or 
OSS, $F(1,40)=1.09, p=.303$. The $R^{2}$ values revealed that children's health and abilities accounted for $4.9 \%$ of shared variability for BEL, $0.3 \%$ for SR, and $0.2 \%$ for OSS.

Table 4

Relative Income Means, Standard Deviations (in Parentheses), and Pearson's Correlations to POSHA-S/Child BEL, SR, and OSS ratings.

\begin{tabular}{lcccc}
\hline & & \multicolumn{3}{c}{ POSHA-S/Child Correlations } \\
\cline { 3 - 5 } Relative Income & M (SD) & BEL & SR & OSS \\
Family and friends & $3.4(.7)$ & -.03 & .23 & .11 \\
Countrymen & $3.2(.8)$ & .07 & .19 & .15 \\
\hline
\end{tabular}

Parent education. Regression analysis of the average number of years of parent education revealed no significant predictive effect on children's stuttering BEL, $F(1,48)$ $=.16, p=.69$ or OSS, $F(1,48)=1.18, p=.28$. However, there was a significant effect on children's SR score, $F(1,48)=4.58, p=.04$. As parent education increased, so did children's SR score, yielding a small but significant correlation of .29. Parent education accounted for $.3 \%$ of shared variability for BEL, $6.8 \%$ for SR, and $0.4 \%$ for OSS.

\section{Exposure to or experience with stuttering.}

Per parent report, four children knew a stutterer but did not stutter themselves, and three children stuttered. Due to the categorical nature of the independent variables, ANOVAs were conducted to examine the degree to which children's reported identification as - or exposure to - a stutterer impacted their POSHA-S/Child summary scores. Results revealed that children who stutter had significantly higher means for SR, $F(1,53)=13.82, p<.00$, and OSS, $F(1,53)=10.39, p<.00$, but not BEL. The stuttering 
group component ratings were higher than the nonstuttering group by an average of 29 units. The Cause component was the only lower rating among the stutterers, by 12 units. Summary scores for the stutterers and nonstutterers were: BEL (stutterers $=39$ nonstutterers $=23)$, SR $($ stutterers $=32$ nonstutterers $=-16)$, OSS $($ stutterers $=36$ nonstutterers $=4$ ). The four children who had previous exposure to a stutterer held generally more positive attitudes than the children with no prior exposure, having an average component rating 6 units higher. However, they held less informed attitudes relative to stuttering causes, traits of stutterers, and how to help. Summary scores for the exposure groups were: BEL (exposure $=19$, no exposure $=22), \mathrm{SR}($ exposure $=-5$, no exposure $=-18)$, OSS $($ exposure $=7$, no exposure $=2$ ). None of the summary scores were significant between the groups.

\section{Personal variables.}

Social cognition. Children's social cognitive skills were based on results from an adapted version of the Theory of Mind Task Battery (Hutchins et al., 2008). Children's responses to each of the eight items were awarded a score of "1" for correct responses or "0" for incorrect responses, yielding a possible total raw score of 8 points. The mean raw score across the 55 participants was 6.3 points $(S D=1.0)$. The highest average item was, "point to the face that is mad," $M=1.0, S D=0.0$. Children's ability to identify other facial expressions (i.e., happy, sad, and scared) was also high, where $M=.98$ and $S D=.1$ for each of those items. The lowest average item was the highest-level task on the adapted test, which required children to integrate situational knowledge with perspective taking $(M=.3, S D=.5)$. Correlations between Theory of Mind Task Battery individual items and total score and POSHA-S/Child summary scores were generally small and 
negative, although two significant, negative correlations pertaining to the BEL subscore emerged (Table 5).

Table 5

Theory of Mind Task Battery Means, Standard Deviations (in Parentheses), and Pearson's Correlations to POSHA-S/Child BEL, SR, and OSS ratings.

\begin{tabular}{llllc}
\hline \multirow{2}{*}{$\begin{array}{l}\text { Theory of Mind Task Battery } \\
\text { Task Description }\end{array}$} & M (SD) & \multicolumn{3}{c}{ POSHA-S/Child Correlations } \\
\cline { 3 - 5 } & & BEL & SR & OSS \\
\hline Emotional recognition (happy) & $.98(.13)$ & -.38 & .15 & -.12 \\
Emotional recognition (sad) & $.98(.13)$ & .26 & .13 & .24 \\
Emotional recognition (mad) & $1.0(.00)$ & - & - & - \\
Emotional recognition (scared) & $.98(.13)$ & .21 & .01 & .14 \\
Inferring others' emotion & $.91(.29)$ & -.24 & -.13 & -.23 \\
Inferring others' beliefs & $.69(.47)$ & -.06 & .00 & -.03 \\
Inferring others' intents & $.49(.50)$ & -.22 & -.01 & -.14 \\
Inferring others' behavior & $.27(.45)$ & -.21 & .10 & -.05 \\
Total Score & $\mathbf{6 . 3 1}(\mathbf{1 . 0 3})$ & -.28 & $\mathbf{. 0 4}$ & -.13 \\
\hline Note. Statistically significant differences $(p \leq .05)$ are indicated by gray shading. & \\
\hline
\end{tabular}

A series of linear regressions were also carried out to investigate the extent to which children's social cognition (as based on their total score) could predict their stuttering attitudes. Regression analyses revealed that the Theory of Mind Task Battery scores significantly predicted POSHA-S/Child BEL scores, $F(1,53)=4.57, p=.028$, but not SR scores, $F(1,53)=.08, p=.78$ or OSS, $F(1,53)=.97, p=.32$. The $R^{2}$ values indicated that children's social cognition accounted for $7.9 \%$ of the shared variability of 
the BEL score, $0.2 \%$ of the SR score, and $1.8 \%$ of the OSS. It should be noted, however, that the range of the Theory of Mind Task Battery scores was restricted, which may explain the non-significant findings.

Health and abilities. None of the health and ability scores (i.e., physical health, mental health, ability to learn, and ability to speak) were significantly correlated to BEL, SR, or OSS ratings (Table 6). Most correlation values showed a small negative effect, ranging from $r=-0.28$ to $r=-0.12$. Those findings were further confirmed in a regression analyses which revealed that the Health and Abilities component score did not significantly predict BEL, $F(1,47)=.21, p=.65 ; \mathrm{SR}, F(1,47)=3.37, p=.07$; or OSS, $F(1,47)=2.06, p=.158$. The $R^{2}$ values revealed that children's health and abilities accounted for $.05 \%$ of the shared variability for BEL, $6.7 \%$ for SR, and $4.2 \%$ for OSS.

Table 6

Health and Ability Means, Standard Deviations (in Parentheses), and Pearson's Correlations to POSHA-S/Child BEL, SR, and OSS ratings.

\begin{tabular}{lllll}
\hline \multirow{2}{*}{$\begin{array}{l}\text { Health and } \\
\text { Ability Rating }\end{array}$} & M (SD) & \multicolumn{3}{c}{ POSH $\boldsymbol{A}-\boldsymbol{S}$ /Child Correlations } \\
\cline { 3 - 5 } & & BEL & SR & OSS \\
\hline Physical Health & $91.8(18.7)$ & -.08 & -.16 & -.15 \\
Mental Health & $89.8(20.4)$ & -.04 & -.28 & -.19 \\
Ability to Learn & $89.8(22.8)$ & -.12 & -.22 & -.21 \\
Ability to Speak & $77.6(35.5)$ & .13 & -.18 & -.03 \\
\hline
\end{tabular}

Children's age. Results revealed no significant effect of children's age on BEL, $F(1,49)=.09, p=.76 ; \mathrm{SR}, F(1,49)=.91, p=.34$; or OSS, $F(1,49)=.66, p=.42$. Children's age accounted for $0.2 \%, 1.8 \%$, and $1.3 \%$ of the variance for BEL, SR, and 
OSS, respectively. Importantly, the variance of ages in this sample was small $(S D=.49)$, which likely contributed to the non-significant effect.

\section{Research Question 3: To what extent does the InterACT program effect change on preschool children's stuttering attitudes? \\ POSHA-S/Child pre- and posttest comparisons.}

Compared to the pretest, POSHA-S/Child posttest means for the 37 nonstuttering children in the experimental group increased for 34/56 ratings (61\%), decreased for 14/56 ratings $(25 \%)$, and remained the same for $8 / 56$ ratings (14\%). Compared to the pre-test, the average change across the 56 POSHA-S/Child ratings was +15 units. Statistically significant differences emerged for $21 / 56(38 \%)$ of those ratings including: $14 / 43(33 \%)$ items, 4/9 (44\%) components, $2 / 3$ (67\%) subscores, and the OSS. Excluding the seven Obesity/Wheelchair ratings, significant changes specific to stuttering emerged for 21/49 ratings (43\%), including 14/39 items (36\%), 4/7 components $(57 \%)$, both subscores, and the OSS. All but four of those 21 changes were in a positive direction (81\%). Effect sizes for significant differences were generally small, averaging .33 (range $=.23$ to .47 ). Table 7 displays the changes $P O S H A-S / C h i l d$ mean ratings.

Children demonstrated greatest improvement in their perceptions of the traits of children who stutter (Pre $=-11$, Post $=29, p=.00$ ). To a statistically significant degree, children were less likely to describe children who stutter as being shy (Pre $=-22$, Post $=$ $30, p=.03)$ and at fault for their stuttering $($ Pre $=-11$, Post $=57, p=.00)$. They were also less likely to describe children who stutter as being nervous and having a bad problem, although the increase in scores did not reach statistical significance. Although somewhat improved, children's belief that children who stutter are [un]able to talk well persisted $($ Pre $=-27$, Post $=-14)$. 
The Helping/Accommodating component was the second most improved component (Pre $=4$, Post $=39, p=.00)$. Of particular note, children were less inclined to tell children who stutter to "slow down" (Pre $=-73$, Post $=19, p=.00)$. Scores for that item increased by 92 units, which was the largest change across all survey items. They were also significantly less likely to finish a stutterer's words (Pre $=-22$, Post $=46, p=$ $.00)$ and laugh at a person who stutters $(\operatorname{Pre}=57, \operatorname{Post}=84, p=.03)$. Further, children more frequently reported that stuttering should not be hidden, and that they would act like there is nothing wrong with stutterers' talking. At the same time, however, children scores on the "I should help" component decreased, but not significantly (Pre $=51$, Post $=30)$.

Social Distance/Sympathy was the component with the third highest unit change $(\operatorname{Pre}=17$, Post $=42, p=.00)$. Specifically, children expressed significantly less worry if their doctor, sibling, friend, or they themselves stuttered. They were also less worried if their parent, teacher, or neighbor stuttered, but not to a significant level. The average unit change for the seven "worry" items was +39 , which is substantially higher than their mean POSHA-S/Child rating change of +15 . It should be noted that children held quite positive attitudes for many of the Social Distance/Sympathy items prior to the program. Not surprisingly, ratings for those items changed only marginally following the program and did not reach significance. For example, before the program, most children reported that children who stutter are "fun to play with," which only slightly increased following the program (Pre $=73$, Post $=76$ ). This was also the case for the items, "I would feel sorry for children who stutter" (Pre $=73$, Post $=73$ ), and, "I would be patient when 
talking to children who stutter" $($ Pre $=89$, Post $=100)$. Notably, the latter item is the only item for which all 37 participants had a uniformly "yes" response following the program.

The Causes of stuttering component was the fourth most improved, but not to a statistically significant degree $($ Pre $=-4$, Post $=11)$. Children were much less likely to attribute stuttering to germs (Pre $=-19, \operatorname{Post}=30, p=.01)$, a learned behavior (Pre $=-30$, Post $=8)$, and something bad that happened (Pre $=19$, Post $=30)$. At the same time, they became less likely to indicate that stuttering is a genetic trait $($ Pre $=38$, Post $=16)$, and slightly more likely to note that stuttering comes from something we can't see (Pre $=27$, Post $=24)$. Although slightly more accurate, their belief that stuttering comes from God persisted following the program $($ Pre $=-57$, Post $=-41)$.

Although the Potential component did not improve $($ Pre $=73$, Post $=68)$, it remained the highest rated component both before and after the program. Importantly, children's belief that children who stutter can do the same thing as others increased to a significant level (Pre $=19$, Post $=59, p=.03)$. Even though the means decreased, their belief that children who stutter can be anything they want to be when they grow up (Pre = 89$, Post $=70)$ and make good choices $($ Pre $=89$, Post $=78)$ remained positive. Neither of those decreased scores was statistically significant. The item "can make friends" also remained positive, but the mean significantly decreased following the program (Pre $=95$, Post $=62,(p=.01)$.

The Who Should Help component also decreased marginally following the program, but not significantly $($ Pre $=32$, Post $=26)$. Respondents' beliefs about who should help children who stutter were fairly well informed both before and after the program. In general, they reported that help should come from the parents of children 
who stutter $($ Pre $=78$, Post $=62)$ and a speech-language pathologist $($ Pre $=78$, Post $=73)$. Although they generally believed that other stutterers could help, that item significantly decreased $($ Pre $=54$, Post $=19, p=.05)$.

Finally, the Experience component remained the lowest component at pre and posttest, but the mean score significantly decreased following the program (Pre $=-68$, Post $=-89, p=.00)$. Parents' initial report of stutterers known to the child was used for both the pre and posttest analyses, therefore that item mean did not change (Pre $=-97$, Post $=-97)$. However, children became significantly less inclined to report that they stutter, have a family member or friend who stutters, or know anyone else who stutters $($ Pre $=-46$, Post $=-83, p=.00)$.

Children's subscores and OSS significantly increased following the program. The BEL subscore increased by 11 units (Pre $=22$, Post $=33, p=.03$ ), suggesting that children held generally positive or informed attitudes about stuttering and people who stutter following the program. The SR subscore increased by 13 units (Pre $=-16$, Post $=-$ $3, p=.00)$, indicating that children's knowledge of how to interact with people who stutter also improved. It should be noted that the low posttest SR score is primarily attributed to children's and parents' report of limited stuttering experience; otherwise, the majority of items and component scores were quite high. The OSS increased 12 units $($ Pre $=3$, Post $=15, p=.00)$, which is suggestive of a significant positive effect of the Inter $A C T$ program on children's overall stuttering attitudes.

Children's pre and post stuttering attitudes were further analyzed relative to their perceptions of obesity and wheelchair-use. The Obesity/Wheelchair subscore reflects the means of children's preferences for each attribute along with their experience with 
persons who are obese or use a wheelchair, as reported by a parent. Children's experience with obesity was -51 , and -83 for wheelchair use. As previously noted, children's stuttering experience was -68 at pretest and -89 at posttest. Accordingly, children's rankordered experience for the three attributes was obesity $>$ stuttering $>$ wheelchair use at pretest, and obesity $>$ wheelchair-use $>$ stuttering at posttest. Before and after the program, the children indicated a moderately high preference for stuttering (Pre $=49$, Post $=49)$, followed by a somewhat high preference for wheelchair-use (Pre $=14$, Post $=$ $32)$, and very low preference for obesity $($ Pre $=-63$, Post $=-81)$. Posttest scores revealed no change in preference for stuttering, an 18 unit increase for wheelchair use, and a 18 unit decrease for obesity; however, none of the changes were significant.

\section{Table 7}

Pre and Post POSHA-S/Child Means and Standard Deviations (in Parentheses), Units of Change, Significance Values, Z Scores, and Effect Sizes for Significant Differences for 37 Participants.

\begin{tabular}{|c|c|c|c|c|c|c|}
\hline POSHA-S/Child Variable & $\begin{array}{c}\text { Pre } \\
(N=37)\end{array}$ & $\begin{array}{c}\text { Post } \\
(N=37)\end{array}$ & $\begin{array}{l}\text { Units of } \\
\text { Change }\end{array}$ & Sig. & $\begin{array}{c}Z \\
\text { value }\end{array}$ & $\begin{array}{c}\text { Effect } \\
\text { Size }\end{array}$ \\
\hline $\begin{array}{l}\text { OVERALL STUTTERING } \\
\text { SCORE }\end{array}$ & $3(18)$ & $15(23)$ & +12 & .00 & -3.0 & .35 \\
\hline $\begin{array}{l}\text { Beliefs About Children who } \\
\text { Stutter }\end{array}$ & $\underline{22(21)}$ & $33(34)$ & +11 & .03 & $\underline{-2.3}$ & .26 \\
\hline Traits / Personality & $-11(50)$ & $29(57)$ & +40 & .00 & -3.31 & .38 \\
\hline Are at fault ${ }^{\mathrm{a}}$ & $-11(99)$ & $57(83)$ & +68 & .00 & -3.50 & .41 \\
\hline Nervous ${ }^{a}$ & $-5(97)$ & $35(95)$ & +40 & .06 & -1.90 & \\
\hline Shy ${ }^{a}$ & $-22(98)$ & $30(97)$ & +52 & .03 & -2.21 & .23 \\
\hline Have a bad problem ${ }^{\text {a }}$ & $8(98)$ & $35(95)$ & +27 & .23 & -1.21 & \\
\hline
\end{tabular}




\begin{tabular}{|c|c|c|c|c|c|c|}
\hline Can talk well & $-27(96)$ & $-14(100)$ & +13 & .46 & -.75 & \\
\hline Stuttering Should Be Helped & $32(26)$ & $26(44)$ & -6 & .41 & -.82 & \\
\hline \multicolumn{7}{|l|}{ by... } \\
\hline Speech-language pathologist & $78(63)$ & $73(69)$ & -5 & .66 & -.45 & \\
\hline Other people who stutter & $54(80)$ & $19(100)$ & -35 & .05 & -1.9 & .23 \\
\hline Medical doctor ${ }^{\text {a }}$ & $-84(55)$ & $-51(87)$ & +33 & .06 & -1.90 & \\
\hline Parent & $78(63)$ & $62(79)$ & -16 & .37 & -.91 & \\
\hline Stuttering is Caused by... & $-4(43)$ & $11(48)$ & +15 & .07 & -1.81 & \\
\hline Came from their mom or dad & $38(92)$ & $16(99)$ & -22 & .40 & -.85 & \\
\hline \multicolumn{7}{|l|}{ when they were born } \\
\hline Learning $^{\text {a }}$ & $-30(97)$ & $8(101)$ & +38 & .09 & -1.70 & \\
\hline Something bad that happened ${ }^{a}$ & $19(100)$ & $30(97)$ & +11 & .66 & -.45 & \\
\hline God/Allah ${ }^{\text {a }}$ & $-57(83)$ & $-41(93)$ & +16 & .41 & -.83 & \\
\hline Germs like those that make & $-19(100)$ & $30(97)$ & +49 & .01 & -2.50 & .29 \\
\hline \multicolumn{7}{|l|}{ you sick ${ }^{a}$} \\
\hline Something we can't see ${ }^{\text {a }}$ & $27(96)$ & $24(98)$ & -3 & .82 & -.23 & \\
\hline Potential & $73(38)$ & $68(57)$ & -5 & .63 & -.49 & \\
\hline Can make friends & $95(33)$ & $62(79)$ & -33 & .01 & -2.45 & .28 \\
\hline Do same thing as others & $19(100)$ & $59(80)$ & +40 & .03 & -2.15 & .25 \\
\hline Have any job as adult & $89(46)$ & $70(70)$ & -19 & .23 & -1.21 & \\
\hline Make good choices & $89(46)$ & $78(63)$ & -11 & .32 & -1.00 & \\
\hline Self Reactions to Children & $-16(23)$ & $-3(18)$ & +13 & .00 & $\underline{-3.40}$ & .40 \\
\hline \multicolumn{7}{|l|}{ who Stutter } \\
\hline Accommodating / Helping & $4(43)$ & $39(40)$ & +35 & .00 & -4.08 & .47 \\
\hline Ignore & $-24(98)$ & $-3(101)$ & +21 & .35 & -.94 & \\
\hline
\end{tabular}




\begin{tabular}{|c|c|c|c|c|c|c|}
\hline I should help & $51(87)$ & $30(97)$ & -21 & .16 & -1.41 & \\
\hline Finish the person's words ${ }^{\text {a }}$ & $-22(98)$ & $46(90)$ & +68 & .00 & -3.03 & .35 \\
\hline Tell the person to "Slow & $-73(69)$ & $19(100)$ & +92 & .00 & -3.90 & .45 \\
\hline \multicolumn{7}{|l|}{ down" a } \\
\hline Laugh $^{\text {a }}$ & $57(83)$ & $84(55)$ & +27 & .03 & -2.34 & .27 \\
\hline Should try to hide their & $35(95)$ & $57(83)$ & +22 & .10 & -1.63 & \\
\hline \multicolumn{7}{|l|}{ stuttering $^{\mathrm{a}}$} \\
\hline Social Distance / Sympathy & $17(50)$ & $42(51)$ & +25 & .00 & -3.46 & .40 \\
\hline Fun to play with & $73(69)$ & $76(64)$ & -3 & .89 & -.14 & \\
\hline Be bothered & $51(87)$ & $62(79)$ & +11 & .48 & -.71 & \\
\hline Feel sorry for them & $73(69)$ & $73(69)$ & $+/-0$ & 1.00 & .00 & \\
\hline Feel patient ${ }^{\text {a }}$ & $89(46)$ & $100(0)$ & +11 & .16 & -1.41 & \\
\hline Worried about my doctor ${ }^{a}$ & $-38(92)$ & $41(93)$ & +79 & .00 & -3.53 & .41 \\
\hline Worried about my teacher ${ }^{a}$ & $-8(101)$ & $14(100)$ & +22 & .21 & -1.27 & \\
\hline Worried about my neighbor ${ }^{\text {a }}$ & $-14(100)$ & $19(100)$ & +33 & .06 & -1.90 & \\
\hline Worried about my brother or & $-14(100)$ & $24(98)$ & +38 & .04 & -2.11 & .25 \\
\hline \multicolumn{7}{|l|}{ sister $^{\mathrm{a}}$} \\
\hline Worried about me ${ }^{a}$ & $-8(101)$ & $24(98)$ & +32 & .03 & -2.12 & .25 \\
\hline Worried about a friend & $-35(95)$ & $14(100)$ & +49 & .01 & -2.71 & .32 \\
\hline Worried about a parent & $-14(100)$ & $8(101)$ & +22 & .21 & -1.27 & \\
\hline Preference & $49(69)$ & $49(61)$ & $+/-0$ & .83 & -.211 & \\
\hline Experience & $-68(40)$ & $-89(26)$ & -21 & .00 & -3.37 & .39 \\
\hline Persons known who stutter & $-97(6)$ & $-97(58)$ & $+/-0$ & 1.00 & .00 & \\
\hline \multicolumn{7}{|l|}{ (informant report) } \\
\hline Persons known who stutter & $-46(71)$ & $-83(46)$ & -37 & .00 & -3.37 & .39 \\
\hline
\end{tabular}




\begin{tabular}{llllll}
\hline $\begin{array}{l}\text { (child report) } \\
\text { Obesity/Wheelchair }\end{array}$ & $\underline{\mathbf{- 4 6 ( 2 3 )}}$ & $\underline{\mathbf{- 4 6 ( 2 0 )}}$ & $\underline{+/-\mathbf{0}}$ & $\underline{\mathbf{. 7 0}}$ & $\underline{\mathbf{- . 3 8}}$ \\
$\underline{\text { Subscore }}$ & & & & & \\
Preference & $\mathbf{- 2 4}(\mathbf{3 5})$ & $\mathbf{- 2 4 ( 3 0 )}$ & $+/-\mathbf{0}$ & $\mathbf{. 9 8}$ & $\mathbf{- . 0 3}$ \\
Obesity & $-63(60)$ & $-81(46)$ & -18 & .06 & -1.90 \\
Wheelchair & $14(55)$ & $32(53)$ & +18 & .18 & -1.34 \\
Experience & $\mathbf{- 6 7 ( 2 5 )}$ & $\mathbf{- 6 7 ( 2 5 )}$ & $+/-\mathbf{0}$ & $\mathbf{1 . 0 0}$ & $\mathbf{. 0 0}$ \\
Obesity & $-51(35)$ & $-51(35)$ & $+/-0$ & 1.00 & .00 \\
Wheelchair & $-83(29)$ & $-83(29)$ & $+/-0$ & 1.00 & .00 \\
\hline
\end{tabular}

Note. Statistically significant differences $(p \leq 0.05)$ are indicated by gray shading.

${ }^{a}$ Mean ratings inverted so that higher scores reflect more accurate, sensitive attitudes.

\section{Pilot study comparisons.}

Compared to the pilot study, this study generated 10 more increased POSHAS/Child ratings, one less decreased rating, and nine fewer unchanged ratings (Appendix P). Despite those differences, the mean scores and unit changes for BEL, SR, and OSS were comparable. For the OSS, the experimental group post mean was 15 (unit change $=$ +12 ), and the pilot group post mean was 13 (unit change $=+12$ ). For BEL, the experimental group had a mean of 33 after the program (unit change $=+11$ ), and the pilot group had a mean of 37 (unit change $=+12$ ). For $S R$, the experimental group mean was -3 (unit change $=+13$ ), and -11 in the pilot group (unit change $=+12$ ). As such, the pilot and experimental groups both held more positive SR compared to BEL, and their degree of change was similar. Both groups had highest ratings for the Potential component and lowest ratings for the Experience component before and after the program. However, no consistent pattern of change for the other components was observed. Whereas the groups had similar units of change for some components (i.e., Accommodating/Helping), they 
were notably different in others (i.e., Traits, Social Distance/Sympathy). These inconsistent changes might be a result of the slight methodological differences between the pilot and current study. Overall, however, the pilot and experimental study both pointed to a similar magnitude of stuttering attitude change following the Inter $A C T$ program.

\section{Qualitative pre- and posttest comparisons.}

Video responses. Children's reactions to the POSHA-S/Child stimulus video featuring stuttering avatars was observed and coded as "positive/neutral" or "negative/undesired" according to the procedures previously described. Of the 55 children who took the POSHA-S/Child pretest, 7/55 (13\%) had an overt negative or undesired reaction to the stimulus video. The qualitative findings for those children are consistent with their average POSHA-S/Child SR subscore, which was quite low, -8. A summary of children's negative or undesired responses is shown in Table 8 . By comparison, none of the 37 children in the experimental group responded negatively to the stimulus video following the program. It should be noted, however, that two of the children who expressed a negative or undesired reaction at pretest did not complete a posttest.

Table 8

Descriptions of Children's Negative or Undesired Responses to the POSHA-S/Child Video Stimulus at Pretest.

\section{Participant}

Code

\section{Description of response}

EH-10

Looked at the examiner with confused expression and proceeded to mouth the spoken words of the stuttering avatars.

EH-13 Looked at the examiner with a surprised expression, and grinned as if laughing at the characters. 

EH-14 with their mouth like that?" and, "How can they talk with their mouth like that?"

EH-20 Finished the word "ball," when the girl avatar stuttered on that word.

EH-45 Looked at the examiner with a confused expression and asked, "Why are they talking like that?" during and after the video.

EH-60 Looked at the examiner with a surprised expression when the girl stuttering character prolonged the word, "Sarah."

EH-69 Stated, "I had to keep thinking about what he was saying" in response to the boy stuttering avatar.

Definition of "stuttering." Children's responses to the question "what does the word 'stuttering' mean?" were also documented before and after administering the POSHA-S/Child at before and after the InterACT program. Accordingly, the 55 children who took the pretest had two opportunities to respond to the question, and the 37 children who took the posttest had four opportunities to respond to the question (i.e., Pre-1, Pre-2, Post-1, Post-2). As described previously, their responses were judged as "incorrect" or "correct" and further classified into one of eight subcategories. Children's responses are categorized in Table 9, and all verbatim responses are shown in Appendix Q.

Prior to the pretest, none of the 55 children were able to define the word stuttering (i.e., Pre-1). Thirty-three children (60\%) stated, "I don't know," six children (11\%) had no response, and 16 children (29\%) responded incorrectly. Examples of incorrect responses include, "[stuttering means] you're kind of scared," "mad," and "you're studying something you need to work on.”

Following the administration of the pretest (i.e., Pre-2), 35 children (64\%) provided an accurate definition of stuttering, and 20 children (36\%) gave an incorrect 
definition. Of the 35 correct responses, 13 children (24\%) were able to respond to the question given a semantic or phonemic cue (i.e., "stuttering has to do with the way people ' $t$ '[alk]."), and 21 children (38\%) generated a response independently. Two children described types of stuttering (e.g., "it means they don't finish their words, like they stop a little bit and then keep on going"), four children demonstrated stuttering through imitation (e.g., "when someone talks like this, 'w-w-would you play with me?"”), and 15 children described stuttering as pertaining to the way a person talks, ("it means you can't talk so well.”). Further analysis of the 35 correct responses revealed that 28 children (80\%) gave a neutral appraisal of stuttering (e.g., "the way people talk"), and 7 children (20\%) gave a negative appraisal of stuttering (e.g., "it means you have a really weird talk.").

After completing the InterACT program, but prior to the posttest, the 37 children in the experimental group were once again asked, "what does the word stuttering mean?" (i.e., Post-1). Twenty-eight out of 37 children (76\%) answered the prompt correctly, and the remaining nine answered incorrectly (24\%). Of the correct responses, only two children needed cueing (6\%), and 26 children (70\%) generated a response independently. Most children referenced types of stuttering such as repetitions, prolongations, and blocks (e.g., "it means your voice sounds a little jumpy", "when your words get stretched," "when your words get stuck in your throat"), and others described stuttering as dealing with the way people talk (e.g., "when people don't finish their words fast like other people"). Twenty-three of the 28 children who provided a correct definition gave a positive or neutral appraisal of stuttering (82\%), and 5 children (18\%) gave a negative appraisal (e.g., "that you mess up on your words"). 
Responses to the final prompt, which were elicited immediately following the posttest (i.e., Post-2), revealed that 32 out of 37 children answered correctly $(86.5 \%)$, and 5 children answered incorrectly (13.5\%). Seven children required a phonemic or semantic cue $(19 \%)$, and $24(69 \%)$ responded to the open-ended prompt independently. As with Post-1, most children generated a description of stuttering types (e.g., "it means that their words don't come out or their words stretch or they bounce") or referred to their talking (e.g. "it means you have a different talk"). Twenty-eight of the 32 correct responses were either positive or neutral (87.5\%), and four (12.5\%) were negative (e.g., "when you don't talk too good").

Table 9

Accuracy and Categorization of Children's Responses to the Prompt "What Does the Word 'Stuttering' Mean?" Asked Immediately Before and After the POSHA-S/Child Pretest (Pre-1 and Pre-2) and Posttest (Post-1 and Post-2).

\begin{tabular}{lcccc}
\hline & Pre-1 & Pre-2 & Post-1 & Post-2 \\
\hline Sample Size & $N=55$ & $N=55$ & $N=37$ & $N=37$ \\
$\begin{array}{l}\text { Correct } \\
\text { (\% total) }\end{array}$ & $\mathbf{0 \%}(\boldsymbol{n}=\mathbf{0})$ & $\mathbf{6 4 \%}(\boldsymbol{n}=\mathbf{3 5})$ & $\mathbf{7 6 \%}(\boldsymbol{n}=\mathbf{2 8})$ & $\begin{array}{r}\mathbf{8 6 . 5 \%} \\
(\boldsymbol{n}=\mathbf{3 2})\end{array}$
\end{tabular}

Described types of stuttering

$$
5 \%(n=3) \quad 43 \%(n=16) \quad 35 \%(n=13)
$$

Demonstrated stuttering

$$
7 \%(n=4) \quad 5 \%(n=2) \quad 5 \%(n=2)
$$

Described stutterers' $27 \%(n=15) \quad 22 \%(n=8) \quad 27 \%(n=10)$ talking

Semantic cue $-\quad 13 \%(n=7)$

$3 \%(n=1)$ $16 \%(n=6)$

Phonetic cue

$-\quad 11 \%(n=6)$

$3 \%(n=1)$

$3 \%(n=1)$ 


\begin{tabular}{lcccc}
$\begin{array}{l}\text { Incorrect }(\% \\
\text { total })\end{array}$ & $\mathbf{1 0 0 \%}(\boldsymbol{n}=\mathbf{5 5})$ & $\mathbf{3 6 \%}(\boldsymbol{n}=\mathbf{2 0})$ & $\mathbf{2 4 \%}(\boldsymbol{n}=\mathbf{9})$ & $\mathbf{1 3 . 5 \%}(\boldsymbol{n}=\mathbf{5})$ \\
$\begin{array}{l}\text { I don't } \\
\text { know }\end{array}$ & $60 \%(n=33)$ & $16 \%(n=9)$ & $14 \%(n=5)$ & $5 \%(n=2)$ \\
$\begin{array}{l}\text { Inaccurate } \\
\text { definition }\end{array}$ & $32 \%(n=16)$ & $18 \%(n=10)$ & $10 \%(n=4)$ & $8 \%(n=3)$ \\
$\begin{array}{l}\text { No } \\
\text { response }\end{array}$ & $8 \%(n=6)$ & $2 \%(n=1)$ & - & - \\
\hline
\end{tabular}

The responses from the six children in the control group were also analyzed before and after the initial and follow-up POSHA-S/Child administrations. As with the experimental group, none of the controls correctly defined the word "stuttering" prior to the initial survey. Five out of the six children (83\%) correctly defined the term after the initial survey, three of whom needed a phonemic cue. Prior to the follow-up survey, only two children (33\%) defined the term correctly, and three children $(50 \%)$ generated an accurate definition after the follow-up survey.

\section{Reliability}

\section{Test-rest reliability.}

For the six control participants, comparisons between their initial and follow up POSHA-S/Child scores revealed no significant differences (Table 10). The means for $25 / 59$ survey ratings ( $42 \%$ ) remained exactly the same, including the OSS. Although the second administration of the $P O S H A-S / C h i l d$ revealed increased scores for some ratings, $13 / 59(22 \%)$, and decreased scores for some ratings, $18 / 59(31 \%)$, the average unit change across the 59 ratings was only -2 units. In general, the means for the control group were considerably higher than that of the experimental group. The control group's initial SR, BEL, and OSS were: $-3,34$, and 16 compared to the experimental group's pretest 
scores of $-16,22$, and 3 and posttest scores of $-3,33$, and 15 . The small sample size of the control group likely restricted the variability in attitude scores as would be expected with a larger sample. In addition, the sample size would cause group means to be more sensitive to individual participants with very high or very low stuttering attitudes. Such was the case with one control subject who held a very high stuttering attitude at the initial and follow-up POSHA-S/Child administration (i.e., EH-26).

Table 10

Initial and Follow-up POSHA-S/Child Means and Standard Deviations (in Parentheses), Units of Change, Significance Values, Z Scores, and Effect Sizes for Significant Differences for 6 Control Participants.

\begin{tabular}{|c|c|c|c|c|c|}
\hline $\begin{array}{c}\text { POSHA-S/Child } \\
\text { Variable }\end{array}$ & First & Second & $\begin{array}{l}\text { Units of } \\
\text { Change }\end{array}$ & Sig. & $Z$ value \\
\hline OVERALL & $16(20)$ & $16(21)$ & $+/-0$ & .83 & -.21 \\
\hline \multicolumn{6}{|l|}{ STUTTERING SCORE } \\
\hline Beliefs About Children & $\underline{34(16)}$ & $\underline{36(20)}$ & +2 & .83 & $\underline{-.21}$ \\
\hline \multicolumn{6}{|l|}{ who Stutter } \\
\hline Traits / Personality & $20(51)$ & $13(53)$ & -7 & 1.00 & .00 \\
\hline Are at fault ${ }^{\text {a }}$ & $33(103)$ & $0(110)$ & -33 & .32 & -1.00 \\
\hline Nervous $^{\text {a }}$ & $0(110)$ & $0(110)$ & $+/-0$ & 1.00 & .00 \\
\hline Shy ${ }^{a}$ & $0(110)$ & $0(110)$ & $+/-0$ & 1.00 & .00 \\
\hline Have a bad problem ${ }^{a}$ & $67(82)$ & $100(0)$ & +33 & .32 & -1.00 \\
\hline Can talk well & $0(110)$ & $-33(103)$ & -33 & .32 & -1.00 \\
\hline Stuttering Should Be & $42(20)$ & $42(20)$ & $+/-0$ & 1.00 & .00 \\
\hline \multicolumn{6}{|l|}{ Helped by... } \\
\hline Speech-language & $67(82)$ & $100(0)$ & +33 & .32 & -1.00 \\
\hline
\end{tabular}




\begin{tabular}{|c|c|c|c|c|c|}
\hline \multicolumn{6}{|l|}{ pathologist } \\
\hline Other people who stutter & $100(0)$ & $67(82)$ & -33 & .32 & -1.00 \\
\hline Medical doctor ${ }^{\text {a }}$ & $-67(82)$ & $-100(0)$ & -33 & .32 & -1.00 \\
\hline Parent & $67(82)$ & $100(0)$ & +33 & .32 & -1.00 \\
\hline Stuttering is Caused & $\mathbf{0}(\mathbf{3 0})$ & $6(44)$ & +6 & .46 & -.74 \\
\hline \multicolumn{6}{|l|}{ by... } \\
\hline Genetics & $67(82)$ & $33(103)$ & -34 & .32 & -1.00 \\
\hline Learning ${ }^{a}$ & $-100(0)$ & $-67(82)$ & +33 & .32 & -1.00 \\
\hline Something bad that & $67(82)$ & $67(82)$ & $+/-0$ & 1.00 & .00 \\
\hline \multicolumn{6}{|l|}{ happened $^{\text {a }}$} \\
\hline God/Allah ${ }^{a}$ & $33(103)$ & $33(103)$ & $+/-0$ & 1.00 & .00 \\
\hline Germs ${ }^{a}$ & $0(110)$ & $0(110)$ & $+/-0$ & 1.00 & .00 \\
\hline Something we can't see ${ }^{a}$ & $-67(82)$ & $-33(103)$ & +34 & .32 & -1.00 \\
\hline Potential & $75(42)$ & $83(26)$ & +8 & .32 & -1.00 \\
\hline Can make friends & $100(0)$ & $100(0)$ & $+/-0$ & 1.00 & .00 \\
\hline Do same thing as others & $33(103)$ & $33(103)$ & $+/-0$ & 1.00 & .00 \\
\hline Have any job as adult & $100(0)$ & $100(0)$ & $+/-0$ & 1.00 & .00 \\
\hline Make good choices & $67(82)$ & $100(0)$ & +33 & .32 & -1.00 \\
\hline$\underline{\text { Self Reactions to }}$ & $-3(32)$ & $-4(26)$ & $\underline{-1}$ & .79 & $\underline{-.27}$ \\
\hline \multicolumn{6}{|l|}{ Children who Stutter } \\
\hline Accommodating / & $19(50)$ & $22(17)$ & +3 & .89 & -.14 \\
\hline \multicolumn{6}{|l|}{ Helping } \\
\hline Ignore & $-33(103)$ & $-33(103)$ & $+/-0$ & 1.00 & .00 \\
\hline I should help & $50(84)$ & $33(103)$ & -17 & .79 & -.27 \\
\hline Finish the person's & $33(103)$ & $0(110)$ & -33 & .32 & -1.00 \\
\hline
\end{tabular}


words $^{\text {a }}$

Tell the person to "Slow

$-67(82)$

$-67(82)$

$+/-0$

1.00

.00

down" a

Laugh $^{\text {a }}$

$100(0)$

$100(0)$

$+/-0$

1.00

.00

Should try to hide their

$33(103)$

$100(0)$

$+67$

.157

$-1.41$

stuttering $^{\text {a }}$

Social Distance /

$40(52)$

33 (51)

$-7$

.68

$-.41$

Sympathy

Fun to play with

$100(0)$

$67(82)$

$-33$

32

$-1.00$

Be bothered

$67(82)$

$67(82)$

$+/-0$

1.00

.00

Feel sorry for them

$100(0)$

67 (82)

$-33$

.32

$-1.00$

Feel patient ${ }^{\mathrm{a}}$

$100(0)$

$67(82)$

$-33$

.32

$-1.00$

Worried about my doctor

0 (110)

0 (110)

$+/-0$

1.00

.00

a

Worried about my

0 (110)

0 (110)

$+/-0$

1.00

.00

teacher $^{\text {a }}$

Worried about my

$-33(103)$

$0(110)$

$+33$

.32

$-1.00$

neighbor $^{a}$

Worried about my

0 (110)

0 (110)

$+/-0$

1.00

.00

brother or sister ${ }^{a}$

Worried about me ${ }^{\mathrm{a}}$

33 (103)

0 (110)

$-33$

.56

$-.58$

Worried about a friend

33 (103)

$33(103)$

$+/-0$

1.00

.00

Worried about a parent

33 (103)

$33(103)$

1.00

.00

Preference

33 (82)

67 (2)

$+34$

.157

$-1.41$

Experience

$-67(53)$

$-67(51)$

+/- 0

1.00

.00 


\begin{tabular}{|c|c|c|c|c|c|}
\hline $\begin{array}{l}\text { Persons known who } \\
\text { stutter (informant repo }\end{array}$ & $-67(77)$ & $-67(77)$ & $+/-0$ & 1.00 & .00 \\
\hline $\begin{array}{l}\text { Persons known who } \\
\text { stutter (child report) }\end{array}$ & $-67(55)$ & $-67(82)$ & $+/-0$ & 1.00 & .00 \\
\hline Obesity/Wheelchair & $\underline{-37(30)}$ & $-53(16)$ & $\underline{-16}$ & .18 & $\underline{-1.34}$ \\
\hline$\underline{\text { Subscore }}$ & & & & & \\
\hline Preference & $0(63)$ & $-33(41)$ & -33 & .18 & $\underline{-1.34}$ \\
\hline Obesity & $-17(98)$ & $-50(55)$ & -33 & .41 & -.82 \\
\hline Wheelchair & $0(71)$ & $-17(75)$ & -17 & 1.00 & .00 \\
\hline Experience & $-73(21)$ & $-73(21)$ & $+/-0$ & 1.00 & .00 \\
\hline Obesity & $-60(44)$ & $-60(44)$ & $+/-0$ & 1.00 & .00 \\
\hline Wheelchair & $-87(33)$ & $-87(33)$ & $+/-0$ & 1.00 & .00 \\
\hline
\end{tabular}

\section{Inter-rater reliability.}

Twenty percent of the 55 participants who took the initial POSHA-S/Child ( $n=$ 11 ), and $20 \%$ of the 43 participants who took a follow-up POSHA-S/Child $(n=9)$ were randomly selected for inter-rater reliability testing. Selected participants are notated in Appendix L. An examiner who did not carry out the initial survey watched each of those subject's video recordings and independently scored the "yes/no" POSHA-S/Child items (i.e., 40 items) and screening form. Items requiring the child to select pictures depicting a child who is obese, in a wheelchair, and who stutters, as well as the Theory of Mind Task Battery, were not factored into the inter-rater reliability scores, as participants' selections could not be seen in the videos. For the 11 participants whose initial POSHA-S/Child surveys were rescored, there were a total of five disparate examiner ratings out of a total 440 possible judgments (i.e., 40 items for 11 participants), yielding an inter-rater 
agreement of $99 \%$. For the participant screening form, a total of 11 disparate ratings emerged for 44 possible judgments (i.e., 4 items for 11 participants), yielding an interrater agreement of $75 \%$. For the 9 participants whose follow-up POSHA-S/Child surveys were rescored, there were a total of six disparate examiner ratings out of a total 360 possible judgments (i.e., 40 items for 9 participants), yielding a total inter-rater agreement of $98 \%$. For the participant screening form, a total of six disparate ratings emerged for 36 possible judgments (i.e., 4 items for 9 participants), yielding an inter-rater agreement of $83 \%$. Clearly, the POSHA-S/Child child scores generated a higher agreement rate compared to the screening form, with the video ratings being consistently lower than the face-to-face ratings. For the 17 disparate ratings, 9 (53\%) were rated one point lower, and $8(47 \%)$ were rated one point higher. It should be pointed out that the video recordings often lacked or enhanced environmental nuances that could only be detected face-to-face. For example, ambient noise was often amplified in the recordings, which may have led to lower ratings relative to a participants' attention or intelligibility. At the same time, lack of face-to-face interaction with the child may have led to inflated judgments relative to his or her ability to understand and follow directions. Reasons such as these may have caused the overall percentage of agreement to decrease. Finally, two examiners coded children's responses to the question, "what does the word stuttering mean?" as either "correct" or "incorrect" and further categorized their responses into one of eight categories. A total of 184 responses (55 at Pre-1 and Pre-2, and 37 at Post-1 and Post-2) were coded. The examiners agreed on the coding for 164 responses (89\%), and discussed disparate ratings until 100\% agreement was reached. 


\section{Chapter 5: Discussion}

The impetus for this study was to extend epidemiological research in stuttering attitudes and respond to calls for attitude change among young children. The study was driven by three purposes. First, it sought to measure preschool children's stuttering attitudes prior to any education about the disorder. It was hypothesized that children would hold unfavorable attitudes, particularly dealing with their knowledge about stuttering causes and what to do when talking with a stuttering peer. Second, the study examined the degree to which various predictors explained those attitudes. Children's social cognition and experience with or exposure to stuttering were hypothesized to have a strong effect, whereas parent attitudes, socioeconomic status, and the child's age and health and abilities were expected to have little to no effect. Third, and arguably most importantly, this was the first known study to measure the impact of an educational program on preschool children's stuttering attitudes. Children's attitudes were predicted to improve, especially with regard to their knowledge about the disorder and skills when interacting with a stutterer. Salient findings and implications relative to each of those purposes are discussed. Limitations of the current study and suggested future directions are also advanced.

\section{Stuttering Attitudes of Nonstuttering Preschool Children Beliefs about stuttering.}

Findings from this study showed that preschool children's baseline knowledge about stuttering was limited. This is not surprising, given that none of the children had an accurate conceptualization of the word "stuttering" prior to the initial POSHA-S/Child administration. Consistent with the study by Weidner, St. Louis, Burgess, and colleagues 
(2015), respondents in this study attributed stuttering to a learned behavior, an act of God, or germs. When interpreted against the backdrop of children's cognitive developmental trajectory, these findings are not unexpected. First, stuttering as a learned behavior might relate to the rapid growth in children's semantic and lexical skills during the preschool years. Often, children's linguistic demands to answer and ask questions, tell short stories, maintain a conversation, and so on, exceed their capacity to maintain fluent speech. As a result, they may exhibit an increase in disfluency (Starkweather \& Gottwald, 1990). From this perspective, children may be inclined to believe that learning — especially that which is related to lexical and semantic gains - is associated with stuttering. Second, children's belief that stuttering comes from germs is possibly linked to their knowledge that germs threaten one's physical well being (Ergazaki, Saltapida, \& Zogza, 2010). Preschool children are constantly reminded by teachers and caregivers to minimize the spread of germs as to prevent the spread of undesirable illness. In fact, several of the classrooms included in this study required children and visitors to wash their hands before entering. Messages such as these may cause children to associate germs with all undesirable conditions. Third, theological explanations may be at play for children's tendency to report that stuttering comes from God. Children's conceptualization of God is reportedly quite rigid during the preschool years, and becomes increasingly more abstract with age (Ladd, McIntosh, \& Spilka, 1998). As such, preschool children tend to credit God as the sole cause of various phenomena (e.g., illness). Interestingly, children from a predominately Christian society, including those included in this study, appear to have a higher tendency to affirm that stuttering comes from God compared to children from a predominately Muslim society (Weidner, St. Louis, Nakısc1, et al., 2015). The reasons 
underlying those differences are yet to be fully understood. Despite their many inaccurate perceptions, children were also likely to report that stuttering is an inherited trait. This is somewhat surprising, given that it typically is not until the school-age years that children understand that a person can be born with a disorder or disability (Tamm \& Prellwitz, 2001).

Children's preferences for stuttering were highest compared to obesity and wheelchair-use, upholding previous research (Weidner, St. Louis, Burgess et al., 2015; Weidner, St. Louis, Nakısc1, et al., 2015). The explanation for stuttering as the highestrated condition remains unclear. However, in the context of wheelchair use and obesity, a speech disorder is a considerably less noticeable condition (Diamond \& Hestenes, 1996). Children can readily see a person who is obese or who is in a wheelchair, but must detect stuttered speech through attentive listening. Therefore, the physical and/or health consequences of being obese or in a wheelchair might be more obvious to a young child than the ramifications of stuttering. Children's favorable rating of wheelchair-use aligns with child disability research (Van Hooser, 2009). Even though children understand that people in wheelchairs are physically limited, Van Hooser (2009) showed that they perceive wheelchair users as being friendly. Compared to the other attributes, obesity ranked quite low. This follows a line of research in child developmental psychology, which has shown that preschoolers hold a strong negative bias toward obesity (Kornilaki, 2014). Their rejection of obesity might stem from their real-life encounters with obese persons, in that children in the current study had the most reported experience with obesity compared to the other attributes. Such encounters might contribute to children's knowledge about the physical and health consequences associated with the condition (e.g., 
breathing difficulties and diminished physical endurance). Children's preferences for the three attributes (i.e., stuttering, wheelchair-use, and obesity) were inversely associated with their parent-reported experiences with those conditions. That is, the more experience children had with a condition, the lower their preference rating. Information about the duration and quality of those interactions would help explain why this may have occurred.

\section{Beliefs about people who stutter.}

Evidence of a "stuttering stereotype" abounds, and results of the present study further support that it exists among children as early as the preschool years. Children in this study frequently expressed "worry" if anyone close to them stuttered (i.e., family member, neighbor, teacher, doctor, or themselves). In addition, they consistently affirmed that stutterers are "[un]able to talk well, nervous, and shy." Children 6- to 13-years-old have also generated similar descriptions of stuttering speakers (Franck et al., 2003; Hartford \& Leahy, 2007; Panico et al., 2015), and these descriptions persist throughout adulthood (see Hughes, 2015 for a review).

Respondents' negative perceptions about stutterers' traits did not appear to influence their beliefs about stutterers' life potential or social competency. Similar to Weidner, St. Louis, Burgess, et al. (2015), respondents consistently noted that children who stutter can make good choices, can do the same thing as others, and can be anything they want to be when they grow up. Perhaps most importantly, out of all of the POSHAS/Child items, respondents had the most positive attitude toward stutterers' ability to make friends. Previous research has shown that 4- and 5-year-olds had higher preference for a fluent friend versus a stuttering friend (Ezrati-Vinacour et al., 2001). Even though the present study did not distinguish between children's preferences for fluent or 
stuttering friends, respondents noted that stutterers are "fun to play with." Taken together, the findings between these studies might suggest that young children's perceptions of stutterers are not deep-seated, but rather are in a state of flux. If that assumption is true, preschool might be an optimal period in which to facilitate knowledge of stuttering and foster mutually positive socialization between typically fluent and stuttering children.

\section{Self reactions toward people who stutter.}

Children in this study had a strong desire to interact with stuttering children, but their knowledge about how to do so appropriately was inconsistent. Encouragingly, children would not laugh at a stutterer and did not believe that stuttering should be hidden. They reportedly would not be bothered by stuttering, a finding that was recently confirmed in older children (Panico et al., 2015). Further, they expressed that they would feel patient with and sorry for a child who stutters. Yet, even though children were apparently motivated to help and interact with stuttering peers, they reported inclinations to finish stutterers' words and tell them to "slow down." Such responses are reportedly common among nonstuttering listeners (Reitzes, 2012), but generally undesired by stuttering children and adults (Rodriguez et al., 2015; Weidner, Coleman, et al., 2015). One might wonder about the impact of nonstutterers' negative or undesired listener reactions on young children who stutter. Langevin and colleagues (2009) noted, "preschoolers who stutter may be at risk for experiencing social penalties and limitations to growth, social skills, and formation of friendships related to compromised communication skills" (p. 272). Although the present study cannot definitively confirm or reject the possibility of negative social consequences for stuttering preschoolers, it 
certainly underscores the need to educate young children about specific social considerations when talking with a stutterer.

\section{Predictive Factors on Children's Stuttering Attitudes Parental attitudes.}

Significant differences emerged for over half of the items shared between the adult and child versions of the POSHA-S. The differences primarily dealt with traits of stutterers and how to react toward stuttered speech, with children holding predominately worse or less informed attitudes than their parents. Children were more inclined than their parents to rate stutterers as being "shy," "nervous," and "at fault" for their stuttering. In addition, they were more likely to react in unhelpful or undesired ways (e.g., saying "slow down"). The measured group differences support the proposition that young children's perceptions of persons they consider "different" are driven by affective process, not by cognitive processes as with older children and adults (Aboud, 1988). Accordingly, young children's attitudes often diverge from those held by their family or culture, especially compared to older children's attitudes. Such was the case in the study by Özdemir and colleagues (2011b) that showed Turkish school-aged children hold comparable attitudes to their adult family and community members. This pattern was further observed in American kindergarten children whose attitudes aligned more closely with that of the general public compared to younger, preschool-aged children (Weidner, St. Louis, Burgess, et al., 2015) (even though the kindergarteners' attitudes were as positive of those of adults). As such, it appears that preschool-aged children's perceptions about stutterers' traits are relatively uninfluenced by their parents' perceptions, but may 
become increasingly more sensitive to familial and/or societal influences as they grow older.

Although preschool children's stuttering attitudes did not reflect their parents' nuanced knowledge about stuttering and stutterers, there was an apparent relationship between the groups' adherence to core principles underlying positive social interactions. For example, both groups would refrain from laughing at a stutterer, would not be bothered by stuttering, and would feel patient when talking to a stutterer. As well, both parents and children reported positive impressions of stutterers' ability to make friends, have any job, and make good choices. As such, it seems that preschoolers hold similar foundational social knowledge to that of their parents, but not necessarily stutteringspecific knowledge

\section{Demographic factors.}

Even though this study was carried out using convenience sampling, participants represented diverse income and educational levels. Families' relative income scores ranged from -83 to $100(M=14)$, and parent education levels ranged from 8 to $21 \mathrm{yrs}(M$ $=18 \mathrm{yrs}$ ). Regression analyses revealed that income did not predict children stuttering attitudes, thus upholding previous reports (Özdemir et al., 2011b; Weidner, St. Louis, Burgess, et al., 2015). However, there was a significant, positive correlation between parents' education level and children's POSHA-S/Child Self Reaction subscore. This is somewhat perplexing, especially because parent education was not correlated to their own $P O S H A-S$ scores. Given that this is the first reported study to investigate the predictive effect of parent education on children's stuttering attitudes, it is necessary to gather more evidence before any speculations about these relationships can be advanced. 


\section{Exposure to or experience with stuttering.}

Children's personal experience with stuttering or prior contact with stutterers appeared to have an important impact on their stuttering attitudes. Three groups were examined: children who stuttered $(n=3)$, children with prior contact with a stutterer $(n=$ 4), and children who had no stuttering exposure prior to watching the POSHA-S/Child stimulus video $(n=48)$. Recognizing that the very small number of children in the stuttering exposure and experience samples severely limits the robustness of conclusions, the following preliminary findings emerged. The children who stuttered held significantly better self reactions than nonstuttering children. It can be hypothesized that children's first hand experience with stuttering shaped their perceptions of helpful and unhelpful listener supports. Recent research has shown that school-aged children who stutter and adults who stutter hold similar opinions about what constitutes desired support by nonstutterers (Rodriguez et al., 2015; Weidner, Coleman, et al., 2015). It is worth noting that ratings of the few stutterers in this study align with those of slightly older children and adults. Interestingly, however, the children in the stuttering group were less informed about stuttering causes compared to the nonstuttering group. It is uncertain why this occurred, but it may reflect misinformation or messages that the stutterers received about their speech. Furthermore, although it cannot be confirmed in this study, parents of stuttering children have been documented to have little knowledge about the causes of stuttering, which may contribute to stuttering children's misunderstanding about the disorder (Al-Khaledi et al., 2009).

Nonstuttering children with prior contact with stutterers held slightly better stuttering attitudes than nonstuttering children with no prior contact. As observed among 
children who actually stuttered, children in the contact group had better self reactions toward stutterers than the no-contact group. Langevin (2009) reached similar conclusions, positing that school-aged children's prior contact with a stutterer was a strong determinant of their attitudes toward stuttering peers. Other research with adolescents and adults has also shown that exposure to stuttering tends to enhance one's attitudes and reactions toward it (Flynn \& St. Louis, 2011; Klassen, 2002; St. Louis \& George, 2008; St. Louis, Kuhn, \& Lytwak, 2015; St. Louis \& Rogers, 2011a). At the same time, results from this study showed that the contact group had lower ratings about stuttering causes than the no-contact group. Such was also the case in the stuttering versus nonstuttering groups.

Taken together, these preliminary results suggest that children who have dealt with stuttered speech — either personally or as a listener-are likely to be more informed about how to react to it. For example, they reported less likelihood to finish words of a stuttering speaker or say, "slow down." Additionally, it appears that children with any degree of stuttering experience are quick to develop explanations for the aberrant speech patterns they observe, which are often incorrect. Their understanding of the disorder might be based on external messages they receive (e.g., a parent who inaccurately explains the disorder), or other internal factors yet to be realized. Thus, the need to teach children accurate information about the causes of stuttering is further justified.

\section{Personal factors.}

Social cognition. This is the first known study to examine the relationship between children's stuttering attitudes and their social cognitive skills (e.g., perspective taking and making inferences). The hypothesis predicting a positive, significant 
relationship between children's social cognitive skills and their stuttering attitudes was not upheld. In fact, there was a significant negative association between children's social cognitive skills and their Beliefs subscore, and a small, non-significant, positive relationship to their Self Reaction subscore.

Developmental factors are likely to account for the negative relationship between children's social cognition and their beliefs about stuttering. During the preschool years, children's social cognitive skills rapidly develop. They become increasingly more perceptive and recognize that others have different experiences, perceptions, knowledge, emotions, and attributes than their own (Wellman et al., 2001). It would seem that growth in skills in those domains would make children more aware of and sensitive toward others' differences. Results from this study, however, countered that expectation. Children with higher social cognitive skills had lower beliefs ratings, particularly pertaining to stuttering causes and potential of stutterers. Therefore, it cannot be assumed that children's adeptness in social cognition necessarily improves their stuttering attitudes.

It was also somewhat surprising that children's social cognitive skills did not significantly predict their self reactions toward stutterers. Children with advanced social cognitive skills are reportedly more sensitive toward others' experiences and perspectives during social interactions (Slaughter et al., 2015). As such, it would be expected that children with advanced skills in this area would have better reactions toward stuttering peers. It is speculated that children's generally limited experience with the disorder, coupled with their lack of knowledge how to interact appropriately with stutterers, supersedes the influence of social cognitive skills. 
Health and abilities. Children's parent-reported mental health, physical health, ability to learn, and speaking ability were each examined relative to their $P O S H A-$ S/Child summary scores. Most correlations were negative and small, and none reached significance. This is consistent with the adult research, which has failed to elucidate predictive power for respondents' health and abilities (St. Louis, 2015). It should be noted that children's health and abilities ratings were positively skewed, which restricted the variability of scores within each domain. Parents in the USA have been previously observed to report high ratings on their children's health and abilities, reasons for which are not known (e.g., Weidner, St. Louis, Burgess, et al., 2015; Weidner, St. Louis, Nak1sc1 et al., 2015). Future studies that wish to examine the influence of children's health and abilities may consider examining each domain via an alternate, objective measurement and not simply parental report.

Age. Although this study did not reveal a significant effect of children's age on their overall stuttering attitude, the correlation between the variables was positive. That no significant differences emerged for this predictor was somewhat expected, given the restricted age of variability of ages represented. However, the positive correlation between age and attitudes uphold the notion that stuttering attitudes change in a positive direction with age (Weidner, St. Louis, Burgess, et al., 2015). This pattern has also been observed in children's attitudes toward physically disabled peers (Hong et al., 2014). It will be important for future studies in stuttering attitude research to include slightly older children, so that the effect of age can be more clearly understood. 


\section{Effectiveness of the Inter $A C T$ program}

\section{Stuttering attitude change.}

Results contribute new evidence that preschoolers' stuttering attitudes are amenable to improvement following the newly developed InterACT program. As hypothesized, children demonstrated significant improvement relative to their beliefs about stuttering and stutterers, as well as their self reactions toward people who stutter. The degree of attitude change observed in this study was comparable to that which occurred in the earlier pilot study. Because six children in the control group experienced no mean change in their overall stuttering attitudes, it is reasonable to conclude that the program — not extraneous, confounding variables—was responsible for attitude change.

Were these improvements simply the result of "teaching to the test?" Fifteen POSHA-S/Child items were either directly or indirectly addressed in the content of the Inter $A C T$ video lessons. Of those, six (40\%) significantly improved, six (40\%) improved, two (13\%) decreased, and one (7\%) significantly decreased. Of the 23 POSHA-S/Child items not addressed in the videos, 14 (61\%) improved. Thus, while it may be partially true that the overall improvement in attitudes was related to "teaching to the test," it is also clear that if entirely true, improvement in all of those 15 items would be expected, and improvement in other items might not be observed at all. It appears, therefore, that the positive impact of the program transcended that which was directly or indirectly addressed in the content of the program stimuli.

Beliefs about stuttering. Prior to participating in the InterACT program, none of the children could define the term "stuttering," suggesting they had no accurate conceptualization of the disorder. However, by the end of program, almost all of the children in the experimental group (i.e., 32 out of 37) generated appropriate definitions. 
They variously described types of stuttering, distinguished stuttering from fluent talking, and demonstrated stuttered speech. Comparatively, most children in the control group were able to define the term immediately following the $P O S H A-S / C h i l d$ stimulus video, but they generally did not retain it between the initial and follow-up survey administrations. It appears, therefore, that the $P O S H A-S / C h i l d$ stimulus video and a scripted definition of stuttering did not have as strong an impact as the InterACT program did on children's acquisition and retention of a meaningful definition. Typically, nonstutterers' acquisition of the word "stuttering" begins to emerge around 9 years of age (Culatta \& Sloan, 1977), but the use of the term does not predicate awareness of stuttered speech (Ezrati-Vinacour et al., 2001). This study contributes new findings to those reports, showing that most preschool children are able to acquire and retain the term, given consistent concrete models and descriptions of the disorder.

Following the program, children appeared to have somewhat better knowledge overall about the causes of stuttering. Only one item, "stuttering comes from germs," significantly improved. This is not surprising given that the "germs" item was directly addressed in the video, but other causes (e.g., stuttering comes from God, learning, something bad that happened) were not. Nevertheless, the qualitative and quantitative findings support the utility of the InterACT program on improving children's general knowledge about the disorder. These results are particularly important, as it has been suggested that children's basic knowledge about a disorder promotes more effective socialization with peers who are different (Hong et al., 2014).

Beliefs about people who stutter. Children experienced their largest positive changes relative to their perceptions of the traits of stutterers. Following the program, 
they were significantly less inclined to describe children who stutter as "shy" and at fault for their stuttering. Although not to a significant degree, they were also less likely to indicate that children who stutter are nervous or have a bad problem. Respondents' belief that stutterers are "[un]able to talk well" improved, but their ratings remained low following the program. It seems, therefore, that the program helped children to distinguish between the personality characteristics of a stuttering speaker from that of speech characteristics. This is an important finding, given that adults have often failed to make such a distinction (Woods \& Williams, 1976). Children's improved attitudes toward the traits of stutterers are likely tied to the content of the videos. For example, the stuttering character is asked, "Does stuttering mean you're nervous or shy?" to which he responds, "No, stuttering doesn't mean I am nervous or shy."

It should be noted that children's beliefs about people who stutter did not uniformly increase. Specifically, their perceptions of stutterers' life potential worsened following the program, and their belief that children who stutter can "make friends" significantly decreased. This is particularly puzzling, given that the InterACT puppetry videos stress that children who stutter (or who are different) are able to make friends. Future iterations of the program may consider placing even greater emphasis on positive socialization between dissimilar peers.

Self reactions toward people who stutter. As predicted, children also demonstrated significant gains on items dealing with how to interact with peers who stutter. They showed increased knowledge about what are helpful and unhelpful listener supports. The InterACT videos stressed these supports in two separate scenes. The narrator summarized positive supports, stating, "Hannah was patient with Ben. Hannah 
waited for Ben to talk and was not bothered by his stuttering. She did not tell him to slow down or finish his words." In addition to learning how to interact with stutterers, children became significantly less worried if persons close to them stuttered, such as a sibling, friend, or parent. The videos did not directly address those items, indicating that children experienced attitude change beyond what was explicitly presented.

As with many attitude change studies (e.g., Abdalla \& St. Louis, 2014; Flynn \& St. Louis, 2011; Kuhn \& St. Louis, 2015), this study presented hypothetical scenarios and did not directly measure children's actual behavior toward a stuttering peer. Even so, children were less likely to demonstrate overt negative or undesired reactions to the POSHA-S/Child stimulus video. None of the children had an obvious adverse reaction to the video following the program, compared to the first showing of the video in which $13 \%$ of children had such a reaction. Further, children's reported experience with stuttering (i.e., persons known or personal experience) more closely aligned with parental reports following the Inter ACT program. This suggests that children's ability to accurately judge stuttered speech in both themselves and others improved.

Obesity/Wheelchair Scores. Both before and after the program, children held the highest preference for stuttering, followed by wheelchair-use, and then by obesity. Their preference for stuttering was unchanged, whereas their preference for wheelchair-use increased, and decreased for obesity. Importantly, because the task requires children to differentially select one trait from a pair, increased ratings for one trait (i.e., wheelchair) leads to decreased ratings of another (i.e., obesity). It should be noted that the program starred a stuttering character, featured a child in a wheelchair, and did not show or mention an obese child at all. Both the stuttering and wheelchair-bound children were 
depicted in a favorable light. As such, it is not surprising that children's strong preference for stuttering persisted following the program and their preferences for wheelchair-use improved.

\section{Implications}

This study squarely addressed prior calls to educate young, typically fluent children about stuttering (Hartford \& Leahy, 2007; Murphy \& Quesal, 2002; Murphy, et al., 2007). Unlike preceding attitude change studies with older individuals, this is among the first to address negative stuttering attitudes among preschool aged children. The results generated important, practical implications for both children who do and do not stutter.

It was clear that the nonstuttering preschoolers held negative or uninformed attitudes about stuttering, even when their first exposure to the disorder was a short video portraying stuttering characters. Importantly, however, their attitudes became increasingly more sensitive and informed following the InterACT program. Children were motivated to learn about stuttering and other conditions, and expressed a strong desire to help stuttering children. If we wish to capitalize on those factors, educational programming to improve stuttering attitudes might be maximized during the preschool years. It is hoped that such efforts will help nonstuttering children to become more tolerant and accepting of stutterers, and perhaps even extend those improved attitudes toward persons with other disorders.

It is inevitable that children who stutter must deal with their peers' stuttering attitudes, whether or not those attitudes are desired. This study confirms that if peers' negative stuttering attitudes go unchanged, children who stutter might be at higher risk 
for social punishment (Ezrati-Vinacour et al., 2001; Langevin et al., 2009; Griffin and Leahy, 2007). The study confirms that, as early as preschool, stuttering children are likely to be classified as being nervous, shy, and as having inferior speaking abilities. They are likely to endure these pejorative stereotypes long-term, and might become victims of social distancing, and/or teasing and bullying as a result (Blood \& Blood, 2004; Langevin, 2015; Langevin, et al., 1998; Mooney \& Smith, 1995; Yaruss, et al., 2004). However, if peers' negative stuttering attitudes are mitigated during their formative preschool years, social punishment directed toward stuttering children might be prevented altogether. A supportive communication environment could facilitate improvement in the quality and quantity of stutterers' social interactions. This could have a profound impact not only on their communication skills, but also on their social and emotional well-being.

\section{Limitations and future directions}

Because this study is the first of its kind, many of the points advanced in this discussion are inevitably speculative. Several caveats pertaining to the methodology and instrumentation used in the study warrant discussion so that future research in children's stuttering attitude research may progress efficiently and effectively.

Foregoing research, in conjunction with the current study, provides preliminary evidence of the POSHA-S/Child's concurrent and construct validity, translatability, and test-retest reliability (St. Louis, Weidner, et al., 2016; Weidner, St. Louis, Burgess, et al., 2015; Weidner, St. Louis, Nakısc1 et al., 2015). Although those findings uphold the credibility of POSHA-S/Child scores obtained in the current study, the psychometric properties of the instrument have not yet been fully established. Statistical guidelines for instrument validation recommend 10 to 20 participants for each survey rating (Grimm \& 
Yarnold, 2000). This would require the acquisition of 560 to 1,120 participants before validation of the $P O S H A-S / C h i l d$ can be fully realized. In order to achieve that aim, it will be necessary to establish a network of research collaborators who are well trained in using the POSHA-S/Child. Any data they obtain can then be compiled into a master database and psychometrically analyzed (e.g., factor analysis, test-retest reliability, and internal consistency). In addition to the POSHA-S/Child, future studies might also utilize other well-established, objective indices of stuttering attitudes such as the Peer Attitudes Toward Children who Stutter scale (Langevin, 2009), KiddyCAT (Vanryckeghem \& Brutten, 2007) or other physiological measures, such as skin conductance (Guntupalli et al., 2007). Doing so would not only corroborate POSHA-S/Child results, but also help to establish the concurrent validity of the measure.

The children included in this study were obtained using convenience sampling within one small north-central West Virginia city, thus precluding any widespread generalizations of the findings. It will be important that future studies involve children from different geographic regions, cultures, languages, and socio-economic statuses. Doing so would not only advance our epidemiological understanding about the etiology of stuttering attitudes, but also facilitate broader generalizations of young children's attitudes. Research with adults has reported that nonprobability convenience sampling is an adequate means by which to collect data initially (St. Louis, 2015), but probability sampling schemes, such as those described by Özdemir et al. (2011a) and Valente et al. (2014), will be an important longer-term goal.

This is the first study to investigate the impact of the InterACT program on children's stuttering attitudes. As such, there is not yet sufficient data to make conclusive 
judgments about its widespread utility. It is only through the continued implementation of the program that such conclusions can be confidently reached. Also, the design used in this study prohibits any determinations about the maintenance of children's attitude change. Future studies should examine stuttering attitudes of children who did and did not participate in the program at various intervals (e.g., 1 month, 3 months, 12 months). Those results would provide critical information about the long-term efficacy of the program. As well, comparisons between the experimental and control groups would help to isolate the effect of the program from other extraneous variables (e.g., age and development).

The procedures employed in the various preschool sites, although comparable, were necessarily adapted to adhere to each classroom's unique constraints, preferences, and schedules. For example, the Inter $A C T$ program was carried out in small groups for three classroom sites, and with the full classroom in the other three sites. Although results revealed no confounding influence of one's classroom, children appeared to be most attentive and compliant when the program was carried out in a full-classroom setting. Future installments of the InterACT program might consider either obtaining parental consent for all children in one classroom, or gaining an administrator's permission to conduct the program in a small group outside of the main classroom.

The ultimate goal of this line of research is to determine whether or not the Inter $A C T$ program has an impact on the lives of children who stutter. Based on the current results, it is uncertain whether or not improvements in children's reactions to stuttering characters would translate to real-life interactions with actual persons who stutter. Two suggestions to address this issue are advanced. First, it is recommended that 
an additional qualitative component be included that prompts children to explain their responses to survey items. For example, following the survey, the administrator might state, "I notice that you said you would be worried if you stuttered. Tell me a little more about that." Open-ended prompts such as those would help to elucidate children's cognitive processes involved in attitude change, and explain how and why those changes occurred. Second, future research to investigate children's application of the knowledge and skills gained from the InterACT program will likely unfold in a series of carefully planned longitudinal case studies. As conducted by Langevin and colleagues (2009), naturalistic interactions between stuttering children and typically fluent peers should be observed before and after the InterACT program. Qualitative observations would serve to corroborate quantitative $P O S H A-S / C h i l d$ findings. In addition, it would bolster the Inter $A C T$ program as having evidenced-based applicability to children's actual social interactions with stuttering peers. Until then, however, much of the groundwork for this line of research needs to be laid.

\section{Conclusion}

This study is among the first to examine the feasibility of improving nonstuttering children's stuttering attitudes, so that their beliefs about stuttering and social acceptance of stuttering peers might be strengthened. In addition, it contributes important new findings relative to the epidemiology of stuttering attitudes and factors that are suspected to influence young children's stuttering attitudes. Based on the findings of this study, it is clear that children's negative or uninformed attitudes about stuttering and people who stutter are amenable to improvement. Children had a significant positive response to the Inter $A C T$ program, as evidenced by their increased knowledge about stuttering and how 
to interact with stuttering peers. Results of this study strongly support the continued expansion of this line of research, and suggest that efforts to improve stuttering attitudes might be particularly effective during the preschool years. 


\section{References}

Abdalla, F. A., \& St. Louis, K. O. (2012). Arab school teachers' knowledge, beliefs and reactions regarding stuttering. Journal of Fluency Disorders, 37, 54-69.

Abdalla, F. A., \& St. Louis, K. O. (2014). Modifying attitudes of Arab school teachers toward stuttering. Language, Speech, and Hearing Services in the Schools, 45, 1425 .

Aboud, F. E. (1988). Children and prejudice. London: Blackwell Publishers.

Al-Khaledi, M., Lincoln, M., McCabe, P., Packman, A., \& Alshatti, T. (2009). The attitudes knowledge and beliefs of Arab parents in Kuwait about stuttering. Journal of Fluency Disorders, 34, 44-59.

Ambrose, N. G., \& Yairi, E. (1994). The development of awareness of stuttering in preschool-children. Journal of Fluency Disorders, 19, 229-245.

Arnold, H. S., \& Li, J. (2016). Associations between beliefs about and reactions toward people who stutter. Journal of Fluency Disorders, 47, 27-37.

Arnold, H. S., Li, J., \& Goltl, K. (2015). Beliefs of teachers versus non-teachers about people who stutter. Journal of Fluency Disorders, 43, 28-39.

Bebout, L., \& Arthur, B. (1992). Cross-cultural attitudes toward speech disorders. Journal of Speech and Hearing Research, 35, 45-52.

Bell, S. K., \& Morgan, S. B. (2000). Children's attitudes and behavioural intentions toward a peer presented as obese. Journal of Pediatric Psychology, 25, 137-145.

Betz, I. R., Blood, G. W., \& Blood, I. M. (2008). University students’ perceptions of preschool and kindergarten children who stutter. Journal of Communication Disorders, 41, 259-273. 
Bigler, R. S., \& Liben, L. (2006). A developmental inter-group theory of social stereotypes and prejudice. In R. Kail (Ed.), Advances in child psychology (pp. 3990). New York: Elsevier.

Blood, G. W., \& Blood, I. M. (2004). Bullying in adolescents who stutter: Communicative competence and self-esteem. Contemporary Issues in Communication Science and Disorders, 31, 69-79.

Boyle, M. P., \& Blood, G. W. (2015). Stigma and stuttering: Conceptualizations, applications, and coping. In K. O. St. Louis (Ed.), Stuttering meets stereotype, stigma, and discrimination: An overview of attitude research (pp. 43-71). Morgantown, WV: West Virginia University Press.

Boyle, M. P., Blood, G. W., \& Blood, I. M. (2009). Effects of perceived causality on perceptions of persons who stutter. Journal of Fluency Disorders, 34, 201-218.

Cameron, L., Rutland, A., Brown, R., \& Douch, R. (2006). Changing Children's Intergroup Attitudes toward Refugees: Testing Different Models of Extended Contact. Child Development, 77, 1208-1219.

Cooper, E. B. (1975). Clinician attitudes toward stutterers: a study of bigotry? Paper presented at the annual convention of the American Speech and Hearing Association, Washington, DC.

Cooper, D. G. (2003). Promoting disability research in preschool (Unpublished doctoral dissertation). Purdue University. West Lafayette, IN.

Cooper, E. B., \& Cooper, C. S. (1996). Clinician attitudes towards stuttering: Two decades of change. Journal of Fluency Disorders, 21, 119-135. 
Craig, A., Blumgart, E., \& Tran, Y. (2009). The impact of stuttering on the quality of life in adults who stutter. Journal of Fluency Disorders, 34, 61-71.

Crowe, T. A., \& Walton, J. H. (1981). Teacher attitudes toward stuttering. Journal of Fluency Disorders, 6, 163-174.

Culatta, R. \& Sloan, A. (1977). The acquisition of the label "stuttering" by primary level school children. Journal of Fluency Disorders, 2, 29-34.

Cvencek, D., Greenwald, A. G., \& Meltzoff, A. N. (2011). Measuring implicit attitudes of 4-year-olds: The Preschool Implicit Association Test. Journal of Experimental Child Psychology, 109, 187-200.

Davis, S., Howell, P., \& Cooke, F. (2002). Sociodynamic relationships between children who stutter and their non-stuttering classmates. Journal of Child Psychology and Psychiatry and Allied Disciplines, 43, 939-947.

Delaney, C. M. (2001). Modification of the negative stutterer stereotype. In H.-G. Bosshardt, J. S. Yaruss, \& H. F. M Peters (Eds.), Theory, research, treatment and self-help: Proceedings of the Third World Congress of Fluency Disorders (pp. 614618), Nijmegen, The Netherlands: Nijmegen University Press.

Derman-Sparks, L. (1989). Anti-bias curriculum tools for empowering young children. New York, New York: National Association for the Education of Young Children.

Diamond, K. E., \& Hestenes, L. L. (1996). Preschool children's conceptions of disabilities: The salience of disability in children's ideas about others. Topics in Early Childhood Special Education, 16, 458-475.

Dorsey, M., \& Guenther, R. K. (2000). Attitudes of professors and students toward college students who stutter. Journal of Fluency Disorders, 25, 77-83. 
Drayna, D. (2014). A study of the role of the FOXP2 and CNTNAP2 genes in persistent developmental stuttering. Neurobiology of Disease, 69, 23-31.

Ergazaki, M., Saltapida, K., \& Zogza, V. (2010). From young children's ideas about germs to ideas shaping a learning environment. Research in Science Education, 40, $699-715$.

Evans, D., Healey, E. C., Kawai, N., \& Rowland, S. (2008). Middle school students' perceptions of a peer who stutters. Journal of Fluency Disorders, 33, 203-219.

Ezrati-Vinacour, R., Platzky, R., \& Yairi, E. (2001). The young child's awareness of stuttering-like disfluency. Journal of Speech, Language, and Hearing Research, 44, $368-380$.

Flavell, J. H. (1999). Cognitive development: Children's knowledge about the mind. Annual Review of Psychology, 50, 21-45.

Flynn, T. W., \& St. Louis, K. O. (2011). Changing adolescent attitudes toward stuttering. Journal of Fluency Disorders, 36, 110-121.

Franck, A. L., Jackson, R. A., Pimentel, J. T., \& Greenwood, G. S. (2003). School-age children's perceptions of a person who stutters. Journal of Fluency Disorders, 28, 115.

Gabel, R. M. (2015). Job discrimination associated with stuttering in adults. In K. O. St. Louis (Ed.), Stuttering meets stereotype, stigma, and discrimination: An overview of attitude research (pp. 91-105). Morgantown, WV: West Virginia University Press.

Gabel, R. M., Blood, G. W., Tellis, G., \& Althouse, M. T. (2004). Measuring role entrapment of people who stutter. Journal of Fluency Disorders, 29, 27-49. 
Gabel, R. M., Hughes, S., \& Daniels, D. E. (2008). Effects of stuttering severity and therapy involvement on role entrapment of people who stutter. Journal of Communication Disorders, 41, 146-158.

Gelman, S. A., Collman, P., \& Maccoby, E. E. (1986). Inferring properties from categories versus inferring categories from properties: The case of gender. Child Development, 57, 396-404.

Gertner, B. L., \& Rice, M. L. (1994). Influence of communicative competence on peer preferences in a preschool classroom. Journal of Speech and Hearing Research, 37, 913-923.

Griffin, M., \& Leahy, M. M. (2007). Young children's (3-5 year old) perceptions of a dysfluent speaker. In J. Au-Yeung \& M. M. Leahy (Eds.), Proceedings of Fluency Disorders (pp. 217-222). Dublin, Ireland: The International Fluency Association.

Grimm, L. G. \& Yarnold, P. R. (2000). Reading and understanding multivariate statistics. Washington, DC: American Psychological Association.

Guntupalli, V. K., Everhart, D., Kalinowski, J., Nanjundeswaran, C., \& Saltuklaroglu, T. (2007). Emotional and physiological responses of fluent listeners while watching the speech of adults who stutter. International Journal of Language \& Communication Disorders, 42, 113-129.

Guralnick, M. J., Connor, R. T., Hammond, M. A., Gottman, J. M., \& Kinnish, K. (1996). The peer relations of preschool children with communication disorders. Child Development, 67, 471-489. 
Hartford, E., \& Leahy, M. M. (2007). The perceptions of primary school children of a person who stutters. In J. Au-Yeung \& M. M. Leahy (Eds.), Proceedings of Fluency Disorders (pp. 217-222). Dublin, Ireland: The International Fluency Association.

Hollingsworth, S., \& Hollingsworth, J. (2015). Everyone is different. InterACT program. Punxsutawney, PA: Hollingsworth Recording.

Hong, S., Kwon, K., \& Jeon, H. (2014). Children's attitudes towards peers with disabilities: Associations with personal and parental factors. Infant and Child Development, 23, 170-193.

Hughes, S. (2008). Exploring attitudes toward people who stutter: A mixed model approach (Doctoral dissertation). Retrieved from https://etd.ohiolink.edu/rws etd/document/get/bgsu1213188444/inline.

Hughes, S., Gabel, R., Roseman, C., \& Daniels, D. (2015). An interdisciplinary training program in stuttering: Raising awareness and changing attitudes. In K. O. St. Louis (Ed.), Stuttering meets stereotype, stigma, and discrimination: An overview of attitude research (pp. 243-252). Morgantown, WV: West Virginia University Press.

Hurst, M. I., \& Cooper, E. B. (1983a). Employer attitudes toward stuttering. Journal of Fluency Disorders, 8, 1-12.

Hurst, M. I., \& Cooper, E. B. (1983b). Vocational rehabilitation counselors' attitudes toward stuttering. Journal of Fluency Disorders, 8, 13-27.

Hutchins, T., Prelock, P. A., \& Chace, W. (2008). Test-retest reliability of Theory of Mind tasks representing a range of content and complexity and adapted to facilitate the performance of children with ASD. FADD, 23, 195-206. 
Hutchins, T., Prelock, P. A., \& Bonazinga Bouyea. (2014). Technical Manual for the Theory of Mind Inventory and Theory of Mind Task Battery. Retrieved from www.theoryofmindinventory.com.

Junuzović-Žunić, L., Weidner, M. E., Reichel, I., Cook, S., St. Louis, K. O., Ware, M. B. (2015). Effects of fluency disorders coursework on students' stuttering attitudes in two countries. In K. O. St. Louis (Ed.), Stuttering meets stereotype, stigma, and discrimination: An overview of attitude research (pp. 226-242). Morgantown, WV: West Virginia University Press.

Hughes, S. (2015). Attitudes toward stuttering: An annotated bibliography. In K. O. St. Louis (Ed.), Stuttering meets stereotype, stigma, and discrimination: An overview of attitude research (pp. 310-350). Morgantown, WV: West Virginia University Press.

Ip, M. L., St. Louis, K. O. Myers, F. L., \& An Xue, S. (2012). Stuttering attitudes in Hong Kong and Mainland China. International Journal of Speech-Language Pathology, 14, 543-556.

Irani, F., Gabel, R., Hughes, S., Swartz, E., \& Palasik, S. (2009). Role entrapment of people who stutter reported by K-12 teachers. Contemporary Issues in Communication Sciences and Disorders, 36, 48-56.

Killen, M., \& Rutland, A. (2011). Children and social exclusion: Morality, prejudice, and group identity. New York: Wiley-Blackwell Publishers.

Klassen, T. R. (2002). Social distance and the negative stereotype of people who stutter. Journal of Speech-Language Pathology and Audiology, 26, 90-99. 
Klompas, M., \& Ross, E. (2004). Life experiences of people who stutter, and the perceived impact of stuttering on quality of life: Personal accounts of South African individuals. Journal of Fluency Disorders, 29, 275-305.

Kornilaki, E. N. (2014). Obesity bias in preschool children: Do the obese adopt anti-fat views?. Hellenic Journal of Psychology, 11, 26-46.

Kuhn, C. D. \& St. Louis, K. O. (2015, November). Attitudes toward stuttering of middle school students before \& after a stuttering video. Poster presented at the Annual Convention of the American Speech-Language-Hearing Association. Denver, CO.

Ladd, K. L., McIntosh, D. N., \& Spilka, B. (1998). Children's God concepts: Influences of denomination, age, and gender. International Journal for the Psychology of Religion, 8, 49-56.

Langevin, M. (2000). Teasing and Bullying: Unacceptable Behaviour program.

Edmonton, Alberta: Institute for Stuttering Treatment and Research.

Langevin, M. (2009). The Peer Attitudes Toward Children who Stutter Scale: Reliability, known groups validity, and negativity of elementary school-age children's attitudes. Journal of Fluency Disorders, 34, 72-86.

Langevin, M. (2015). Changing attitudes toward stuttering: What children liked about a stuttering education resource. In K. O. St. Louis (Ed.), Stuttering meets stereotype, stigma, and discrimination: An overview of attitude research (pp. 304-309), Morgantown, WV: West Virginia University Press.

Langevin, M., Bortnick, K., Hammer, T., \& Wiebe, E. (1998). Teasing/bullying experienced by children who stutter: Toward development of a questionnaire. Contemporary Issues in Communication Science and Disorders, 25, 12-24. 
Langevin, M., Packman, A., \& Onslow, M. (2009). Peer responses to stuttering in the preschool setting. American Journal of Speech-Language Pathology, 18, 264-276.

Langevin, M., \& Prasad, N. G. N. (2012). A stuttering education and bullying awareness and prevention resource: a feasibility study. Language, Speech, and Hearing Services in the Schools, 43, 344-358.

Lass, N. J., Ruscello, D. M., Pannbacker, M. D., Schmitt, J. F., \& Everly-Myers, D. S. (1989). Speech-language pathologists' perceptions of child and adult female and male stutterers. Journal of Fluency Disorders, 14, 127-134.

Levy, S. R., \& Killen, M. (2008). Intergroup attitudes and relations in childhood through adulthood: An introduction. In S. R. Levy \& M. Killen (Eds.), Intergroup attitudes and relations in childhood through adulthood (pp. 3-15). New York: Oxford University Press.

Li, J., \& Arnold, H. S. (2015). Reactions of teachers versus non-teachers toward people who stutter. Journal of Communication Disorders, 56, 8-18.

MacMillan, M., Tarrant, M., Abraham, C., \& Morris, C. (2014). The association between children's contact with people with disabilities and their attitudes towards disability: A systematic review. Developmental Medicine \& Child Neurology, 56, 529-546.

Manning, W. (2010). Clinical decision making in the diagnosis and treatment of fluency disorders. ( $3^{\text {rd }}$ ed.). Clifton Park, NY: Delmar.

McGee, L., Kalinowski, J. \& Stuart, A., 1996. Effect of a videotape documentary on high school students' perceptions of a high school male who stutterers. Journal of SpeechLanguage Pathology and Audiology, 20, 240-246. 
Mooney, S. \& Smith, P. K. (1995). Bullying and the child who stammers. British Journal of Special Education, 22, 24-27.

Mulvey, K. L., Hitti, A., \& Killen, M. (2010). The development of stereotyping and exclusion. Wiley Interdisciplinary Reviews: Cognitive Science, 1, 597-606.

Murphy, W. P., \& Quesal, R. W. (2002). Strategies for addressing bullying with the school-age child who stutters. Seminars in Speech and Language, 23, 205-212.

Murphy, W. P., Yaruss, J. S., \& Quesal, R. W. (2007). Enhancing treatment for schoolage children who stutter: II. Reducing bullying through role-playing and selfdisclosure. Journal of Fluency Disorders, 32, 139-162.

Özdemir, R. S., St. Louis, K. O., \& Topbaş, S. (2011a). Public attitudes toward stuttering in Turkey: Probability versus convenience sampling. Journal of Fluency Disorders, $36,262-267$.

Özdemir, R. S., St. Louis, K. O., \& Topbaş, S. (2011b). Stuttering attitudes among Turkish family generations and neighbors from representative samples. Journal of Fluency Disorders, 36, 318-333.

Panico, J., Healey, E. C., \& Knopik, J. (2015). Elementary school students’ perceptions of stuttering: A mixed model approach. Journal of Fluency Disorders, 45, 1-11.

Reitzes, P. (Ed). (2012). Stuttering: Inspiring Stories and Professional Wisdom. Stutter Talk Publication: New York.

Rodriguez, M., Irani, F., St. Louis, K. O., Scaler Scott, K., Gabel, R., Weidner, M. E., Hughes, S., \& Langevin, M. (2015, November). DOs \& DON’Ts revisited: A comprehensive report from stuttering adults. Poster presented at the American Speech-Language-Hearing Association, Denver, CO. 
Ruscello, D. M., Lass, N. J., Schmitt, J. F., \& Pannbacker, M. D. (1994). Special educators' perceptions of stutterers. Journal of Fluency Disorders, 19, 125-132.

Slaughter, V., Imuta, K., Peterson, C. C., \& Henry, J. D. (2015). Meta-Analysis of Theory of Mind and Peer Popularity in the Preschool and Early School Years. Child Development, 86, 1159-1174.

St. Louis, K. O. (1999). Person-first labeling and stuttering. Journal of Fluency Disorders, 24, 1-24.

St. Louis, K. O. (2011). The Public Opinion Survey of Human Attributes-Stuttering (POSHA-S): Summary framework and empirical comparisons. Journal of Fluency Disorders, 36, 256-261.

St. Louis, K. O. (2012a). Male versus female attitudes toward stuttering. Journal of Communication Disorders, 45, 246-253.

St. Louis, K. O. (2012b). POSHA-S public attitudes toward stuttering: Online versus paper surveys. Canadian Journal of Speech-Language Pathology and Audiology, $36,116-122$.

St. Louis, K. O. (2012c). Research and development for a public attitude instrument for stuttering. Journal of Communication Disorders, 45, 129-146.

St. Louis, K. O. (2015). Epidemiology of public attitudes toward stuttering. In K. O. St. Louis (Ed.), Stuttering meets stereotype, stigma, and discrimination: An overview of attitude research (pp. 7-42). Morgantown, WV: West Virginia University Press.

St. Louis, K. O. (2016, February). Measuring public attitudes toward stuttering: From a simple idea to a successful 17-year research program. Presented at the West Virginia University College of Education \& Human Services, Morgantown, WV. 
St. Louis, K. O., \& George, R. D. (2008, November). Attitudes toward stuttering: In search of a gold standard. Poster presented at the Annual Convention of the SpeechLanguage-Hearing Association, Chicago, IL.

St. Louis, K. O., \& Lass, N. J. (1981). A survey of communicative disorders students' attitudes toward stuttering. Journal of Fluency Disorders, 6, 49-79.

St. Louis, K. O., LeMasters, S. N., \& Poormohammad, A. (2015). Public attitudes toward males versus females who stutter: United States and Iran. In K. O. St. Louis (Ed.), Stuttering meets stereotype, stigma, and discrimination: An overview of attitude research (pp. 165-177). Morgantown, WV: West Virginia University Press.

St. Louis, K. O., Lubker, B. B., Yaruss, J. S., \& Aliveto, E. F. (2009). Development of a prototype questionnaire to survey public attitudes toward stuttering: Reliability of the second prototype. Contemporary Issues in Communication Sciences and Disorders, 36, 101-107.

St. Louis, K. O., Kuhn, C. D., \& Lytwak, L. (2015). The Appraisal of the Stuttering Environment (ASE): A new tool to measure stuttering attitudes in the client's environment. In K. O. St. Louis (Ed.), Stuttering meets stereotype, stigma, and discrimination: An overview of attitude research (pp. 255-273). Morgantown, WV: West Virginia University Press.

St. Louis, K. O., Przepiórka, A. M, Beste-Guldborg, A., Williams, M. J., Błachnio, A., Guendouzi, J., Reichel, I. K., \& Ware, M. B. (2014). Stuttering attitudes of students: Professional, intracultural, and international comparisons. Journal of Fluency Disorders, 39, 34-50. 
St. Louis, K. O., Reichel, I., Yaruss, J. S., \& Lubker, B. B. (2009). Construct and concurrent validity of a prototype questionnaire to survey public attitudes toward stuttering. Journal of Fluency Disorders, 34, 11-28.

St. Louis, K. O., \& Roberts, P. M. (2010). Measuring attitudes toward stuttering: Englishto-French translations in Canada and Cameroon. Journal of Communication Disorders, 43, 361-377.

St. Louis, K. O., \& Rogers, A. L. (2011a, November). Predicting stuttering attitudes: Familiarity with stuttering, mental illness, and obesity. Poster presented at the Annual Convention of the American Speech-Language-Hearing Association, San Diego, CA. St. Louis, K. O., \& Rogers, A. L. (2011b, November). Predicting stuttering attitudes from socioeconomic indicators: Education, occupation, and income. Poster presented at the Annual Convention of the American Speech-Language-Hearing Association, San Diego, CA.

St. Louis, K. O., Sønsterud, H., Carlo, E. J., Heitmann, R. R., \& Kvenseth, H. (2014). Cluttering versus stuttering attitudes in Norway and Puerto Rico. Journal of Fluency Disorders, 42, 21-34.

St. Louis, K. O., Sønsterud, H., Junuzović-Žunić, L., Tomaiuoli, D., DelGado, F., Caparelli, E., Theiling, M., ... Węsierska, M. (2016). Public attitudes toward stuttering in Europe: Within-country and between-country comparisons. Journal of Communication Disorders, 62, 115-130.

St. Louis, K. O., Weidner, M. E., \& Mancini, T. M. (2016). Comparing parents' and young children's attitudes toward stuttering. Journal of Speech Pathology \& Therapy, 1, 1-10. 
St. Louis, K. O., Williams, M. J., Ware, M. B., Guendouzi, J., \& Reichel, I. (2014). The Public Opinion Survey of Human Attributes-Stuttering (POSHA-S) and Bipolar Adjective Scale (BAS): Aspects of validity. Journal of Communication Disorders, $50,36-50$.

Starkweather, C. W., Gottwald, S. R. (1990). The demands and capacities model II: Clinical applications. Journal of Fluency Disorders, 15, 143-157.

Tamm, M., \& Prellwitz, M. (2001). 'If I had a friend in a wheelchair': children's thoughts on disabilities. Child: Care, Health and Development, 27, 223-240.

Valente, A. R., Jesus, L., Leahy, M., \& St. Louis, K. O. (2014, March) Attitudes and knowledge of the Portuguese population about stuttering. Paper presented at the European Symposium on Fluency Disorders. Antwerp, Belgium.

Van Hooser, K. (2009). An investigation of preschool-aged children's perceptions of their peers with a disability (Unpublished Master's thesis). Available from Graduate Theses and Dissertations database.

Van Riper, C. (1973). The treatment of stuttering. Englewood Cliff, New Jersey: Prentice Hall.

Vanryckeghem, M., \& Brutten, G. (2007). The KiddyCAT: Communication attitude test for preschool and kindergarten children who stutter. San Diego, CA: Plural Publishing.

Vanryckeghem, M., Brutten, G. J., \& Hernandez, L. M. (2005). A comparative investigation of the speech-associated attitude of preschool and kindergarten children who do and do not stutter. Journal of Fluency Disorders, 30, 307-318. 
Weidner, M. E., (2015). InterACT Program. Morgantown, WV. Morgantown, WV: MC Speech Books.

Weidner, M. E., Coleman, C. E., St. Louis, K. O., Scaler Scott, K., Tokach, S., Croasdale, S., Irr, A. (2015, November). What is \& is not helpful in stuttering management: Perspectives of children who stutter. Poster presented at the Annual Convention of the American Speech-Language-Hearing Association, Denver, CO.

Weidner, M. E. \& St. Louis, K. O. (2014). The Public Opinion Survey of Human Attributes-Stuttering/Child (POSHA-S/Child). Morgantown, WV: Populore.

Weidner, M. E. \& St. Louis, K. O. (2015, November). Peer education about stuttering: Clinical implications of stuttering attitude research in preschool \& kindergarten children. Seminar presented at the American Speech-Language-Hearing Association, Denver, CO.

Weidner, M. E., St. Louis, K. O., \& Burgess, M. E., \& LeMasters, S. N., (2015). Attitudes toward stuttering of nonstuttering preschool and kindergarten children: A comparison using a standard instrument prototype. Journal of Fluency Disorders, 44, 74-87.

Weidner, M. E., St. Louis, K. O, Nakısc1, E., \& Özdemir, S. (July, 2015). Comparison of preschoolers' stuttering attitudes in Turkey and the USA. Poster presented at the International Fluency Association Conference, Lisbon, Portugal.

Wellman, H. M., Cross, D., \& Watson, J. (2001). Meta-analysis of theory-of-mind development: The truth about false belief. Child Development, 72, 655-684.

Węsierska, K., Błachnio, A., Przepiórka, A., St. Louis, K. O. (2015, October). Zmiana postaw wobec jąkania $w$ Polsce - wstępne doniesienia z badań [Changing attitudes 
towards stuttering in Poland: Preliminary study report]. Paper presented at the International Conference on Speech-Language Therapy: Modern Trends in Logopaedic Diagnosis and Therapy. Chorzów, Poland.

Węsierska, K., Węsierska, M., St. Louis, K. O., Beste-Guldborg, A. (2015). A comparison of stuttering knowledge and attitudes of Polish SLPs and SLP students. In K. O. St. Louis (Ed.), Stuttering meets stereotype, stigma, and discrimination: An overview of attitude research (pp. 216-225). Morgantown, WV: West Virginia University Press.

Westwood, D., \& Ho, R. (2013). Buddy Poke (Mobile application software). Retrieved from http://itunes.apple.com

Woods, C. L., \& Williams, D. E. (1976). Traits attributed to stuttering and normally fluent males. Journal of Speech and Hearing Research, 19, 267-278.

Yairi, E., \& Ambrose, N. (2013). Epidemiology of stuttering: 21st century advances. Journal of Fluency Disorders, 38, 66-87.

Yaruss, J. S., Murphy, W. P., Quesal, R. W., \& Reardon, N. A. (2004). Bullying and teasing: Helping children who stutter. New York: National Stuttering Association 
Appendix A

Public Opinion Survey of Human Attributes-Stuttering/Child and Picture Stimuli

Copyrighted. Not available for online distribution. 


\section{Appendix B}

Public Opinion Survey on Human Attributes-Stuttering

Copyrighted. Not available for online distribution. 
Appendix C

Theory of Mind Task Battery (Adapted) and Scoring Form

Copyrighted. Not available for online distribution. 


\section{Appendix D}

Participation Screening Instrument

Copyrighted. Not available for online distribution. 


\author{
Appendix E \\ InterACT Puppetry Video Scripts
}

Written by Mary Weidner in consultation with:

Ken O. St. Louis

Christine J. Schimmel

Craig E. Coleman

Ben J. Sala

Copyrighted. Not available for online distribution. 
Appendix $F$

InterACT Theme Song Lyrics

Lyrics by: Seana Hollingsworth

Music by: Jim Hollingsworth

Copyrighted. Not available for online distribution. 
Appendix $G$

InterACT Discussion Placards

Copyrighted. Not available for online distribution. 
Appendix $H$

InterACT Coloring/Activity Book

Copyrighted. Not available for online distribution. 


\section{Appendix I}

West Virginia University Institutional Review Board Approval Letter

Not available for online distribution. 
Appendix $J$

Letter of Permission to Conduct Research

Not available for online distribution. 
Appendix $K$

Cover Letter and Consent Form

Not available for online distribution. 
Appendix $L$

Classroom of Attendance (C1, C2, C3...C6) and Group Assignment/s for Research Question Analyses (RQ1, 2, 3, control) for the 73 Consented Children.

\begin{tabular}{|c|c|c|c|}
\hline Code & Classroom & Research Analysis & $\begin{array}{l}\text { Reason for exclusion } \\
\text { (if applicable) }\end{array}$ \\
\hline $\mathrm{EH}-1^{\mathrm{b}}$ & $\mathrm{C} 1$ & RQ1, 2, 3 & - \\
\hline $\mathrm{EH}-2^{\mathrm{c}}$ & $\mathrm{C} 1$ & RQ1, 2 & - \\
\hline $\mathrm{EH}-3^{\mathrm{c}}$ & $\mathrm{C} 1$ & RQ1, 2, 3 & - \\
\hline $\mathrm{EH}-4$ & $\mathrm{C} 1$ & Excluded & comprehension concerns \\
\hline $\mathrm{EH}-5^{\mathrm{bc}}$ & $\mathrm{C} 1$ & RQ1, 2, 3 & - \\
\hline EH-6 & $\mathrm{C} 1$ & Excluded & comprehension concerns \\
\hline $\mathrm{EH}-7^{\mathrm{ac}}$ & $\mathrm{C} 1$ & RQ 1, 2, Control & - \\
\hline $\mathrm{EH}-8^{\mathrm{a}}$ & $\mathrm{C} 1$ & RQ1, 2, 3 & - \\
\hline $\mathrm{EH}-9^{\mathrm{c}}$ & $\mathrm{C} 1$ & $\mathrm{RQ} 1,2,3$ & - \\
\hline $\mathrm{EH}-10^{\mathrm{c}}$ & C3 & RQ1, 2, 3 & - \\
\hline $\mathrm{EH}-11^{\mathrm{b}}$ & C3 & $\mathrm{RQ1}, 2,3$ & - \\
\hline EH-12 ${ }^{b c}$ & C3 & $\mathrm{RQ} 1,2,3$ & - \\
\hline EH-13 & C3 & RQ1, 2, 3 & - \\
\hline $\mathrm{EH}-14^{\mathrm{c}}$ & C3 & RQ1, 2 & - \\
\hline $\mathrm{EH}-15^{\mathrm{a}}$ & C3 & RQ1, 2, 3 & - \\
\hline $\mathrm{EH}-16^{\mathrm{c}}$ & C3 & RQ1, 2 & - \\
\hline EH-17 & C3 & Excluded & non-compliant \\
\hline $\mathrm{EH}-18^{\mathrm{c}}$ & $\mathrm{C} 3$ & RQ1, 2, Control & - \\
\hline EH-19 & $\mathrm{C} 3$ & RQ1, 2, 3 & - \\
\hline $\mathrm{EH}-20^{\mathrm{c}}$ & C3 & $\mathrm{RQ1}, 2,3$ & - \\
\hline EH-21 & C3 & Excluded & absent \\
\hline EH-22 & C3 & Excluded & comprehension concerns \\
\hline $\mathrm{EH}-23^{\mathrm{ac}}$ & C3 & RQ 1, 2, Control & - \\
\hline EH-24 & $\mathrm{C} 3$ & $\mathrm{RQ} 1,2,3$ & - \\
\hline EH-25 & $\mathrm{C} 2$ & RQ1, 2, 3 & - \\
\hline EH-26 & $\mathrm{C} 2$ & RQ2, Control & stutterer \\
\hline EH-27 & $\mathrm{C} 2$ & Excluded & non-compliant \\
\hline $\mathrm{EH}-28^{\mathrm{ac}}$ & $\mathrm{C} 2$ & RQ1, 2 & - \\
\hline $\mathrm{EH}-29^{\mathrm{c}}$ & $\mathrm{C} 2$ & RQ1, 2, 3 & - \\
\hline $\mathrm{EH}-30^{\mathrm{c}}$ & $\mathrm{C} 2$ & RQ1, 2 & - \\
\hline EH-31 & $\mathrm{C} 2$ & Excluded & non-compliant \\
\hline $\mathrm{EH}-32^{\mathrm{c}}$ & $\mathrm{C} 2$ & RQ1, 2, 3 & - \\
\hline $\mathrm{EH}-33^{\mathrm{c}}$ & $\mathrm{C} 2$ & RQ1, 2 & - \\
\hline EH-34 & $\mathrm{C} 2$ & Excluded & absent \\
\hline EH-35 & $\mathrm{C} 2$ & RQ1, 2 & - \\
\hline $\mathrm{EH}-36^{\mathrm{abc}}$ & $\mathrm{C} 2$ & RQ1, 2, 3 & - \\
\hline $\mathrm{EH}-37^{\mathrm{b}}$ & $\mathrm{C} 2$ & $\mathrm{RQ} 1,2,3$ & - \\
\hline EH-38 & $\mathrm{C} 2$ & Excluded & comprehension concerns \\
\hline EH-39 & $\mathrm{C} 2$ & RQ1, 2, 3 & - \\
\hline EH-40 & $\mathrm{C} 2$ & Excluded & comprehension concerns \\
\hline $\mathrm{EH}-41^{\mathrm{c}}$ & $\mathrm{C} 2$ & RQ1, 2, 3 & - \\
\hline EH-42 & $\mathrm{C} 2$ & Excluded & comprehension concerns \\
\hline EH-43 & $\mathrm{C} 2$ & Excluded & absent \\
\hline
\end{tabular}




\begin{tabular}{|c|c|c|c|}
\hline EH-46 & $\mathrm{C} 3$ & $\mathrm{RQ} 1,2,3$ & - \\
\hline $\mathrm{EH}-47^{\mathrm{ac}}$ & $\mathrm{C} 3$ & RQ1, 2, 3 & - \\
\hline $\mathrm{EH}-48^{\mathrm{c}}$ & $\mathrm{C} 3$ & RQ1, 2 & stutterer \\
\hline EH-49 & $\mathrm{C} 4$ & Excluded & non-compliant \\
\hline $\mathrm{EH}-50^{\mathrm{c}}$ & $\mathrm{C} 4$ & RQ1, 2, 3 & - \\
\hline $\mathrm{EH}-51^{\mathrm{c}}$ & $\mathrm{C} 4$ & $\mathrm{RQ} 1,2,3$ & - \\
\hline $\mathrm{EH}-52^{\mathrm{bc}}$ & $\mathrm{C} 4$ & RQ1, 2, Control & - \\
\hline EH-53 & C6 & Excluded & comprehension concerns \\
\hline EH-54 & C6 & Excluded & absent \\
\hline $\mathrm{EH}-55^{\mathrm{c}}$ & C6 & $\mathrm{RQ1}, 2,3$ & - \\
\hline $\mathrm{EH}-56^{\mathrm{c}}$ & C6 & $\mathrm{RQ} 1,2,3$ & - \\
\hline EH-57 & C6 & RQ1, 2 & - \\
\hline $\mathrm{EH}-58^{\mathrm{c}}$ & C6 & $\mathrm{RQ} 1,2,3$ & - \\
\hline $\mathrm{EH}-59^{\mathrm{c}}$ & C6 & $\mathrm{RQ} 1,2$ & - \\
\hline $\mathrm{EH}-60^{\mathrm{ac}}$ & $\mathrm{C} 5$ & $\mathrm{RQ} 1,2,3$ & - \\
\hline EH-61 ${ }^{\text {ac }}$ & $\mathrm{C} 5$ & RQ2 & stutterer \\
\hline $\mathrm{EH}-62^{\mathrm{c}}$ & $\mathrm{C} 5$ & RQ1, 2, 3 & - \\
\hline EH-63 ${ }^{c}$ & $\mathrm{C} 5$ & $\mathrm{RQ} 1,2,3$ & - \\
\hline EH-64 bc & $\mathrm{C} 5$ & $\mathrm{RQ} 1,2,3$ & - \\
\hline $\mathrm{EH}-65^{\mathrm{c}}$ & $\mathrm{C} 5$ & RQ1, 2, 3 & - \\
\hline $\mathrm{EH}-66^{\mathrm{c}}$ & $\mathrm{C} 5$ & RQ1, 2, 3 & - \\
\hline $\mathrm{EH}-67^{\mathrm{c}}$ & $\mathrm{C} 5$ & $\mathrm{RQ} 1,2,3$ & - \\
\hline EH-68 & $\mathrm{C} 1$ & Excluded & comprehension concerns \\
\hline EH-69 ${ }^{b c}$ & $\mathrm{C} 5$ & $\mathrm{RQ} 1,2,3$ & - \\
\hline $\mathrm{EH}-70^{\mathrm{ac}}$ & $\mathrm{C} 5$ & RQ1, 2, 3 & - \\
\hline EH-71 & C6 & Excluded & comprehension concerns \\
\hline EH-72 & C6 & Excluded & comprehension concerns \\
\hline EH-73 & C6 & $\mathrm{RQ} 1,2,3$ & - \\
\hline
\end{tabular}


Appendix $M$

Mean POSHA-S Demographic Ratings for 38 Parent Respondents

\begin{tabular}{|c|c|}
\hline Demographic Variable & $P O S H A-S$ mean \\
\hline Sample Size & 38 \\
\hline Age $(y r)$ & $37.86(9.83)$ \\
\hline Education (yr) & $17.87(3.85)$ \\
\hline Male / Female (\%) & $14 \% / 86 \%$ \\
\hline Student / Working (\%) & $92 \% / 2.6 \%$ \\
\hline Married / Parent (\%) & $86.84 \% / 100 \%$ \\
\hline Income Score $(-100$ to +100$)$ & 23 \\
\hline Race (Caucasian) $(\%)$ & $100 \%$ \\
\hline Religion (Christian / Jewish / Other) (\%) & $60 \% / 3 \% / 37 \%$ \\
\hline \multicolumn{2}{|l|}{ Self Identification (\%) } \\
\hline Multilingual & $18.42 \%$ \\
\hline Intelligent & $50.00 \%$ \\
\hline Left Handed & $5.26 \%$ \\
\hline Obese & $7.89 \%$ \\
\hline Mentally Ill & $7.89 \%$ \\
\hline Stuttering & $0.00 \%$ \\
\hline \multicolumn{2}{|l|}{ No Persons Known (\%) } \\
\hline Intelligent & $0.00 \%$ \\
\hline Left Handed & $7.89 \%$ \\
\hline Obese & $0.00 \%$ \\
\hline Mentally Ill & $5.26 \%$ \\
\hline Stuttering & $34.21 \%$ \\
\hline \multicolumn{2}{|l|}{ Health and Abilities $(-100$ to +100$)$} \\
\hline Physical Health & 43 \\
\hline Mental Health & 49 \\
\hline Ability to Learn & 66 \\
\hline Ability to Speak & 76 \\
\hline \multicolumn{2}{|l|}{ Life Priorities } \\
\hline Be safe and secure & 88 \\
\hline
\end{tabular}


Spend time alone

Attend social events

Imagine new things

Help less fortunate

Have exciting experiences

Practice my religion

Earn money

Do job/duty

Get things done

Solve big problems

Impression of persons who [are]... (-100 to

$+100)$

Intelligent

Left Handed

Obese

Mentally Ill

Stuttering

Use a wheelchair

Desire to want to be someone who [is]...

$(-100$ to +100$)$

Intelligent

Left Handed

Obese

Mentally Ill

Stuttering

In a wheelchair

Amount known about people who [are]...

$(-100$ to +100$)$

Intelligent

Left Handed

Obese

Mentally Ill

Stuttering

In a wheelchair 
Appendix $N$

Images of the Six Classroom Sites for Individual Testing and InterACT Program Lessons

Pictures not printed due to confidentiality. 
Appendix $O$

Schedule of Classroom Visits for Pre and Post Data Collection and InterACT Lessons

\begin{tabular}{|c|c|c|c|c|}
\hline Week & Day & Time & $\begin{array}{c}\text { Classroom } \\
\text { Location }\end{array}$ & $\begin{array}{c}\text { Purpose of } \\
\text { Visit }\end{array}$ \\
\hline 1 & Wednesday, March 9 & $8: 45$ & $\mathrm{C} 1$ & Pretesting \\
\hline \multirow{4}{*}{2} & Monday, March 14 & $8: 30$ & $\mathrm{C} 3$ & Pre-test \\
\hline & Tuesday, March 15 & $9: 15$ & $\mathrm{C} 1$ & Pretesting \\
\hline & Wednesday, March 16 & $9: 15$ & $\mathrm{C} 1$ & Lesson 1 \\
\hline & Friday, March 18 & $9: 15$ & $\mathrm{C} 2$ & Pretesting \\
\hline \multirow{4}{*}{3} & Monday, March 21 & $9: 15$ & $\mathrm{C} 1$ & Lesson $2 \&$ \\
\hline & Tuesday, March 22 & $8: 30$ & $\mathrm{C} 3$ & Pretest \\
\hline & Wednesday, March 23 & $9: 15$ & $\mathrm{C} 2$ & Lesson 1 \\
\hline & Thursday, March 24 & 9:00 & $\mathrm{C} 3$ & Lesson 1 \\
\hline \multirow{3}{*}{4} & Wednesday, March 30 & $9: 15$ & $\mathrm{C} 2$ & Lesson 2 \& \\
\hline & & & & $\begin{array}{l}\text { Post-testing } \\
\text { Lesson } 2 \&\end{array}$ \\
\hline & Friday, April 1 & 9:00 & $\mathrm{C} 3$ & Post-testing \\
\hline \multirow{3}{*}{5} & Monday, April 4 & $8: 30$ & $\mathrm{C} 4$ & Pretest \\
\hline & Wednesday, April 6 & 9:00 & $\mathrm{C} 4$ & Pretest \\
\hline & Friday, April 8 & $9: 00$ & $\mathrm{C} 4$ & Lesson 1 \\
\hline \multirow{4}{*}{6} & Tuesday, April 12 & 10:00 & $\mathrm{C} 5$ & Pretesting \\
\hline & Wednesday, April 13 & $9: 00$ & $\mathrm{C} 4$ & $\begin{array}{l}\text { Lesson } 2 \& \\
\text { Post-testing }\end{array}$ \\
\hline & Thursday, April 14 & 10:00 & $\mathrm{C} 5$ & Pretesting \\
\hline & Friday, April 15 & 10:00 & $\mathrm{C} 5$ & Lesson 1 \\
\hline \multirow{4}{*}{7} & Tuesday, April 19 & 10:00 & C6 & Pretesting \\
\hline & Wednesday, April 20 & 10:00 & $\mathrm{C} 5$ & $\begin{array}{l}\text { Lesson } 2 \& \\
\text { Post-testino }\end{array}$ \\
\hline & Thursday, April 21 & 10:00 & $\mathrm{C} 6$ & Lesson 1 \\
\hline & Friday, April 22 & 10:00 & $\mathrm{C} 5$ & Post-testing \\
\hline 8 & Tuesday, April 26 & 10:00 & C6 & $\begin{array}{l}\text { Lesson } 2 \& \\
\text { Post-testing }\end{array}$ \\
\hline
\end{tabular}




\section{Appendix $P$}

POSHA-S/Child Means and Standard Deviations Before and After the InterACT Program for the Pilot and Experimental Groups

\begin{tabular}{|c|c|c|c|c|}
\hline POSHA- & Pre & Post & Pre & Post \\
\hline S/Child & Pilot & Pilot & Experimental & Experimental \\
\hline Variable & $(N=6)$ & $(N=6)$ & $(N=37)$ & \\
\hline \multicolumn{5}{|l|}{ OVERALL } \\
\hline STUTTERING & $1(19.60)$ & $13(24.21)$ & $3(17.86)$ & 15 (23.18) \\
\hline \multicolumn{5}{|l|}{ SCORE } \\
\hline \multicolumn{5}{|l|}{ Beliefs About } \\
\hline Children who & $25(28.85)$ & 37 (33.58) & $22(20.87)$ & 33 (34.10) \\
\hline \multicolumn{5}{|l|}{ Stutter } \\
\hline & $33(20.66)$ & $17(26.58)$ & $-11(50.45)$ & $29(56.68)$ \\
\hline \multicolumn{5}{|l|}{ Personality } \\
\hline Are at fault ${ }^{a}$ & $67(81.65)$ & $33(103.28)$ & $-11(99.40)$ & $57(83.47)$ \\
\hline Nervous ${ }^{\text {a }}$ & $100(.00)$ & $67(81.65)$ & $-5(97.03)$ & $35(94.92)$ \\
\hline Shy ${ }^{\text {a }}$ & $67(81.65)$ & $100(.00)$ & $-22(97.57)$ & $30(96.80)$ \\
\hline \multicolumn{5}{|l|}{ Different from } \\
\hline others/Have a bad & $-67(81.65)$ & $-83(40.82)$ & $8(98.26)$ & 35 (94.92) \\
\hline \multicolumn{5}{|l|}{ problem $^{\text {a }}$} \\
\hline Can talk well & $0(109.54)$ & $-33(103.28)$ & $-27(96.17)$ & $-14(100.45)$ \\
\hline \multicolumn{5}{|l|}{ Stuttering } \\
\hline Should Be & 17 (51.64) & 33 (25.82) & $32(26.12)$ & $26(43.50)$ \\
\hline \multicolumn{5}{|l|}{ Helped by... } \\
\hline $\begin{array}{l}\text { Speech-language } \\
\text { pathologist }\end{array}$ & $33(103.28)$ & $100(.00)$ & 78 (62.96) & 73 (69.32) \\
\hline Other people who & & & & \\
\hline stutter & $33(103.28)$ & $11(103.28)$ & $54(80.26)$ & $19(99.55)$ \\
\hline Medical doctor ${ }^{a}$ & $-33(103.28)$ & $-100(.00)$ & $-84(55.35)$ & $-51(86.99)$ \\
\hline
\end{tabular}


Parent

Caused by...

33 (103.28)

$100(.00)$

78 (62.96)

$62(79.41)$

Came from their

mom or dad when

they were born

$-6(57.41)$

36 (52.09)

$-4(43.03)$

11 (47.91)

(Genetics)

Learning $^{\text {a }}$

Something bad

that happened ${ }^{\mathrm{a}}$

33 (103.28)

God/Allah ${ }^{\mathrm{a}}$

33 (103.28)

33 (103.28)

$-57(83.47)$

$-41(92.68)$

Germs like those

that make you

$-67(81.65)$

67 (81.65)

$-19(99.55)$

$30(96.80)$

sick $^{\mathrm{a}}$

Something we

can't see $^{\mathrm{a}}$

Potential

Can make friends

Do same thing as

others

Have any job as

adult

Make good

choices

-33 (103.28)

54 (74.86)

63 (58.63)

$67(81.65)$

$67(81.65)$

19 (99.55)

59 (79.79)

50 (83.67)

67 (81.65)

$67(81.65)$

89 (45.85)

$70(70.18)$

Self Reactions to

Children who

$\underline{-23(20.52)}$

$-11(18.90)$

$-16(23.08)$

$\underline{-3(18.02)}$

$\underline{\text { Stutter }}$

Accommodating

/ Helping

$-6(25.09)$

28 (49.07)

4 (42.96)

39 (40.49)

Ignore

-33 (103.28)

$-100(.00)$

$-24(98.33)$

-3 (101.34)

I should help

33 (103.28)
$100(.00)$

$51(86.99)$
$16(98.64)$

8 (101.05)

$30(96.80)$

$24(98.33)$

68 (56.78)

$62(79.41)$

78 (62.96)

89 (45.85)$$
\text { -78 (62.96) }
$$ 
Finish the

person's words ${ }^{\text {a }}$

0 (109.54)

33 (103.28)

$-22(97.57)$

$46(90.05)$

Tell the person to

"Slow down" a

$-67(81.65)$

33 (103.28)

$-73(69.32)$

$19(99.55)$

Laugh $^{\mathrm{a}}$

0 (109.54)

67 (103.28)

$57(83.47)$

$84(55.35)$

Should try to hide

their

33 (103.28)

33 (103.28)

35 (94.92)

$57(83.47)$

stuttering $^{\text {a }}$

Social Distance /

Sympathy

35 (50.94)

21 (58.15)

17 (49.51)

42 (50.74)

Fun to play with

$100(.00)$

67 (81.65)

73 (69.32)

$76(64.14)$

Be bothered

0 (109.54)

33 (103.28)

$51(86.99)$

$62(79.41)$

Feel sorry for

$100(.00)$

$100(.00)$

73 (69.32)

$73(69.31)$

them

Feel patient ${ }^{\mathrm{a}}$

$100(.00)$

$67(81.65)$

89 (45.85)

$100(0.00)$

Worried about

0 (109.54)

-33 (103.28)

$-38(92.35)$

$41(92.68)$

my doctor ${ }^{a}$

Worried about

33 (103.28)

$0(109.54)$

$-8(101.02)$

$14(100.45)$

my teacher ${ }^{\text {a }}$

Worried about

my neighbor ${ }^{a}$

67 (81.65)

$-33(103.28)$

$-14(100.45)$

19 (99.55)

Worried about

my brother or

0 (109.54)

$0(109.54)$

$-14(100.45)$

$24(98.33)$

sister $^{\mathrm{a}}$

Worried about me

0 (109.54)

0 (109.54)

$-8(101.05)$

24 (98.33)

a

Worried about a

$0(109.54)$

33 (103.28)

$-35(94.92)$

$14(100.45)$

friend

Worried about a

parent

-33 (103.28)

-33 (103.28)

$-14(100.45)$

$8(101.05)$

Preference

$50(54.77)$

$50(83.67)$

$49(69.10)$

49 (60.65) 


\begin{tabular}{|c|c|c|c|c|}
\hline Experience & $-98(3.35)$ & $-81(28.44)$ & $-68(40.08)$ & $-89(26.45)$ \\
\hline \multicolumn{5}{|l|}{ Persons known } \\
\hline who stutter & $-95(7.61)$ & $-95(7.61)$ & $-97(5.70)$ & $-97(57.7)$ \\
\hline \multicolumn{5}{|l|}{ (informant report) } \\
\hline \multicolumn{5}{|l|}{ Persons known } \\
\hline who stutter (child & $-100(.00)$ & $-69(49.83)$ & $-46(70.78)$ & $-83(45.76)$ \\
\hline \multicolumn{5}{|l|}{ report) } \\
\hline \multicolumn{5}{|l|}{ Obesity/ } \\
\hline Wheelchair & $-41(24.78)$ & $-41(31.05)$ & $\underline{-46(23.11)}$ & $\underline{-46(19.90)}$ \\
\hline \multicolumn{5}{|l|}{ Subscore } \\
\hline Preference & $-25(27.39)$ & $-25(41.83)$ & $-24(35.09)$ & $-24(30.33)$ \\
\hline Obesity & $-50(54.77)$ & $-50(83.67)$ & $-63(59.83)$ & $-81(46.18)$ \\
\hline Wheelchair & $0(.00)$ & $0(.00)$ & $14(55.00)$ & $32(52.99)$ \\
\hline Experience & $-57(26.58)$ & $-57(26.58)$ & $-67(25.04)$ & $-67(25.04)$ \\
\hline Obesity & $-50(26.58)$ & $-50(26.58)$ & $-51(35.45)$ & $-51(35.44)$ \\
\hline Wheelchair & $0(33.47)$ & $0(33.47)$ & $-83(29.12)$ & $-83(29.12)$ \\
\hline
\end{tabular}




\section{Appendix $Q$}

Children's Verbatim Responses to the Prompt "What Does the Word 'Stuttering' Mean?" Asked Immediately Before and After the POSHA-S/Child Pretest (Pre-1 and Pre-2) and Posttest (Post-1 and Post-2).

\begin{tabular}{|c|c|c|c|c|}
\hline Code & Pre -1 & Pre-2 & Post-1 & Post-2 \\
\hline EH-1 & I don't know & I don't know & You can't talk right & $\begin{array}{l}\text { I don't } \\
\text { know, } \\
\text { they're all } \\
\text { the same }\end{array}$ \\
\hline EH-2 & I don't know & correct with semantic cue & - & - \\
\hline EH-3 & I don't know & correct with semantic cue & $\begin{array}{l}\text { That your words aren't } \\
\text { coming out }\end{array}$ & $\begin{array}{l}\text { People's } \\
\text { words don't } \\
\text { come out }\end{array}$ \\
\hline EH-5 & I don't know & I don't know & Words get stuck & $\begin{array}{l}\text { Words get } \\
\text { stuck }\end{array}$ \\
\hline $\begin{array}{c}\text { EH-7 } \\
\text { (control) }\end{array}$ & I don't know & $\begin{array}{l}\text { Correct with phonemic } \\
\text { cue }\end{array}$ & That word & Do \\
\hline EH-8 & I don't know & $\begin{array}{l}\text { Correct with phonemic } \\
\text { cue }\end{array}$ & They don't talk & $\begin{array}{l}\text { Correct } \\
\text { with } \\
\text { semantic } \\
\text { cue }\end{array}$ \\
\hline EH-9 & I don't know & I don't know & I don't know & $\begin{array}{l}\text { I don't } \\
\text { know }\end{array}$ \\
\hline EH-10 & $\begin{array}{l}\text { Stuttering } \\
\text { means splat }\end{array}$ & The way people talk & $\begin{array}{l}\text { Stuttering means your words } \\
\text { get stuck }\end{array}$ & $\begin{array}{l}\text { Stuttering } \\
\text { means your } \\
\text { voice gets } \\
\text { stuck }\end{array}$ \\
\hline EH-11 & I don't know & No response & Be different & Be different \\
\hline EH-12 & I don't know & $\begin{array}{l}\text { When someone talks like } \\
\text { this "w-w-would you like } \\
\text { to play with me?" }\end{array}$ & To talk like this "s-s-Sarah" & $\begin{array}{l}\text { To talk like } \\
\text { this "I } \\
\text { liiiiike c-c- } \\
\text { can run fast }\end{array}$ \\
\hline EH-13 & I don't know & $\begin{array}{l}\text { It means that your throat } \\
\text { isn't feeling so good }\end{array}$ & $\begin{array}{l}\text { Stuttering is the way people } \\
\text { talk }\end{array}$ & $\begin{array}{l}\text { It means } \\
\text { like if } \\
\text { you're } \\
\text { talking } \\
\text { doesn't feel, } \\
\text { sound so } \\
\text { good }\end{array}$ \\
\hline EH-14 & I don't know & Different & - & - \\
\hline EH-15 & $\begin{array}{l}\text { It means } \\
\text { something } \\
\text { goes strange }\end{array}$ & $\begin{array}{l}\text { It means when you talk } \\
\text { very long }\end{array}$ & $\begin{array}{l}\text { It's when your words get } \\
\text { stretched }\end{array}$ & $\begin{array}{l}\text { It means } \\
\text { when your } \\
\text { words get } \\
\text { bounced }\end{array}$ \\
\hline EH-16 & I don't know & I don't know & - & - \\
\hline $\begin{array}{l}\text { EH-18 } \\
\text { (control) }\end{array}$ & $\begin{array}{l}\text { I don't know } \\
\text { I've never } \\
\text { heard that } \\
\text { before }\end{array}$ & $\begin{array}{l}\text { Uh, that you are not } \\
\text { talking so good }\end{array}$ & You're not talking so good & $\begin{array}{l}\text { When you } \\
\text { don't talk } \\
\text { too good }\end{array}$ \\
\hline EH-19 & No response & $\begin{array}{l}\text { Someone that learns to } \\
\text { talk }\end{array}$ & $\begin{array}{l}\text { Your words get stuck } \\
\text { sometimes }\end{array}$ & $\begin{array}{l}\text { Your words } \\
\text { get stuck or } \\
\text { they don't } \\
\text { come out }\end{array}$ \\
\hline
\end{tabular}




\begin{tabular}{|c|c|c|c|c|}
\hline EH-20 & $\begin{array}{l}\text { It means that } \\
\text { you're kind } \\
\text { of scared }\end{array}$ & Communicate & $\begin{array}{l}\text { They sound out their words } \\
\text { then talk }\end{array}$ & $\begin{array}{l}\text { Correct } \\
\text { with } \\
\text { semantic } \\
\text { cue }\end{array}$ \\
\hline $\begin{array}{c}\text { EH-23 } \\
\text { (control) }\end{array}$ & No response & $\begin{array}{l}\text { It means you can't talk so } \\
\text { well }\end{array}$ & Don't talk very well & $\begin{array}{l}\text { Means you } \\
\text { don't talk so } \\
\text { well }\end{array}$ \\
\hline EH-24 & I don't know & $\begin{array}{l}\text { When people like talk } \\
\text { funny and when they don't } \\
\text { finish their words all the } \\
\text { way like uh-uh }\end{array}$ & $\begin{array}{l}\text { When people don't finish } \\
\text { their words fast like other } \\
\text { people }\end{array}$ & $\begin{array}{l}\text { When } \\
\text { people } \\
\text { don't finish } \\
\text { their words } \\
\text { fast like } \\
\text { other } \\
\text { people }\end{array}$ \\
\hline EH-25 & I don't know & I don't know & I don't know & $\begin{array}{l}\text { When their } \\
\text { words get } \\
\text { stuck }\end{array}$ \\
\hline $\begin{array}{c}\text { EH-26 } \\
\text { (control) }\end{array}$ & I don't know & Correct with semantic cue & I don't know & $\begin{array}{l}\text { I don't } \\
\text { know }\end{array}$ \\
\hline ЕH-28 & I don't know & $\begin{array}{l}\text { To help everybody when } \\
\text { they're hurt }\end{array}$ & - & - \\
\hline EH-29 & I don't know & $\begin{array}{l}\text { I don't know stated } \\
\text { "mean" in sentence } \\
\text { completion task }\end{array}$ & If your voice gets stuck & $\begin{array}{l}\text { I don't } \\
\text { know }\end{array}$ \\
\hline EH-30 & Mad & Talking really well & - & 一 \\
\hline EH-32 & I don't know & Correct with phonetic cue & When your words get stuck & $\begin{array}{l}\text { When voice } \\
\text { gets stuck }\end{array}$ \\
\hline EH-33 & Sad & Site word & - & - \\
\hline EH-35 & I don't know & $\begin{array}{l}\text { Correct with phonemic } \\
\text { cue }\end{array}$ & - & - \\
\hline EH-36 & $\begin{array}{l}\text { I don't } \\
\text { know }\end{array}$ & $\mathrm{Be}$ & I don't know & Think \\
\hline EH-37 & I don't know & Correct with semantic cue & $\begin{array}{l}\text { When your words get stuck } \\
\text { in your throat }\end{array}$ & $\begin{array}{l}\text { Words get } \\
\text { stuck }\end{array}$ \\
\hline EH-39 & Girl & $\begin{array}{l}\text { It means "k-k" (imitated } \\
\text { stuttering) }\end{array}$ & When your voice gets stuck & $\begin{array}{l}\text { It's when } \\
\text { your voice } \\
\text { gets stuck } \\
\text { "da da da" } \\
\text { but they } \\
\text { talk okay }\end{array}$ \\
\hline EH-41 & $\begin{array}{l}\text { That you're } \\
\text { mad }\end{array}$ & Correct with semantic cue & $\begin{array}{l}\text { That you talk different and } \\
\text { your words get stuck }\end{array}$ & $\begin{array}{l}\text { That your } \\
\text { voice is like } \\
\text { different } \\
\text { and words } \\
\text { come out } \\
\text { differently }\end{array}$ \\
\hline $\begin{array}{c}\text { EH-44 } \\
\text { (control) }\end{array}$ & $\begin{array}{l}\text { It means like } \\
\text { you stutter- } \\
\text { it means you } \\
\text { study }\end{array}$ & $\begin{array}{l}\text { It means you stutter and } \\
\text { you like you stuttering it } \\
\text { means like you in a } \\
\text { wheelchair and you tiny } \\
\text { bit stutter }\end{array}$ & When you stutter? & $\begin{array}{l}\text { It means } \\
\text { like you } \\
\text { cant talk, } \\
\text { you stutter, } \\
\text { p-p-play }\end{array}$ \\
\hline EH-45 & I don't know & Doesn't talk very well & - & - \\
\hline ЕН-46 & No response & Correct with semantic cue & $\begin{array}{l}\text { When people's words } \\
\text { get... when you can't say stuff } \\
\text { that are right }\end{array}$ & $\begin{array}{l}\text { When } \\
\text { peoples } \\
\text { words don't } \\
\text { get... when } \\
\text { they cant } \\
\text { say things } \\
\text { right }\end{array}$ \\
\hline
\end{tabular}




\begin{tabular}{|c|c|c|}
\hline ЕН-47 & $\begin{array}{l}\text { Stuttering } \\
\text { means that } \\
\text { you're } \\
\text { studying } \\
\text { something } \\
\text { you need to } \\
\text { work on }\end{array}$ & $\begin{array}{l}\text { Means that people kinda } \\
\text { shake but its not really } \\
\text { like that - its when } \\
\text { something scares you }\end{array}$ \\
\hline EH-48 & $\begin{array}{l}\text { It means } \\
\text { you're shy }\end{array}$ & $\begin{array}{l}\text { It means you have a really } \\
\text { weird talk }\end{array}$ \\
\hline EH-50 & $\begin{array}{l}\text { It means the } \\
\text { word "c" }\end{array}$ & $\begin{array}{l}\text { "w-w-w" (imitated } \\
\text { stuttering) }\end{array}$ \\
\hline EH-51 & I don't know & I don't know \\
\hline $\begin{array}{c}\text { EH-52 } \\
\text { (control) }\end{array}$ & I don't know & Correct with semantic cue \\
\hline EH-55 & I don't know & Do \\
\hline
\end{tabular}

EH-56 Means you talk different

It means you talk different No response

EH-57 No response

EH-58 I don't know

EH-59 No response

EH-60 Be

EH-61 I don't know

EH-62 Scared

EH-63 I don't know

EH-64 Scared

EH-65 I don't know It's like you mess up on your words

\section{I don't know}

Correct with semantic cue

It means that they talk that they don't finish their words like they stop a little bit and keep on going

Has to do with the way people talk; they were born that way; god made them that way

I don't know

The way people talk

I don't know

The word stuttering means stuff

That they can't finish their words

Means you have a different

It means you have a different talk Has to do with the way people talk People how they talk Means how people talk Correct with semantic cue It means you talk different

It means that their words don't come out or their words stretch or they bounce

It means rain

Correct

with phonemic

cue

Correct with semantic cue It mean you cant talk well

Make do

It means you cant talk well

Make do

Can't talk

well

Correct

with

semantic

cue

That you mess up on your words

That you mess up on words Correct with semantic cue It means you do this ka-ka

Mean you do this kaka It mean th-th-th-that what the word start with

EH-67 Scared Scared 
EH-69 I don't know Means you talk different $\quad$ You talk like different $\quad$ You talk different

EH-70 No response When you're helping somebody

EH-73 I don't know Correct with phonetic cue
It means your voice sounds a little jumpy

Correct with phonetic cue
It means your words are jumpy Correct with semantic cue 